\title{
DIGITALCOMMONS
}

@WAYNESTATE —

Wayne State University

Law Faculty Research Publications

Law School

1-1-1989

\section{Transcendental Nonsense, Metaphoric Reasoning, and the Cognitive Stakes for Law}

Steven L. Winter

Wayne State University, swinter@wayne.edu

\section{Recommended Citation}

Steven L. Winter, Transcendental Nonsense, Metaphoric Reasoning, and the Cognitive Stakes for Law, 137 U. Pa. L. Rev. 1105 (1989). doi: $10.2307 / 3312131$

Available at: http://digitalcommons.wayne.edu/lawfrp/5

This Article is brought to you for free and open access by the Law School at DigitalCommons@WayneState. It has been accepted for inclusion in Law Faculty Research Publications by an authorized administrator of DigitalCommons@WayneState. 


\title{
TRANSGENDENTAL NONSENSE, METAPHORIG REASONING, AND THE GOGNITIVE STAKES FOR LAW
}

\author{
STEVEN L. WinTER $\dagger$
}

Table of Contents

I. InTRODUCING LAW to Cognition . . . . . . . . . 1107

II. Transcendental Nonsense: Philosophy and the EXPERIENTIALIST ENTERPRISE . . . . . . . . . . 1114

A. A Meditation on the Birth of Knowledge ...... 1115

1. The Contemporary Philosophical Impasse... 1117

2. The Experientialist Alternative ......... 1129

B. Experientialism and its Empirical Bases...... 1136

1. Color and Prototype Effects .......... 1136

a. The neurophysiology of color perception 1137

b. The multidimensionality of color cognition ..................... 1140

2. Up-down and other Image-Schemata ...... 1142

a. The metaphorical structuring of concepts 1143

b. The function of image-schemata ....... 1146

3. Gategorization and Cognitive Models ...... 1148

C. Coherence, Communication, and "Truth"..... 1156

III. METAPHORIC REASONING: "Relativity's LAws" IN THE "Fields" of Precedent . . . . . . . . . . . . . . . 1159

A. What's a Metaphor For? .............. 1162

B. The Hart/Fuller Debate, or "When Is a Vehicle a Vehicle?" ........................ 1172

G. Structured Indeterminacy, or "Duncan Kennedy Meets H.L.A. Hart" ................ 1180

D. Metaphor Makes Its Move . . . . . . . . . 1199

+ Associate Professor, University of Miami School of Law; B.A. Yeshiva College 1974; J.D. Columbia 1977. Copyright by Steven L. Winter 1988. Many, many thanks to George Lakoff, Mark Johnson, Lynn Winter, Jeremy Paul, Martha Minow, Michael Fischl, Jennifer Jaff, Eve Sweetser, Mary Coombs, Lois Weithorn, Jim Kainen, and Terry Tracht. Peter Gabel has my gratitude both because he is so serious about ideas and because he is such a good sport. Special thanks to Tony Amsterdam, who taught me so many of these things by living them daily. 
IV. The Cognitive Stakes: Metaphor, Meaning, and the Possibility of Rights . . . . . . . . . . . . 1206

A. Talking About Law ................. 1207

B. The Possibility of Rights ............. 1224

V. A Concluding Homage to Cover and Cohen ... 1234

"Look! See! Move! The need to see; the room to move, in consonance with tradition. A key. The fact as clear as the job is pressing." +

The law reviews are filled with debate about the very foundations of our discipline. What are "rights"? How does one do "law"? Is it different from other forms of reason and debate, such as politics, emotional argument, or literary criticism? In a recent article I tacitly addressed this question by employing a theory based on empirical studies of human cognition to explore the history, development, and dysfunctionality of the constitutional doctrine of standing. ${ }^{1}$ I used the theory as an analytic instrument in service of insight -- a cognitive standpoint from which to observe and unpack the animating considerations of standard legal doctrine. This experientialist epistemology proved to be a useful tool, both for critique and for reconstruction.

Although I made no claims about an explicitly normative role for cognitive theory, implicit in that piece was the notion that law is no different than any other product of human cognition. Here, I want to make that premise explicit. I will focus on the theory itself, including the empirical studies on which it is based, and relate its central insights to the way we think about law. The ongoing project - of which this is a first step - is to reconceptualize law in light of what we are learning

†t Llewellyn, Holmes, 35 Colum. L. Rev. 485, 489 (1935).

1 Winter, The Metaphor of Standing and the Problem of Self-Governance, 40 Stan. L. Rev. 1371 (1988) [hereinafter Standing and Metaphor]. The major explanations of the central themes of this emerging cognitive theory are presented in G. Lakoff, Women, Fire, and Dangerous Things: What Categories Reveal About the Mind (1987), and M. Johnson, The Body in the Mrnd: The Bodily Basis of MEaning, Imagination and Reason (1987). There is already a fair amount of work building on and applying the insights of experientialism to a variety of disciplines. In addition to my own work in law, there are: R. LANGACKER, FoundAtions of Cognitive Grammar (1987) (cognitive linguistics); Cultural Models in Language and Thought (D. Holland \& N. Quinn, eds. (1987)) (cultural anthropology)[hereinafter $\mathrm{D}$. Holland \& $\mathrm{N}$. QuinN]; M. Turner, Death is THE Mother of Beauty: Mind, Metaphor, Griticism (1987) (literature); G. LakofF \& M. Turner, More than Cool Reason: A Field Guide to Poetic Metaphor (1989) (literature); and E. Sweetser, From Etymology to Pragmatics: The Mind-as-Body Metaphor in Semantic Structure and Semantic Change (Cambridge Univ. Press, forthcoming 1990) (etymology and semantics). The groundbreaking effort is G. LAKOFF \& M. JohnSON, Metaphors We Lrve By (1980). 
- about the human mind. The ultimate goal is to describe a concept of law that is cognitively meaningful ${ }^{2}$ and which better enables us to harness the power of our understanding to transform the world in which we live.

\section{INTRODUCING LAW TO GOGNITION}

"They do things better with logarithms. . . yet unwritten is
my table of logarithms, the index of the power to which a
precedent must be raised to produce the formula of
justice."3

The power and pertinence of cognitive theory is that it provides a way of understanding law which makes it possible to continue in and build upon the legal tradition without allowing the mistaken assumptions of conventional legal analysis to blind us to the insights of its critics. The traditional view of law is largely dependent upon objectivist assumptions about reasoning and categorization. ${ }^{4}$ For purposes of this essay, I use the term "objectivist" to capture a general position that has

2 By "cognitively meaningful," I mean a concept of law rooted in and coherent with the processes of human rationality. Although my meaning will be clear only later in this essay, I want, however, strongly to distinguish my approach from Steve Fuller's version of the "cognitive" limitations on legal theory. See Fuller, Playing Without a Full Deck: Scientific Realism and the Cognitive Limits of Legal Theory, 97 YALE L.J. 549 (1988). For reasons I shall explicate below, Fuller's approach is doubly mistaken. On one hand, he undervalues the human intellectual capacity, treating our cognitive processes as too fallible effectively to perceive the world around us except by accident. $I d$. at $551 \mathrm{n}$. 5 . On the other hand, he overstates our ability to conceptualize an objective, scientific "reality" beyond those very same perceptive capacities. See infra notes $37,79,88 \& 126$. Two substantially related efforts that draw on early developments in cognitive theory are Lopez, Lay Lawyering, 32 UCLA L. REv. 1 (1984), and Feinman, The Jurisprudence of Classification, 41 STAN. L. REv. 661, 696-717 (1989). See discussion infra note 145 . For a more sensitive and sensible exposition of the implications of human intellectual frailties for legal theory, see Schlag, Missing Pieces: A Cognitive Approach to Law, 67 TEx. L. Rev. (forthcoming May 1989).

3 B. Cardozo, The Paradoxes of Legal Science 1-2 (1928).

- In a subsequent article on the jurisprudential implications of cognitive theory tentatively entitled The Metaphoric Structure of Legal Objectivity - I hope to develop further the degree to which our concepts of law and of legal reasoning unconsciously depend upon objectivist assumptions. For further discussion of the questions of meaning, indeterminacy, and the ways that the cognitive process operates in law, see Winter, The Cognitive Dimension of the Agon Between Legal Power and Narrative Meaning, 87 MICH. L. REv. (forthcoming August 1989) [hereinafter "Legal Power and Narrative Meaning"].

I use terms such as "objectivist," "subjectivist," and "relativist," with caution, fully aware that they "have been used with shifting meanings," R. BERNSTEIN, BEyond Objectivism and Relativism: Science, Hermeneutics, and Praxis 7 (1983), that each general position has stronger and weaker versions, and that there are a variety of hybrid positions: One may, for example, be objectivist about facts but relativist about value, and vice versa. 
three familiar subparts. First, it treats the world as filled with determinate, mind-independent objects with inherent characteristics unrelated to human interactions. Second, it understands categorization either as about natural sets of objects in the world or, when it recognizes categorization as humanly constructed, as about objects with ascertainable properties or criteria that establish their commonality. Finally, it treats reasoning as about propositions and principles that are capable of "mirroring" those objects and accurately describing their properties and relations. ${ }^{5}$ This is the paradigm that animates most of our conscious thinking as we go about our daily business in the world. It is, however, mistaken. As I discuss in Part II, surprisingly little of human rationality actually fits this paradigm.

The objectivist position typically is seen in contradistinction to either that of the subjectivist or that of the radical relativist. By "subjectivist" I refer to an approach that treats doctrines, rules, and categories as mere expressions of an actor's purposes, desires, or beliefs, and thus as virtually infinitely manipulable. In general, the positions I refer to as "relativist" assert that reasoning and categorization are not natural or given, but rather are relative to particular languages, cultures, histories, or conceptual schemes. ${ }^{6}$ Both the subjectivist and relativist posi-

S Rorty writes: "'Reason,' as the term is used in the Platonic and Kantian traditions, is interlocked with the notions of truth as correspondence, of knowledge as discovery of essence, of morality as obedience to principle." R. RORTY, Pragmatism, Relativism, and Irrationalism, in ConseQuences of PRAGMATISM 160, 172 (1982) [hereinafter R. RORTY, CONSEQUENCES].

- Perhaps more than the other two terms, the designation "relativist" connotes a wide variety of positions. See G. LAKOFF, supra note 1, at 304; P. FEyerabend, Notes on Relativism, in FAREWELL TO REASON 19 (1987) (describing different degrees and kinds of relativism). One of the varieties of relativism that I have identified in the text, usually referred to as "ontological relativism," maintains that objects are only individuated relative to a conceptual scheme. Other varieties fall under the rubric of "radical relativism." In using the term "relativist" as I do, however, I mean to exclude the "anything goes" connotation of the term in which "[r]elativism is the view that every belief on a certain topic, or perhaps about any topic, is as good as every other." R. RORTY, CONSEQUENCES, supra note 5, at 166. As Rorty recognizes: "No one holds this view . . ., [e]xcept for the occasional cooperative freshman. . .."Id.

Because I shall later be critical of important portions of Rorty's approach, it bears saying that this disagreement should not obscure my admiration for his work nor the degree to which I am indebted to him for my understanding of the even larger number of areas in which I find his approach is useful. Indeed, with the recent publication of his CONTINGENCY, IRONY, AND SOLIDARITY, There is greater convergence than previously on the question that really matters. Compare R. RORTY, CONTINGENCY, IRONY, AND SOLIDARITY xvi (1989) [hereinafter R. RORTY, ConTINGENCY] ("Human solidarity . . . is to be achieved not by inquiry but by imagination, the imaginative ability to see strange people as fellow sufferers."), with Standing and Metaphor, supra note 1 , at 1515 ("Because I can see me in you (the self in others), I can be motivated to act for you as if I were acting for myself. The stranger, thus, can be metaphor for the self."), and with Legal Power and Narrative Meaning, supra note 4, at 67 ("[T]he imaginative processes of cognition enable [us] to achieve a degree of empathy and to 
tions reject the objectivist assumption that there is a single, privileged view of reality: They offer in its place a vision in which every person or group has an equally valid, but different perspective on the world. What I want to suggest is that this two-dimensional opposition of objectivism and either subjectivism or relativism is an inadequate basis for understanding law as a human rational endeavor. I offer in its place an approach based on empirical evidence from the cognitive sciences, ${ }^{7}$ an approach that provides a more complex, multidimensional view of human rationality.

As this essay has developed through discussions and drafts, I have found it difficult to communicate this multidimensional approach because the objectivist view is so deeply entrenched in the legal profession. Many of us unconsciously understand the process of legal reasoning as a movement from abstract general principles - derived from constitutional provisions, statutes, or "holdings" of judicial opinions - to the decision of concrete cases. ${ }^{8}$ In using the objectivist methodology, one first abstracts from a case or authoritative legal text those principles or determinative facts - the necessary and sufficient criteria - that express its "essential" character. One then decides the next case by determining whether it corresponds to this abstracted version of the previous one.

Owen Fiss' recent work on the first amendment ${ }^{\theta}$ is an excellent example of the objectivist methodology. Fiss describes the Bill of Rights

understand [another's] experience by means of [our] own.").

7The "cognitive sciences" connotes an interdisciplinary effort that cuts across neuroscience, psychology, linguistics, anthropology, artificial intelligence, and philosophy. For a discussion of the connections between these various efforts and the common features that they share, see H. Gardner, The Mind's New Science: A History of the Cognitive Revolution 28-45 (2d ed. 1987).

${ }^{8}$ See R. Dworkin, Taking Rights Seriously 134-36 (1977) (distinguishing between an idea or principle, a "concept," and its particular expression, a "conception"); R. Dworkin, Law's EMPIRE 70-72 (1986) (same); Fiss, Why the State? 100 HARv. L. REv. 781, 783 (1987) ("[a]djudication is one process by which these abstract ideals are given concrete meaning and expression and are thereby translated into rights."); Wechsler, Toward Neutral Principles of Constitutional Law, 73 HaRv. L. REv. 1, 15 (1959) ("I put it to you that the main constituent of the judicial process is precisely that it must be genuinely principled, resting with respect to every step that is involved in reaching judgment on analysis and reasons quite transcending the immediate result that is achieved.").

This view of the reasoning process is so ingrained that even the staunchest critics of objectivism in law are wont to fall back upon it. For example, Mark Tushnet argues that: "We can gain an interpretive understanding of the past by working from commonalities in the use of large abstractions to reach the unfamiliar particulars of what those abstractions really meant in the past." Tushnet, Following the Rules Laid Down: A Critique of Interpretivism and Neutral Principles, 96 HARv. L. REv. 781, 804 (1983). For a further discussion of the flaw in Tushnet's hermeneutic assertion, see infra note 129.

- See Fiss, supra note 8; Fiss, Free Speech and Social Structure, 71 Iowa L. Rev. 1405, 1425 (1986). I provide a cognitive account of first amendment doctrine infra text accompanying notes 259-308. 
as a charter of ideals and principles, and adjudication as the process by which we make those values real. In his view, the crux of modern free speech law is that there is a conflict "over the mediating principle that gives fullest expression to that ideal." $10 \mathrm{He}$ would recast the central focus of the first amendment from "the autonomy principle" to "the public debate principle."11 As a first principle, "public debate" would support a more activist role for the State, ${ }^{12}$ and would yield very different outcomes in certain cases. ${ }^{13}$

The traditional approach is extraordinarily vulnerable to criticism from both the subjectivist and relativist perspectives. The traditional approach assumes that principles "mediate." But mediation is possible only if two conditions are met: (1) the principles must accurately correspond to our social world; and (2) there must be a logical, propositional trajectory from principle to concrete application. If these two conditions are not met, objectivity is impossible; the "mediating" principles will themselves be colored by value assumptions and their application skewed by individual purposes.

The subjectivist position denies the plausibility of both conditions (1) and (2) and, accordingly, finds objectivity impossible. The subjectivist argues that the "public debate principle" could be invoked to justify many inconsistent outcomes. Reasoning from principle has, thus, only the appearance of objectivity. As such, it has the vice of false legitimation without the saving grace of real constraint. ${ }^{14}$

Part of what is troubling about the subjectivist approach to law is that it assumes that we have more trouble communicating than we ac-

10 Fiss, supra note 8 , at $784-85$.

11 Id. at $785-86$.

$12 I d$. at 786.

13 Fiss, supra note 9 , at $1423-24$.

14 The text presents one, necessarily caricatured version of the radical indeterminacy critique leveled at objectivist methodology by many associated with the critical legal studies movement. See, e.g., Singer, The Player and the Cards: Nihilism and Legal Theory, 94 Yale L.J. 1, 59 (1984) ("[legal rules] are incoherent because they are constructed in ways that make it impossible for them to satisfy their own claims to determinacy, objectivity, and neutrality."); Kelman, Interpretive Construction in the Substantive Criminal Law, 33 STAN. L. REv. 591, 672 (1981) ("It is illuminating and disquieting to see that we are nonrationally constructing the legal world over and over again; it is a privilege to discern some structure to this madness ...., structuring the practices of others is a funny and fun form of dismissal."); Kennedy, The Structure of Blackstone's Commentaries, 28 Buffalo L. Rev. 205, 215 (1979) (stating that legal thinking is based upon a fundamental contradiction and that the existence of "legitimated doctrinal categories gives the law student . . . a false sense of orderliness of legal thought" when in fact lawyers have "consciously made and remade the categories to fit their [subjective] purposes"). 
tually do. For example, Mark Tushnet asks us to consider a conversation in which one party uses the denotative term "arbogast." The listener asks for an explanation, but to no avail: The speaker's "explanation shows that his entire vocabulary rests on the way that he has lived until that moment."15 Because everyone's experience is unique, the listener must

think her way into [the speaker's] life, so that she can understand what he means through understanding how he has developed. In this story, "understanding what [the speaker] means when he says 'arbogast" " plays the role of "following the rule in Roe v. Wade" or "remaining faithful to the framers' meaning of 'due process.' "16

Although the relativist position shares subjectivism's rejection of the objectivist's notion of "fit" or "correspondence" with a knowable, determinate reality, the relativist tries to avoid subjectivism's solipsistic pitfall. The relativist understands knowledge and rationality to be determined only by social convention. In this view, legal doctrines are often masks for power because they purport to derive from the neutral application of objective reason by a disinterested judiciary when, all the while, they are merely expressions of the needs or values of the culture's elites. $^{17}$

The relativist and subjectivist positions are often intertwined, as is the case in Tushnet's work. Only pages before he presents the "arbogast" passage illustrating the subjectivism of meaning, for example, Tushnet offers a "coherence" view of meaning and rationality: "[W]e can understand what we think and do only with reference to the social matrix within which we find ourselves." 18 If the coherence view is cor-

15 Tushnet, supra note 8 , at 825 .

${ }^{16} I d$.

17 See Brest, Interpretation and Interest, 34 STAN. L. REV. 765, 770-72 (1982) (constitutional interpretation is unavoidably affected by privileged background and status of judicial decisionmakers); Kennedy, Legal Education as Training for Hierarchy, in The Politics of Law: A Progressive Critique 47-48 (D. Kairys ed. 1982) (There is a bias in favor of "hierarchy and domination, which . . . look[s] as though it flows from and is required by legal reasoning rather than being a matter of politics and economics."); Kennedy, supra note 14, at 217-18 (Those involved in legal reasoning "have always been members of a ruling class."); M. TUSHNET, RED, White AND Blue: A Critical ANalysis of Constitutional Law 144 (1988) ("At most judges can interpret 'their' community's values.").

18 Tushnet, supra note 8 , at 785 . The coherence view of meaning is related to a view of the indeterminacy of reference of language terms. In this view, words do not "fit" the world at all: One can only speak meaningfully of language systems; the only constraint is internal consistency; and the meaning of any single term is determined solely by its relations to other units in the language network. Logically, the coherence view can take one of two forms: social or subjectivist. The more typical form is the 
rect, and meaning is a function of an entire network or belief system, then legal rules can only acheive determinacy if the entire social matrix is secured by consensus. But if there were such a consensus, law would be superfluous. ${ }^{19}$

Whether taken singly or in combination, the subjectivist and relativist positions reject any a priori foundations for knowledge and meaning. It is this threatening skeptical stance that leads defenders of objectivism to lambast these critics as "nihilistic."20 Neither side of this tense debate is realistic, however, because neither objectivism, on the one hand, nor subjectivism or relativism, on the other, captures the complex reality of law as the product of a human rationality that, although grounded in human experience, is largely imaginative and metaphoric. Or, to put it another way, both sides of the debate are right in part. The objectivist is correct that legal materials reproduce themselves in predictable patterns of decisionmaking that can be usefully studied. ${ }^{21}$

social coherence view of meaning in which social conventions determine which of a variety of possible ways are used by a particular holistic system to "carve up" the world. This is the view espoused by Tushnet in the excerpt quoted in the text above. On the other hand, his "arbogast" conversation, quoted supra at text accompanying notes $15-16$, is a subjectivist-tinged version of the coherence view. In this view, each individual can have an internally coherent language system not shared with others. In Part II, I explain why the social coherence view inevitably leads to the more solipsistic subjectivist view. See infra text accompanying notes 77-78.

19 See Tushnet, supra note 8 , at 799, 826-27.

20 Examples include Carrington, Of Law and the River, 34 J. LEGAL EDUc. 222, 227 (1984); Fiss, Objectivity and Interpretation, 34 STAN. L. REv. 739, 740-41 (1982); Moore, Moral Reality, 1982 WIs. L. REv. 1061, 1063-64; see also Stick, Can Nihilism be Pragmatic? 100 HaRv. L. Rev. 332, 393 (1986) (describing the nihilist or "irrationalist" position as seeking "to deny totally the existing legal discourse and build[] everything anew").

${ }_{21}$ Joe Singer has recently argued that there is a difference between "predictability" and "determinacy," and that this difference is primarily one of perspective. In this view, the lawyer as counselor sees law as predictable in application, while the lawyer as judge or advocate sees it as infinitely manipulable: "in every interesting case, lawyers can generate plausible, conventional legal arguments on both sides of the question." Singer, The Reliance Interest in Property, 40 Stan. L. REv. 611, 624 n.40 (1988); accord Tushnet, supra note 8 , at 819 \& n.119.

One problem with this position is that it adopts overly simplified views both of counselling and of advocacy. No counselor worth her salt would fail to advise a client of the grey areas. And no advocate who cares to win would be content merely with generating "plausible" arguments. In each case, the challenge of the lawyer's craft is to devise $e x$ ante (i.e., with predictability) a position that will prevail ex post. This requires a sense of both the pliability of legal materials available to a judge and the kinds of constraints that she will find persuasive. To be successful either as counselor or as advocate, one must simultaneously understand both the partial predictability and relative indeterminacy of law.

To put the same thought in terms of cognitive theory, one must be aware that the legal system is motivated - but not determined - by certain cognitive structures. "There is a big difference between giving principles that motivate, or make sense of, a system, and giving principles that generate, or predict, the system." G. LAKOFF, supra 
But the process is not truly and completely "objective," so it is not immune from a value-oriented critique. The process is, rather, situated in the experiences of actual human beings and is shaped by the ways they understand their experience.

My hope is that, by using an approach based on empirical evidence from the cognitive sciences, we can redescribe the legal process in a way that will promote reconstruction. We are not condemned to endless rounds in which we criticize and deconstruct; rather we can understand and reconstruct. A richer view of reason should yield a richer sense of law. Then, instead of fighting about freedom and constraint in legal reasoning and judicial decisionmaking, we can concentrate on the business of making humane law within the limits of human imagination. ${ }^{22}$

This piece inaugurates that project by establishing two premises. First, recent developments in cognitive theory make it possible to describe the underlying, unconscious structure of how we think about law. Second, awareness of this structure can help us think about the normative questions that confront us. What is at stake in this project is our ability effectively to harness the transformative potential of law. ${ }^{23}$ The purpose of such an undertaking is to resuscitate and reinvigorate

note 1 , at 96 . It is the skillful manipulation of these motivating structures that allows lawyers frequently to predict, sometimes to constrain, and often to persuade other legal actors.

Accordingly, Singer's earlier explanation of the coexistence of indeterminacy and predictability is the more persuasive. Singer, supra note 14, at 19-25. There he recognizes that the "existing structure of legal argumentation orients thought to a predictable scheme." Id. at 21 . He argues, however, that these structures are maintained by social convention rather than logic. Id. at 22 ("Convention, rather than logic, tells us that judges will not interpret the Constitution to require socialism."). See also Singer, Legal Realism Now, 76 GaL. L. REv. 465, 472-73 (1988) (describing Llewellyn's account of advocacy and decisionmaking and recharacterizing "plausible" arguments as those that are "persuasive").

${ }_{22}$ Cf. Williams, Critical Legal Studies: The Death of Transcendence and the Rise of the New Langdells, 62 N.Y.U. L. REv. 429, 491-96 (1987) (the subjectivist critique of law presupposes the subject/object dichotomy when law is given meaning only as a "form of life"). In some sense, both Williams' article and this one can be described as "neo-crit." Williams, however, stakes out her position on law along Wittgensteinian lines. In contrast, this piece is premised on a substantially different approach to philosophical and linguistic theory. In an important sense, this essay is neither mainstream nor "crit," but rather unabashedly Lakoffian.

${ }^{23}$ This vision of transformative law, dialogically elaborated by socially situated humans is central to the projects of other scholars. Drucilla Cornell provides a sophisticated treatment of these issues that combines the insights of Hegel with the pragmatism of Charles Sanders Peirce. Cornell, Institutionalization of Meaning, Recollective Imagination, and the Potential for Transformative Legal Interpretation, 136 U. PA. L. Rev. 1135 (1988); see also Grey, Holmes and Legal Pragmatism, 41 Sran. L. Rev. (forthcoming 1989) (describing Holmes' jurisprudence as a potential model for a more pragmatist and aesthetic legal practice). 
the concept of legal rights as a meaningful modality of social change. My efforts toward this end are intended as a homage to two people who, for me at least, help point the way: Felix Cohen and Robert Cover.

This essay proceeds as follows: Part II discusses the empirical underpinnings of experientialist theory and locates the approach in the context of contemporary philosophical debate concerning the basis of human knowledge. In a series of four subsections, Part III explores the implications of the experientialist approach for the debate about determinacy and objectivity in traditional legal analysis. I examine several classic legal texts that discuss the process of legal reasoning, and offer an experientialist analysis that focuses on the importance of metaphor in the ongoing construction of law. My purpose here is not merely to make a point about the ubiquity and necessity of metaphor in human thought (as even some skeptics are willing to concede). Rather, I explain the use of metaphor in constructing a framework for both a more realistic concept of law and a more meaningful concept of rights. I examine the growth of first amendment doctrine to demonstrate the way that metaphor actually works in legal reasoning. I use the insight provided by this analysis to extend Felix Cohen's analysis of the structure and functioning of precedents and other legal rules as products of sociological phenomena. Finally, I employ this analysis to shed a very different light upon the indeterminacy debate and its stepchild, the critique of rights.

Part IV attempts to establish a cognitive baseline for reconstructing a legal practice that revivifies rights as an effective medium for social transformation. Drawing on the work of Robert Cover, I develop an approach that emphasizes the grounding of legal concepts in ordinary experience and their institutionalization and elaboration by the imaginative means of human cognition. Perhaps not surprisingly, this experientialist approach to rights also rejects the objectivist, syllogistic nature of conventional rights analysis. I close with the argument that an understanding which puts people, and not the State, at the center of the process can empower us to reinvigorate and give meaningful content to the concept of "rights."

\section{Transcendental Nonsense: Philosophy and the EXPERIENTIALIST ENTERPRISE}

"We share the same biology/ Regardless of ideology/ What might save us me and youl Is that the Russians love their 
children too."24

In this Part, I will present the experientialist approach and locate it within contemporary philosophical debate concerning the character of knowledge. Focusing on the work of Richard Rorty, I begin by examining some basic epistemological questions. I then discuss the empirical work that provides evidence for experientialism - an approach to human understanding that is simultaneously relativist and realist. The central insight of this approach is that human knowledge is grounded in our direct physical and social experience with the world, but is elaborated indirectly, largely by means of metaphor and the extension of idealized cognitive models. ${ }^{25}$ Understanding the parameters of the process by which human rationality is grounded and elaborated allows us to account for both the relative plasticity of human logic and the possibility of meaningful intersubjective communication. It also suggests a way for us to remain free from the fear of nihilism that leads many to cling to the objectivist paradigm.

\section{A. A Meditation on the Birth of Knowledge}

What is reason? How do we come to knowledge? I will start my reflections on objectivity and subjectivity in a Coverian mode by consulting the Midrash. ${ }^{26}$ The Midrash gives two accounts of the basis of human knowledge. The first concerns the coming to knowledge of the patriarch Abraham. According to rabbinic tradition, Abraham observed all of the commandments even though he lived some four hundred years before the revelation of the Law at Sinai. ${ }^{27}$ The midrash says that 1985).

${ }^{24}$ Sting, Russians, on The Dream of the Blue Turtles (A \& M Records

${ }^{25}$ The concept of metaphor used in experientialism refers not to a mere rhetorical device, but rather to a cognitive process by which we use a concrete, experienced source domain to structure and understand a more abstract domain. See Standing and Metaphor, supra note 1 , at 1383-84, 1491-94. The concept of an idealized cognitive model ("ICM") is explained infra, notes 145-47 and accompanying text. See also Standing and Metaphor, supra note 1, at 1385-86. In that article, I discuss the role of the private rights model in our standard thinking about adjudication as an ICM that structures our understanding of the concept of justiciability. Id. at 1388-90, 1410-13, 1459$60,1475-78$.

${ }^{28}$ The Midrash is the collection of rabbinic parables that was part of the development of the Oral Law starting in the fifth century B.C.E., and extending well into the third and fourth centuries C.E. See Epstein, Foreword to 1 The Midrash RabaH Xxxiii (D. Freeman \& M. Simon trans. 3d ed. 1983) [hereinafter D. FreEman \& M. SIMON].

${ }^{27}$ See 1 D. Freedman \& M. Simon, supra note 26, at 373-74; see Commentary of Rashi (Rabbi Shlomo ben Yitzchak) on Genesis 15:13 (translation from original Hebrew by the author). According to the Midrash, God revealed to Abraham the fact of the Revelation of the Torah at Sinai, but not its contents. See 1 D. FreEdMAN \& M. SimoN, supra note 26 , at 375 . 
Abraham came to this knowledge (the Torah) by learning from his kidneys. ${ }^{28}$ In the second midrash, an angel teaches all of God's knowledge to each child while it is still in the womb. Just before birth, however, the angel presses the child's upper lip, causing it to forget all it has learned; the process of education is then the process of recalling that which was innate before birth. ${ }^{28}$

Although both entail a description of the experience of knowledge as internal to the individual, these midrashim are in tension. The first midrash suggests that Abraham came to knowledge on his own, acknowledging subjectivity in this attainment. The midrash of the child's prenatal education, however, superimposes a parable of a knowledge that is external on a tale of knowledge as inborn. Thus, the midrash of the child can be seen as an attempt to harmonize with an objectivist, monotheistic theology, the discordant message of subjectivity in Abraham's coming to knowledge. We experience knowledge as innate only because it has been seeded within us; the child can come to knowledge only because knowledge is an exogenous, transcendental given. And because knowledge has been seeded, Abraham can come to God's Truth by meditation and internal reflection. Or, recast from an agnostic point of view, the midrash of the child harmonizes the dialectic of our epistemological experience - the experience of both subjectivism and objectivism in our coming to knowledge.

There is, however, a radically different way to interpret these texts. The midrash of Abraham is also a strong statement of embodiment that suggests the central role of metaphor. Abraham studied the operation of his kidneys, which separate and expurgate toxins from the body. The kidney metaphor of the midrash intimates that Abraham adopted a similar, meditative methodology to identify and purge from his belief system the prevailing theological and cultural practices of idolatry ${ }^{30}$ and child sacrifice. ${ }^{31}$ Left in their place were the precepts of

282 D. Freedman \& M. Simon, supra note 26, at 540 ("[W]hence then did [Abraham] learn the Torah? The . . . Holy One, blessed be $\mathrm{He}$, made his two kidneys serve like two teachers for him, and these welled forth and taught him wisdom . . ."). This midrash is based on an interpretation of Psalms 16:7 ("I will bless God who advised me; even in the night my kidneys instructed me.") (translation from original Hebrew provided by the author). ed. 1961).

${ }^{29}$ See The Babylonian Talmud (Seder Tohoroth), Niddah, 212 (I. Epstein

${ }^{30}$ In the traditional Jewish account, Abraham's father left Ur of the Chaldees to go to Canaan, see Genesis 11:31, because of an incident between Abraham and King Nimrod. This incident was precipitated by Abraham's destruction of his father's idols. Nimrod had Abraham cast into a fiery furnace, but Abraham was not killed. See $1 \mathrm{D}$. Freedman \& M. Simon, supra note 26, at 310-11; see Commentary of Rashi on Genesis 11:31 (translation from original Hebrew by the author). I examine this mid- 
monotheism ${ }^{32}$ and humanism ${ }^{33}$ that became Judaism's central contributions to Western culture.

This suggests a different axis upon which to view the tension between these two midrashim. The common thread in each midrash is that there is no mind/body dichotomy. In each, the basis of knowledge is somehow innate, embodied in the human organism. Thus, Abraham comes to understand and shape his cultural practices by studying his kidneys and the way they function. Similarly, although the fetus has absorbed the potential for all knowledge within her, this knowledge is repressed as a result of the angel's touch. As in the former account, the midrash of the child is an attempt to harmonize a sense of the embodiment of knowledge with the precepts of a theological, objectivist belief. But in this view, the midrash of the child also mystifies a unitary epistemological experience by suggesting (on alternative readings) either an objectivist or a dialectical account of the attainment of knowledge.

\section{The Contemporary Philosophical Impasse}

Can these insights about metaphor and embodiment, and their ability to resolve the dialectic of subjectivism and objectivism, ${ }^{\mathbf{3 4}}$ survive the harmonizing myth? Recent work in cognitive theory suggests that they can. The central role of embodiment is evident in even the most abstract processes of reason, suggesting how inappropriate are the mind/body and subject/object dualisms that have dominated the philosophic tradition.

Rather than taking lived experience as a starting point, as suggested by the midrash of Abraham, the Western philosophical tradition takes an approach to the problem of knowledge much like that of the midrash of the child. In Plato's Meno, for example, Socrates argues that all learning and all teaching is only remembering: "since [the soul] is immortal. . . . we need not be surprised if it can recall the knowledge of virtue or anything else which . . . it once possessed." ${ }^{\prime 35}$ But in

rash in depth in my forthcoming Legal Power and Narrative Meaning, supra note 4, at $22-23$.

31 One way to understand the story of the sacrifice of Issac, Genesis 22:1-13, is in terms of the practice of child sacrifice prevalent in biblical times. See 2 Kings 23:10; Judges 11:30-40. In this view, Abraham's major revelation was the substitution of the ram for his son, of animal sacrifice for human sacrifice. See Genesis 22:13-14.

${ }^{32}$ See Exodus 20:2-5.

33 See, e.g., Leviticus 19:18 ("Love thy neighbor as thyself").

34 See Ricoeur, The Metaphorical Process as Cognition, Imagination, and Feeling, in ON METAPHOR 141, 142 (S. Sacks ed. 1979) ("[T] he question is whether the functioning of metaphorical sense does not put to the test and even hold at bay this very dichotomy.").

35 Plato, Meno, in The Collected Dialogues of Plato 364 (E. Hamilton 
Platonic thought, knowledge is purely transcendental, mathematics and geometry are the purest forms of knowledge ${ }_{2}^{36}$ and the body and the senses are obstructions to the attainment of real knowledge. ${ }^{37}$

From Plato to Kant (to make a particularly breath-taking leap), the central concern of epistemology has been the intellect and its relation to the external world. ${ }^{38}$ For Richard Rorty, this very concern is the problem..$^{38} \mathrm{He}$ characterizes the objectivist tradition of philosophy as focused on the problem of how the mind represents what is understood to be a determinate world.

To know is to represent accurately what is outside the mind; so to understand the possibility and nature of knowledge is to understand the way in which the mind is able to construct such representations. Philosophy's central concern is to be a general theory of representation, a theory which will divide culture up into the areas which represent reality well, those which represent it less well, and those which do not represent it at all (despite their pretense of doing so). ${ }^{40}$

\& H. Cairns ed. 1963); see also Plato, The Republic, in id. at 747-50 (the allegory of the cave).

${ }^{36}$ See Plato, The Republic, in id. at 754-57; see also Plato, Meno, in id. at 365-70 (illustrating recollection with the slave boy solving a geometry problem).

${ }_{37}$ See, e.g., Plato, Phaedo, in id. at 49 (" $[$ t] $]$ he body intrudes . . . into our investigations, interrupting, disturbing, distracting, and preventing us from getting a glimpse of the truth."). Steve Fuller takes an extreme version of this view. Although he assumes a single correct description of "reality," he concludes that human cognitive capacities are ineradicably fallible and that our ability to achieve "truth" is dependent upon "welcomed encounter with error." Fuller, supra note 2, at 558 (emphasis deleted).

38 "Before Kant it is perhaps impossible to find any philosopher who did not have a correspondence theory of truth." H. Putnam, REAson, TRUTH and History 56 (1981). Of course, by making this leap from Plato to Kant (and, shortly, to Rorty), I mean only to keep this essay to manageable length - not to imply that nothing important occurred in between. Rorty's work builds on insights from Nietzsche, Heidegger, Dewey, and Wittgenstein; to focus on his work is a useful, if necessarily incomplete, way to talk about these issues.

39 He identifies it as "the original sin of epistemology." R. Rorty, PhILOsophy and the Mirror of Nature 60 n.32 (1979) [hereinafter R. Rorty, Philosophy]. Rorty uses the term "epistemology" in a univocal sense: for reasons suggested below, he treats all epistemological inquiry as mistakenly dependent on the objectivist assumptions suggested by the mind as mirror metaphor. See infra text accompanying note 47 . $\mathrm{He}$ does, however, refer to Quine's request to let epistemology "be psychology" as the "new epistemology." R. RoRTy, Philosophy, supra, at 220. Joan Williams premises much of her discussion of critical legal studies on the development of a "new epistemology," although her use of this term includes approaches to philosophy that Rorty would not call epistemology at all. See Williams, supra note 22 , at 430 . I use the term "epistemology" in a theory-neutral sense to denote the study of how humans achieve knowledge.

10 R. Rorty, Philosophy, supra note 39, at 3; see also id. at 12 ("The picture which holds traditional philosophy captive is that of the mind as a great mirror, containing various representations."). 
This is the familiar "correspondence" view of meaning and rationality, what Hilary Putnam calls

the perspective of metaphysical realism. On this perspective, the world consists of some fixed totality of mind-independent objects. There is exactly one true and complete description of 'the way the world is'. Truth involves some kind of correspondence relation between words or thought-signs and external things and sets of things. ${ }^{41}$

All epistemology, in Rorty's view, is a mistaken quest forever led astray by the correspondence theory and its assumption that language is capable of "mirroring" objective states of affairs in the world. Rorty rejects the idea of objective, mind-independent truth for three reasons. First, he sees language not as "a medium" such as a mirror "in which we form pictures of reality, but . . . [as] part of the behavior of human beings." 42

To say that truth is not out there is simply to say that where there are no sentences there is no truth, that sentences are elements of human languages, and that human languages are human creations.

Truth cannot be out there - cannot exist independent of the human mind - because sentences cannot so exist, or be out there. The world is out there, but descriptions of the world are not. ${ }^{43}$

Second, Rorty' sees no way to gain access to the world without language, no way to describe what language does or how well it does it without using language, no "way of breaking out of language in order to compare it with something else." "mind" as a meaningful construct. For Rorty, there is only the purely physiological interaction between humans and their environment.

In Rorty's view, the "problem" of mind is simply a question of the relative paucity of our current knowledge of neurophysiology; as we increase our knowledge of neural processes, we should be able to speak directly about them and dispense with the intentionalist model of mind.

$4 \mathrm{H}$. Putnam, supra note 38 , at 49.

12 R. RORTY, CONSEQUENCES, supra note 5 , at xviii.

${ }^{43}$ R. RORTY, CONTINGENCY, supra note 6, at 5.

" R. RORTY, CONSEQUENCES, supra note 5, at xix. In taking both these positions, Rorty is most directly influenced by Wittgenstein. See L. Witrgenstern, PhILosopHICAL INVESTIGATIONS $\S 241$, at 88 e (G. Anscombe trans. 1953) ("It is what human beings say that is true and false; and they agree in the language they use. That is not agreement in opinions but in form of life."). 
As an illustration, Rorty conjures up a hypothetical extraterrestrial culture he calls the Antipodeans, who can dispense entirely with intentionalist concepts such as "pain" in favor of direct talk about the state of their nerves. Instead of "ouch," Antipodeans say "It's my C-fibers again - you know the ones that go off everytime you get burned."45 In this view, "pain" is not something that occurs in the "mind." It is just the way that our culture happens to express the experience. ${ }^{46}$

Rorty does not attempt to solve the mind-body problem. He uses, instead, a strategy that lawyers might call confession and avoidance. Rorty is not suggesting that we notice only the body and relegate the mind to future advances in science. Instead, he is suggesting that we stop worrying about the problem because nothing turns on it. He treats "ouch" and "it's my C-fibers" as the same thing.

[T] The claim (common to Wittgenstein and Dewey) [is] that to think of knowledge which presents a "problem," and about which we ought to have a "theory," is a product of viewing knowledge as an assemblage of representations. . . . The moral to be drawn is that if this way of thinking about knowledge is optional, then so is epistemology. ${ }^{47}$

For Rorty, therefore, this quest is no less mistaken when undertaken by epistemology's successor disciplines - psychology and linguistics. ${ }^{48}$

Much about Rorty's argument against objectivist epistemology is persuasive. It says nothing, however, of how humans achieve and transmit knowledge. Rorty rejects the view that epistemic justification is a matter of a proposition's relationship with an objective state of affairs in the world. Instead, he takes a social coherence view: Epistemic justification is just a matter of a proposition's acceptance by a social group. "It is merely to say that nothing counts as justification unless by reference to what we already accept, and that there is no way to get outside our beliefs and our language so as to find some test other than coherence." ${ }^{\text {99 }}$ Thus, Rorty rejects the possibility of ultimate foundations for knowledge, in favor of what I described in Part I as a purely relativist view. ${ }^{50}$

45 R. RoRTy, PhILOSOPHy, supra note 39 , at 74.

16 See id. at 83 .

47 Id. at 136.

18 See id. at 213-311. For an approach to philosophical issues that takes neuroscience seriously, see P. Churchland, Neurophilosophy: Toward a UNIFIEd ScIENCE OF THE MIND-BRAIN 403-79 (1986).

49 R. RoRty, Philosophy, supra note 39 , at 178 .

so Rorty, of course, would not accept the "relativist" designation. See discussion supra note 6. He equates "relativist" with the radical relativist, "anything goes" position and characterizes himself as a pragmatist. My use of the term "relativist" in this 
The problem is that Rorty's view fails to account for how the social consensus can be achieved. For Rorty, it is all wildly contingent. ${ }^{51}$ $\mathrm{He}$ views language systems as supplanting one another "not to accomplish a higher purpose, but blindly. ${ }^{.52}$ In Rorty's view, we can describe how it happens only through historical/anthropological case studies. ${ }^{53}$ But he cannot begin to describe how it holds together, because in locating knowledge and meaning in simple coherence, he cannot possibly answer the question: Coherent with what?

Rorty has no way to describe or even to talk about "how all the ways of making things hang together hang together." This point is perhaps most evident when we consider the phenomenon that most typifies our sense of mental activity - our ability to utilize language so that others understand what we say. Accounting for coherence is prob-

essay, however, is defined to take these concerns into account. See supra text accompanying notes $6,17-18$.

${ }_{\text {BI }}$ Rorty makes this explicit in the first three chapters of his recent book. See $\mathrm{R}$. Rorty, Contingency, supra note 6, at 3-64; see, e.g., id. at 16 ("Our language and our culture are as much a contingency, as much a result of thousands of small mutations finding niches (and millions of others finding no niches), as are the orchids and the anthropoids.").

${ }^{52}$ Id. at 19.

ss With Wittgenstein, Rorty

claims that if we understand the rules of a language-game, we understand all there is to understand about why moves in that language-game are made (all, that is, save for the extra understanding obtained from inquiries nobody would call epistemological - into, for example, and history of the language, the structure of the brain, the evolution of the species, and the political or cultural ambiance of the players).

R. RoRTy, Philosophy, supra note 39, at 174.

o4 R. RORTY, CONSEQUENCES, supra note 5, at xl. Rorty invokes the idea of describing "how things hang together" as an appropriate thing for post-epistemological philosophy to do. Rorty attributes the phrase to Wilfrid Sellars. See id. at xiv (citing W. Sellars, Science Perception and Reality (1967)).

Mark Johnson offers a fuller discussion of the problems with Rorty's view of language and how it limits his position on the role of philosophy. See generally Johnson, Good Rorty/Bad Rorty: Toward a Richer Conception of Philosophical Inquiry 1-56 (unpublished manuscript). Johnson discusses Rorty's view, set out in R. RoRTY, CoNTINGENCY, supra note 6 , at 11-20, that language-games are holistic coherence systems, and that metaphors have no meaning or cognitive content. In this, Rorty adopts Donald Davidson's view that "to toss a metaphor into a conversation is like suddenly breaking off the conversation long enough to make a face." Id. at 18 (discussing Davidson, What Metaphors Mean, in ON METAPHOR, supra note 34, at 44). Rorty maintains that new metaphors eventually become literalized in a normal discourse: "Old metaphors are constantly dying off into literalness, and then serving as a platform and foil for new metaphors." Id. at 16. Johnson contrasts this view with recent scholarship on metaphor and language development showing the systematicity of metaphor, the consistency of its development from the concrete to the abstract, and the way metaphors provide the means for meaning and rationality to "hang together." Johnson, supra, at 3; see also infra text accompanying notes 119-29 (discussing the concepts of $u p$ and down as examples of such structural metaphors). 
lematic because Rorty "breaks completely with the notion of language as something that can be adequate or inadequate to the world . . . ."55 Instead, Rorty holds a totally materialist view in which we live "in a world of blind, contingent, material forces." mirror, then it is only a bundle of C-fibers and other neurons, somehow magically capable of conversing and being affected by other such neuron-bundles. With no grounding for language, Rorty cannot explain or describe how human linguistic and cultural systems can evolve, stabilize, or function. We are left only with inexplicable Wittgensteinian language-games. As Rorty writes: "[F]or all we know, [the works of Aristotle, St. Paul, and Newton,] were the results of cosmic rays scrambling the fine structures of some crucial neurons in their respective brains." $"$ s?

Indeed, in his most recent work, Rorty adopts just such a view of language and communication. He describes language as a tool, rather than a jigsaw puzzle that fits with the vocabularies of others. ${ }^{58}$ Communication is possible only because we form "passing theories" of the tools our fellow beings employ.

Such a theory is "passing" because it must be constantly corrected to allow for mumbles, stumbles, malapropisms, metaphors, tics, seizures, psychotic symptoms, egregious stupidity, strokes of genius, and the like. . . This strange person, who presumably finds me equally strange, will simultaneously be busy forming a theory about my behavior. If we ever succeed in communicating easily and happily, it will be because her guesses about what I am going to do next, including what noises I am going to make next, and my own expectations about what I will do or say under certain cir-

so R. RoRTy, Contingency, supra note 6 , at 10 .

${ }^{56} \mathrm{Id}$. at 17.

${ }^{57}$ Id.

${ }^{88}$ See id. at 11-12. In adopting a view that language is ungrounded, Rorty agrees with Davidson's general view of language.

Davidson resembles Wittgenstein. Both philosophers treat alternative vocabularies as more like alternative tools than like bits of a jigsaw puzzle. To treat them as pieces of a puzzle is to assume that all vocabularies are dispensable, or reducible to other vocabularies, or capable of being united with all other vocabularies in one grand super-vocabulary. . . . We should restrict ourselves to questions like "Does our use of these words get in the way of our use of those other words?" This is a question about whether our use of tools is inefficient, not a question about whether our beliefs are contradictory.

Id. It is important to note that Rorty's use of the tool metaphor refers primarily to how words relate to one another, rather than how they relate to or affect the world. See infra notes 64-65 and accompanying text. 
cumstances, come more or less to coincide, and because the converse is also true. She and I are coping with each other as we might cope with mangoes or boa constrictors - we are trying not to be taken by surprise. To say that we come to speak the same language is to say . . . that "we tend to converge on passing theories."

As with Tushnet's "arbogast" example, ${ }^{60}$ Rorty's description assumes that we have more trouble communicating than we actually do.

If Rorty's version of coherence defies the reality of communication, it renders empty the notion of progress. Consider his view of the significance of the Galilean Revolution in science. Thomas Kuhn says that we need to make sense of the statement that "when Aristotle and Galileo looked at swinging stones, the first saw constrained fall, the second a pendulum." Rorty replies that "we need make no more of the gestalt-switch in question than the fact that people became able to respond to sensory stimulations by remarks about pendulums, without having to make an intervening inference." 22 Rorty explicitly rejects the notion that Galileo discovered something that Aristotle had missed; Galileo merely "hit upon a tool which happened to work better for certain purposes than any previous tool. Once we found out what could be done with a Galilean vocabulary, nobody was much interested in doing the things which used to be done ... with an Aristotelian vocabulary."

This explanation succeeds as far as it goes, but it fails to say what it means for a language-tool to "work better than any previous tool." Rorty rejects the notion of correspondence with reality; he believes that "the world does not provide us with any criterion of choice . . ., we can only compare languages ... with one another, not with something beyond language called 'fact." "B4 Indeed, Rorty "does not even think that there is anything isolable as 'the purposes which we construct vo-

59 R. Rorty, Contingency, supra note 6, at 14 (discussing Davidson, A Nice Derangement of Epitaphs, in PhIlosophical Grounds of Rationality 157 (R. Grandys \& R. Warner eds. 1986)); of. P. FeYerabend, supra note 6, at 54 ("The parties to a debate . . . need not share any elements (meanings, intentions, propositions) that can be detached from their interaction and examined independently of the role they play in it.").

${ }^{60}$ See supra text accompanying notes $15-16$.

61 T. Kuhn, The Structure of Scientific Revolutions 121 (2d ed. 1970).

${ }_{62}$ R. RORTY, PHILOSOPhy, supra note 39, at 325.

63 R. RoRTy, Contingency, supra note 6, at 19; see also R. RoRTY, PhilosoPHY, supra note 39 , at 331 ("We can just say that Galileo was creating the notion of 'scientific values' as he went along, that it was a splendid thing that he did so, and that the question of whether he was 'rational' in doing so is out of place.").

at R. RORTY, CONTINGENCY, supra note 6 , at 20. 
cabularies and cultures to fulfill' against which to test vocabularies and cultures." ${ }^{\text {(68 }}$ In that case, we cannot say why we like the Galilean vocabulary better, nor can we know that it works better. For all we know, we might have made it to the moon sooner with Aristotle's vocabulary. In principle, Rorty cannot say otherwise. ${ }^{66}$

Rorty's answer to these problems of coherence and meaning is to adapt Kuhn's distinction between "normal science" and "revolutionary science" to talk about "normal discourse" and "abnormal discourse." " 'Normal' science is the practice of solving problems against the background of consensus about what counts as a good explanation of the phenomena and about what it would take for a problem to be solved." "Abnormal discourse" is discourse outside those coherence conventions. This distinction allows Rorty to talk about rationality within a normal discourse, where "[r] igorous argumentation issues in agreement in propositions." 68 But isolating normal discourse in this way does not solve the problem, because the skeptical epistemology Rorty employs offers no account of how the consensus defining the coherence conventions of normal discourse is formed. ${ }^{69}$

${ }^{65}$ R. RoRTy, CONSEQUENCES, supra note 5, at xxxvii. All Rorty can say is that "we produce new and better ways of talking and acting - not better by reference to a previously known standard, but just better in the sense that they come to seem clearly better than their predecessors." Id. See also R. RoRTy, ConTINGENCY, supra note 6, at 13 (a "new vocabulary makes possible, for the first time, a formulation of its own purpose."); id. at 16 ("The idea that language has a purpose goes once the idea of language as medium goes.").

${ }_{88}$ See R. RoRTy, Contingency, supra note 6, at 20 ("[T] here is no way to explain the fact that a Galilean vocabulary enables us to make better predictions than an Aristotelian vocabulary by the claim that the book of nature is written in the language of mathematics.").

${ }_{B 7}$ R. RoRTy, PhILOSOphy, supra note 39, at 320.

${ }^{68}$ R. RORTY, ConsEQuences, supra note 5, at xli.

${ }^{69}$ Rorty's reliance on the normal/abnormal discourse distinction creates another problem of consistency for him. In his recent book, Rorty condemns the practice of drawing distinctions to achieve coherence, which he attributes to Philosophers (capital P) whom he derides as metaphysicians. See R. Rorty, Contingency, supra note 6, at 77 . He writes:

The typical strategy of the metaphysician is to spot an apparent contradiction between two platitudes, two intuitively plausible propositions, and then propose a distinction which will resolve the contradiction. Metaphysicians then go on to embed this distinction within a network of associated distinctions - a philosophical theory - which will take some of the strain off of the initial distinction. This sort of theory-construction is the same method used by judges to decide hard cases, and by theologians to interpret hard texts. That activity is the metaphysician's paradigm of rationality. He sees philosophical theories as converging - a series of discoveries about the nature of such things as truth and personhood, which get closer and closer to the way they really are, and carrying the culture as a whole closer to an accurate representation of reality.

The ironist, however, views the sequence of such theories - such in- 
Rorty's answer is pragmatic, and plausible only on the surface. $\mathrm{He}$ cites law - "at least in the lower courts"70 — as an example of a normal discourse within which rigorous argumentation is possible.

On the pragmatist account, a criterion ([e.g.] what the statute says) is a criterion because some particular social practice needs to block the road to inquiry, halt the regress of interpretations, in order to get something done. . . . If the purposes you are engaged in fulfilling can be specified pretty clearly in advance (e.g., . . . preventing violence in the streets ... .), then you can get it. If they are not (as in the search for a just society ... .), then you probably cannot, and you should not try for it. ${ }^{71}$

This explanation raises two serious problems. The first is a problem of circularity. Rorty's explanation of how a normal discourse achieves closure as a language-game assumes something that he would have to

terlocked patterns of novel distinctions - as gradual, tacit substitutions of a new vocabulary for an old one.

Id. Rorty's initial adaptation of the Kuhnian normal/abnormal discourse distinction leads him to draw additional distinctions to "take some of the strain off the initial distinction." See infra note 71 .

For an excellent view of this problem with distinctions in the context of legal reasoning, see Schlag, Cannibal Moves: An Essay on the Metamorphoses of the Legal Distinction, 40 STAN. L. REv. 929 (1988). Schlag discusses the problem referred to by Rorty in the quote above as the phenomenon of "split proliferation." See id. at 942-44.

An experientialist account of the limited usefulness of distinctions and networks of related distinctions follows from the rejection of the objectivist account of knowledge. Because the experientialist understands "reality" as an unmediated experienced gestalt, she would see each distinction as a way of imposing order or structure on a recalcitrant "reality." But, since each distinction is humanly constructed and not immanent in the world, it will, in a sense, falsify our experience. It is this procrustean tendency that creates the pressure to create further, subsidiary distinctions in an attempt better to "fit" with "reality."

This kind of holistic account is hardly unique to experientialism; it figures in some of the most thoughtful critical legal studies scholarship. See, e.g., Gabel \& Kennedy, Roll Over Beethoven, 36 Stan. L. REv. 1, 40, 43-44, 45-50 (1984) (discussing the ability or usefulness of concepts to capture and express "reality"). But this kind of holistic account is possible only after the renunciation of the "fundamental contradiction." Id. at 15-16, 36-37.

${ }^{30}$ R. RORTY, CONSEQUENCES, supra note 5 , at xli.

7I Id. at xli-xlii (footnotes omitted). Rorty concludes by observing that "[i]f what you are interested in is philosophy, you certainly will not get it . . . "Id. at xlii. Here we see the need to make a further distinction to preserve the answer to the previous contradiction. One of the basic thrusts of Rorty's PhILOSOPHY AND THE MIRROR OF NATURE, supra note 39 , is to dethrone philosophy as the premiere discipline, and to argue that it has no normative or systematic role of theory building. See supra note 39 and accompanying text. To preserve this position, Rorty has to assert that philosophy cannot constitute a normal discourse. Thus, he has to distinguish between normal and abnormal discourse and between disciplines that can be reduced to a normal discourse and those that cannot. 
deny: that the parties to the discourse are already speaking enough of the same language-game that they can "specify pretty clearly in advance 72 the purposes they want to fulfill. Otherwise, the parties would still be formulating "passing theories" of the other's meaning. But because Rorty believes that a "new vocabulary makes possible, for the first time, a formulation of its own purpose,"73 he cannot rely on "purpose" as the platform that supports a new language-game.

The second problem is that of indeterminacy, an all too familiar problem with legal materials. For example, "preventing violence in the streets" is one of those things that we just do not know how to do, the elaborate apparatus of the criminal law notwithstanding. Consider the inconclusive nature of the debate regarding the supposed deterrent effect of the death penalty. ${ }^{74}$ If we cannot agree on something as pragmatic and pressing as stopping crime, how can such a "purpose" form the framework for rigorous argumentation and an entire "normal discourse" like law?

Without the mortar of purpose, Rorty is left with only languagegames held together by vague coherence conventions. But he does not have a way to talk about how coherence happens or how these conventions are transmitted because, in his view, there are no constraints worth speaking of: "the notion that there is such a framework only makes sense if we think of this framework as imposed by the nature of the knowing subject, by the nature of his faculties or by the nature of

72 R. RORTY, CONSEQUENCES, supra note 5, at xli-xlii.

73 R. RORTY, Contingency, supra note 6 , at 13 . In fact, Rorty notes that this is the drawback of his "language as tool" analogy. "The craftsman typically knows what job he needs to do before picking or inventing tools with which to do it. By contrast, someone like Galileo. . . is typically unable to make clear exactly what it is that he wants to do before developing the language in which he succeeds in doing it." Id. at 12-13 (emphasis added).

${ }^{74}$ See, e.g., Baldus \& Cole, A Comparison of the Work of Thorsten Sellin and Isaac Ehrlich on the Deterrent Effect of Capital Punishment, 85 YALE L.J. 170, 173 (1975) (attempting to assess the reliability of statistical evidence as a basis for making inferences about the deterrent effect of capital punishment); Bowers \& Pierce, The Illusion of Deterrence in Isaac Ehrlich's Research on Capital Punishment, 85 YALE L.J. 187, 187 (1975) (arguing that Ehrlich's analysis produces results that seem consistent with the deterrence hypothesis when in fact they are not); Ehrlich, Deterrence: Evidence and Inference, 85 Y ALE L.J. 209, 209 (1975) (criticizing others' misuse of the analytical framework on deterrence Ehrlich developed); Zeisel, The Deterrent Effect of the Death Penalty: Facts v. Faiths, 1976 Sup. CT. Rev. 317, 337 (arguing that the empirical evidence overwhelmingly shows that the death penalty has no deterrent effect). Jack Greenberg invokes an epistemological version of the Heisenberg uncertainty principle to argue that we will never know the truth about the operation of the death penalty because the very process of observation and measurement affects the data. See Greenberg, Capital Punishment as a System, 91 YALE L.J. 908, 909 (1982). See also Binder, Beyond Criticism, 55 U. CHI. L. REv. 888, 893-95 (1988) (demonstrating the indeterminacy of the conviction that imprisonment protects society by reducing crime). 
the medium within which he works."7s Rorty rejects all of these. In so doing, he has rejected each of the three traditional bases for a shared epistemic understanding: (1) the Cartesian conception of the rational ego as the source of all cognitive structure; (2) the Kantian idea of cognitive capacities - sensation, imagination, and reason - that jointly constitute knowledge; and (3) a conception of language as the mediating link between the subject and the world. ${ }^{78}$

Once Rorty dispenses with the notion of language as a medium, the notion of "truth" as correspondence goes with it. As Rorty puts it: " '[T]rue' resembles 'good' or 'rational' in being a normative notion, a compliment paid to sentences that seem to be paying their way and that fit in with other sentences which are doing so." ${ }^{\prime \prime 7}$ Because he understands internal consistency as the only test of meaning, Rorty is inexorably led to the conclusion that any given system - like Galilean physics - is arbitrary. And, because any given system is arbitrary, it follows that any given system can be replaced by any other, equally good, system of meaning.

This line of reasoning leads to what I call "the slide to solipsism." The view that nothing constrains meaning inevitably forces social coherence theorists like Rorty to confront the fact that they cannot describe what maintains coherence across the gulf introduced by intersubjective communication. One is forced to confront the possibility that each individual may have her own internally coherent system of meaning. In that event, intersubjective communication can occur only if we can get inside each other's solipsistic coherence system. This is why Tushnet's social coherence view degenerates into his "arbogast" story; it is why Rorty is inevitably led to adopt Davidson's concept of "passing theories." Because social coherence theory recognizes no constraints save internal consistency, it is forced to move from relativism to subjectivism, and from social coherence to solipsism.

This view of knowledge as having no constraints save internal consistency gives rise to what Richard Bernstein calls the "Gartesian Anxiety."." "Cartesian Anxiety" attends the choice between objectivism and relativism. In its starkest form, it is the tension between foundationalism and nihilism. "Either there is some support for our being, a fixed foundation for our knowledge, or we cannot escape the forces of dark-

75 R. RORTY, PhILOSOPHy, supra note 39 , at 9.

${ }^{26}$ Indeed, the rejection of language as medium explicitly undermines Rorty's reliance on purpose: "The idea that language has a purpose goes once the idea of language as medium goes." R. RORTY, CoNTINGENCY, supra note 6, at 16.

$77 \mathrm{R}$. RORTY, CONSEQUENCES, supra note 5, at xxv; accord R. RORTY, CoNTINGENCY, supra note 6 , at 8 .

${ }^{78}$ See R. BeRnSTEIN, supra note 4, at 16. 
ness that envelop us with madness, with intellectual and moral chaos."79 Bernstein describes this tension as pervasive - "at the very center of our being in the world"80 - affecting all forms of discourse and debate. ${ }^{81}$

79 Id. at 18. Bernstein continues:

[A]t the heart of the objectivist's vision, and what makes sense of his or her passion, is the belief that there are or must be some fixed, permanent constraints to which we can appeal and which are secure and stable. At its most profound level the relativist's message is that there are no such basic constraints except those that we invent or temporally (and temporarily) accept. Relativists are suspicious of their opponents because, the relativists claim, all species of objectivism almost inevitably turn into vulgar or sophisticated forms of ethnocentrism in which some privileged understanding of rationality is falsely legitimated by claiming for it an unwarranted universality. The primary reason why the agōn between objectivists and relativists has become so intense today is the growing apprehension that there may be nothing - not God, reason, philosophy, science, or poetry - that answers to and satisfies our longing for ultimate constraints, for a stable and reliable rock upon which we can secure our thought and action.

Id. at 19 .

As an objectivist in regard to truth, Fuller claims that scientific realists "avoid the Cartesian Anxiety entirely by learning to think of themselves as the objects of some more advanced knower's observation." Fuller, supra note 2, at 557. In light of his extreme skepticism about the human cognitive capacity, however, it would be more accurate to say that Fuller avoids the "Cartesian Anxiety" only by firmly planting a foot on each side of the epistemological fence. That is, he is an objectivist about truth, but a skeptic about knowledge. See supra note 37. Fuller's view, however, replicates the problem of ethnocentrism in a serious way. He suggests that, because of human cognitive fallibility, "the outsider may be able to show that the insider, quite literally, does not know what he is doing." Fuller, supra note 2 , at 553 n.9.

${ }^{80} \mathrm{R}$. BERNSTEIN, supra note 4, at 19.

81 In law, the "Cartesian Anxiety" plays itself out as "the sense of entrapment between nihilism on the one hand, and domination on the other." Michelman, The Supreme Court 1985 Term - Foreword: Traces of Self-Government, 100 HaRv. L. REv. 4, 24 (1986) (footnotes omitted). See also Singer, supra note 14, at 49-51. As Rorty characterizes the situation:

Suppose that Socrates was wrong, that we have not once seen the Truth, and so will not, intuitively, recognize it when we see it again. This means that when the secret police come, when the torturers violate the innocent, there is nothing to be said to them in the form "There is something within you which you are betraying. Though you embody the practices of a totalitarian society which will endure forever, there is something beyond those practices which condemns you."

R. RoRTY, Consequences, supra note 5, at xlii. In his most recent book Rorty reponds by

urging that we try to extend our sense of "we" to people whom we have previously thought of as "they." . . . But that solidarity is not thought of as recognition of a core self, the human essence, in all human beings. Rather, it is thought of as the ability to see more and more traditional differences (of tribe, religion, race, customs, and the like) as unimportant when compared with similarities with respect to pain and humiliation the ability to think of people wildly different than ourselves as included in the range of "we." 
Implicit in this discussion, however, is an assumption that there are only two categorical possibilities for the workings of language and rationality: Either objective correspondence is possible, or it is not; either everything is objective, in which case intersubjective meaning is accounted for, or everything is random and contingent, in which case language and meaning are radically indeterminate. As discussed in Part I, however, we will necessarily miss the mark if we are caught within this essentially two-dimensional approach to language and rationality. Rorty's position is no less afflicted. He attempts to escape the "traditional subject/object picture"82 by moving to a materialist account of language and rationality. ${ }^{83}$ But this merely displaces the problem to a higher level and introduces a wider, more angst-prone gulf: Either language is "a third thing which stands in some determinate relation with ... the self and reality" or we must "treat everything - our language, our conscience, our community - as a product of time and chance." In terms of the "Cartesian Anxiety," Rorty's position is worse yet. To avoid the problems of objectivity and skepticism he has obliterated the subject altogether. His position leaves little room for any sense of human agency, reason, or choice.

\section{The Experientialist Alternative}

Rorty takes language as an a priori - a serious inconsistency in light of the skepticism characteristic of his approach. But language and cognition are not armchair constructs; they are empirical phenomena.

R. RoRTY, Contingency, supra note 6, at 192. But cf. Ackerman, Why Dialogue? 86 J. Philosophy 5, 13 (1989) (criticizing Hobbes' attempt to ground liberal neutrality in the shared fear of death).

${ }^{82} \mathrm{R}$. RORTY, CONTINGENCY, supra note 6 , at 10.

${ }_{83}$ See supra text accompanying notes 44-47, 55-57. As with the problem of "mind," Rorty simply disarms the problem of "truth" by confession and avoidance. "To say that we should drop the idea of truth as out there waiting to be discovered is not to say that we have discovered that, out there, there is no truth. . . . [I]t is just the recommendation that we in fact say little about these topics, and see how we get on." R. RoRty, Contingency, supra note 6 , at 8.

${ }^{84} \mathrm{R}$. RORTY, CONTINGENCY, supra note 6 , at 13.

85 Id. at 22. Rorty argues that we need to "become reconciled to the idea that most of reality is indifferent to our descriptions," $i d$. at 7 , that our language is the result of "sheer contingencies," $i d$. at 16 , and that "changing the way we talk : . thereby chang[es] what we want to do and think we are." Id. at 20.

Bernstein, too, criticizes "Rorty's fateful, although shifting, dichotomies - the either/or's that structure his thinking." Bernstein, One Step Forward, Two Steps Backward: Richard Rorty on Liberal Democracy and Philosophy 15 POLITICAL THEORY 538, 549 (1987). Bernstein's critique articulates as well what I have described as Rorty's "slide to solipsism." See id. at 554-55 (noting that Rorty "comes close to suggesting that 'we' are always free to make up what a tradition means for us. . . . [F]or Rorty there never seems to be any effective constraints on $m e$ and $m y$ interpretations."). 
Research in linguistics and the other cognitive sciences indicates that language and thought can be conceived in fuller, multidimensional terms. The bold claim of experientialist epistemology is that a competent model of human knowledge can be developed outside the traditional limitations of the representational/correspondence view, on one hand, and the skeptical or coherence views, on the other. Rorty notwithstanding, there is a framework that provides sufficient constraints to make communication and reason work: the human body and the human brain.

The claim is that reason, language, and knowledge can be understood only in terms of the cognitive process. ${ }^{86}$ That process is embodied; it arises directly from physical experience. ${ }^{87}$ The process is not "objec-

${ }^{86}$ Rorty's view, in contrast, is that: "No roads lead from the discovery of the organism's various interfaces with the world to criticisms of the organism's views about the world, or, more generally, from psychology to epistemology." R. RORTY, PHILOsoPHY, supra note 39 , at 246 . Rorty is correct to the extent he is saying that an understanding of human cognitive processes will not provide a foundational ground from which to identify those views that are objectively "right" and authoritatively reject those that are "wrong."

It does not follow, however, that an understanding of how our cognitive processes work cannot be useful in criticizing and reconstructing what we think we "know." For example, I have described how the standing metaphor and its related ICM (idealized cognitive model), the private rights model, affect the substance of what we think we know about the concept of adjudication. Once this cognitive structure and its impact on our legal reasoning are laid bare, we are empowered to reconstruct our legal concepts in ways that are more useful. See Standing $\mathcal{E}$ Metaphor, supra note 1, at 1458-1508.

${ }^{87}$ Recent developments in neuroscience suggest that, although the genes determine the overall makeup of the brain, they are insufficient to determine its internal structure. Rather, the million billion or so neurons and synapses that compose the brain form various connections as a result of the human organism's experience in the world. See, e.g., G. M. Edelman, Neural Darwinism: The Theory of Neuronal Group SELECTION (1988). The general development of this approach in the field of artificial intelligence as a technique for the study of the human brain goes under the name "connectionism." See P. Churchland, supra note 48, at 458-74.

In its focus on the role of experience in structuring rationality and in the formation of knowledge, experientialism is related in substantial ways to feminist work. See, e.g., Karst, Woman's Constitution, 1984 DukE L.J. 447, 505 ("What [feminists, e.g., Sheila Rowbotham and Jean Bethke Elshtain] are saying is that the vocabulary of women's perspectives, including their moral perspectives, is going to have to grow out of the experience of women."); Schneider, The Dialectic of Rights and Politics: Perspectives from the Women's Movement, 61 N.Y.U. L. REv. 589, 601-02 (1986) ("Feminist theory emphasizes the value of direct and personal experience as the place that theory should begin . . . .") (footnote omitted). For experientialists, as "[f]or feminists, theory is not 'out there,' but rather is based on the concrete, daily, and 'trivial' experiences of individuals, and so emerges from . . . shared experience . . . ." Id. at 603. What experientialism adds is that the contextual, experienced basis of human cognition is not gender specific, but rather common to the human organism regardless of differences that are amplified by processes of socialization.

For an influential account that discusses the impact of the gendered nature of early childhood experience in the formation of sex roles in our culture, see $N$. CHODOROw, The RePRoDuction OF MOtHERING 92-129 (1978). 
tive" in the sense of transcendental truth, but rather is dependent on the kinds of bodies that we have and the ways in which those bodies interact with our environment. It is grounded in a reality that to a very large degree is shared by all human beings. This claim is, therefore, relativist and realist - relativist but not nihilist. The experientialist view is relativist in that it does not depend upon, and in fact rejects, an objectivist, correspondence view of meaning and rationality. It agrees with Rorty and with Putnam that: "There is no God's Eye point of view that we can know or usefully imagine; there are only the various points of view of actual persons reflecting various interests and purposes." to objects, independently of how those signs are employed and by whom." 89

But this does not mean that there is no reality or that "anything goes." Rather, it means that there is no objective description of reality separate from our conceptual schemes. Putnam explains that his "internal realism"

does not deny that there are experiential inputs to knowledge; knowledge is not a story with no constraints except internal coherence; but it does deny that there are any inputs which are not themselves to some extent shaped by our concepts, by the vocabulary we use to report and describe them, or any inputs which admit of only one description, independent of all conceptual choices. ${ }^{80}$

Experientialism posits that we form that basic conceptual structure by

${ }^{88} \mathrm{H}$. Putnam, supra note 38 , at 50 . In contrast, Fuller directly asserts that we can usefully invoke such a God's-eye view. See supra note 79. Among the many problems with Fuller's position is that it is vulnerable to his own critique of "precommitment." That is, Fuller argues that "our desire for some end 'precommits' us to interpreting all subsequent events - however unpalatable they may seem in their own right - as positively contributing to that end." Fuller, supra note 2 , at 575 . Thus, although Fuller's extreme skepticism about knowledge should seem to disabuse him of the notion that such an Olympian perspective on reality could be achieved, his own precommitment allows him miraculously to come up with just the right post hoc rationalization of this apparent paradox: "[T]he most persuasive grounds for realism are themselves an artifact of our cognitive fallibility, the depth of which we would not have realized had we not already been committed to realism . . . ." Id. at $551 \mathrm{n} .5$ (emphasis added).

${ }_{89} \mathrm{H}$. Putnam, supra note 38 , at 52.

${ }^{90} \mathrm{Id}$. at 54. Although it may surprise some to find this same point made in an opinion by a mainstream (indeed, conservative) judicial figure, Felix Frankfurter expressed much the same insight: "[T]he concepts by which language expresses an otherwise unrepresentable . . . reality are themselves generalizations importing preconceptions about the reality to be expressed." Culombe v. Connecticut, 367 U.S. 568, 604 (1961) (Frankfurter, J. concurring). 
means of our physical interactions with our environment; that "we are embodied social creatures whose ongoing interactions are imaginative processes that constitute our understanding, our mode of having a world." "91

It may help to give an example at this point. Early in life, we discover that we can obtain desired objects by moving toward them through space. We imagine a source-path-goal structure to this experience. We then use this experience and its projected structure to elaborate all kinds of more abstract purposive activities. Thus, when we complete fifty percent of an intellectual task, like writing an article, for example, we say that we are at the midpoint in our efforts or that we are halfway there. As we near the end of our writing project, we see the light at the end of the tunnel. And, when we finish that article, we say that we have achieved our goal, or that we have completed what we set out to do. ${ }^{92}$

Moreover, the source-path-goal schema motivates a systematic set of journey metaphors that are elaborated to conceptualize "life." Life is a Journey metaphor provides a set of entailments that are mapped from the experienced source domain "journey" to the target domain "life." A journey has a beginning and an end, a distance that is covered, obstacles that must be surmounted, and burdens that have to be carried. Thus, we give our children an education to give them $a$ good start in life. If they act out, we hope that it is just a stage (or something they are going through) and that they will get over it. As adults, we hope they won't be burdened or saddled with financial worries or ill health. We hope that they will go far in life. And we know that, as mortals, they will eventually pass away. Another example of the Life is a Journey metaphor is the familiar individualist who marches to the beat of a different drummer.

91 Johnson, supra note 54, at 51.

92 In Standing and Metaphor, I elaborate on the role of this source-path-goal schema in our thinking about the purposive human activity called adjudication. See Standing and Metaphor, supra note 1, at 1385, 1388-91, 1412, 1457, 1472-78, 1496.

83 The importance of this metaphor is suggested by its systematic recurrence in our culture over several centuries. A familiar poetic version is the soliloquy spoken by Macbeth after hearing of the death of his wife:

To-morrow, and to-morrow, and to-morrow,

Creeps in this petty pace from day to day,

To the last syllable of recorded time;

And all our yesterdays have lighted fools

The way to dusty death. Out, out brief candle!

W. Shakespeare, Macbeth, V.5.19-23. For a discussion of the other conventional metaphors employed in this passage, see G. LAKOFF \& M. TuRner, supra note 1 , at 30-32 (life is a flame); see also id. at 44-46 (discussing another conventional metaphor also used elsewhere in Macbeth - "time moves," in which "time is seen as running"). 
Basic experiences common to the human organism motivate, that is, make sense of, the source-path-goal schema and the Life is a Journey metaphor. This concept of motivation has nothing to do with subjective intent, but rather refers to that which makes meaning possible. Because the human mind understands new input in terms of and by comparison to existing knowledge, the cognitive process begins with unmediated, directly encountered experience. ${ }^{94}$ Meaning is elaborated by imaginative extension of this experience to understand and conceptualize other, more abstract domains. Thus, the experience of moving through space toward a goal makes it possible to conceptualize the source-path-goal schema and to understand the path and journey metaphors and the more abstract domains, like purpose and life, that they structure. The concept of motivation is a central component of cognitive theory; it expresses the process by which meaning and knowledge are made possible, but not determined, by prior experience. It yields a sense of knowledge and meaning as neither arbitrary nor determinate, but rather as systematic and imaginative.

The particular metaphoric elaborations of these basic experiences to structure and talk about both purposive activities and life are not inescapable, required, or determinate aspects of human logic. Rather, we start out with a stock of relatively stable and well-defined experiences that are shared by all human beings, given the general structure and functioning of the human organism in its environment. These basic experiences serve as the preconceptual material of imagination and rationality. ${ }^{95}$ Most of the complex concepts that concern us, however, are understood indirectly by means of our more directly experienced realities. Thus, abstract purposes are understood in terms of movement along a path toward a goal, and the finitude of life is conceptualized as a journey to a final end.

Because it understands meaning and rationality as grounded in the basic experiences of being human, the experientialist epistemology provides a way to address Bernstein's "Cartesian Anxiety." Contrary to Bernstein's description of the radical relativist position, experientialism argues that there are basic constraints. Yet, it avoids the potential ethnocentrism of the objectivist's claim to universality in two ways. First, experientialism recognizes that although these constraints arise from

S4 See infra note 131 and accompanying text.

${ }^{95}$ In addition to the shared metaphors that arise from the homologous experiences of human beings, there are many other metaphors that, like the experiences which motivate marching to the beat of a different drummer, are culturally specific. Since not all cultures share the practices of parades and military marches, not all cultures will provide experience of the social practice that motivates this metaphor and gives it meaning. 
embodied experiences of the human organism in the world, they do not necessarily say anything determinate about the world itself. Second, experientialism acknowledges that, since an indirectly understood concept may be elaborated in more than one way, there is more than one way to understand the world. Embodied experiences may be elaborated to construct meaning in many different fashions; different cultures or subcultures may use the raw materials of experience to conceptualize their world in different ways. ${ }^{96}$ More abstract concepts are likely to show the greatest cultural variation because they are indirect, imaginative extensions of the physical and social experiences that ground them. Thus, experientialism recognizes no "privileged understanding of rationality" in the sense that one way of thinking and talking better represents the world around us. ${ }^{97}$

Although it provides a critical underpinning for much of the account that is to follow, "culture" is one of those slippery concepts that defies simple definition. In one sense, much of the balance of this essay is about the meaning of "culture" - the ways that a group of humans cognize their world. It is a "view of culture as shared knowledge - not a people's customs and artifacts and oral traditions, but what they must know in order to act as they do, to make the things they make, and interpret their experience in the ways they do." ture" is closely related to what Cover calls a nomos. ${ }^{99}$

${ }^{98}$ For example, the nature of our bodies is such that we all experience ourselves as having a front and a back. This is not culturally determined, because we know from experience that we are more successful in the world if we can see where we are going. The basic concepts of front and back are then metaphorically projected onto various inanimate objects. If I am facing a bush, I characterize the portion facing $m e$ as the "front" of the bush. But this metaphoric projection of a front-back orientation to the bush is culturally determined by English language conventions. In Hausa, a language of West Africa, the "front" of the bush is the far side of the bush - i.e., the side that is facing in the same direction as the speaker. G. LAKOFF, supra note 1, at 310.

${ }_{87}$ Experientialism posits that human beings use the same cognitive raw materials to construct different ways of conceptualizing their interactions with the world - some of which are similar across cultures and others that are radically different between cultures and, often, even between subcultures.

[T] ]he belief that there is a God's eye point of view and that one has access to it (that is, being a hard-and-fast objectivist) virtually precludes objectivity, since it involves a commitment to the belief that there are no alternative ways of conceptualizing that are worth considering. . . . [T]o be objective requires one to be a relativist of an appropriate sort.

Id. at 301-02; $c f$. T. Branch, Parting the Waters: America in the King Years 1954-63 at xii (1988) (describing the conviction out of which the civil rights movement "was made, namely that truth requires a maximum effort to see through the eyes of strangers, foreigners, and enemies").

88 Holland \& Quinn, Culture and Cognition, in D. Holland \& N. QuinN, supra note 1 , at 4.

${ }^{99}$ See Cover, The Supreme Court 1982 Term - Foreword: Nomos and Narrative, 97 Harv. L. REv. 4, 4-6 (1983). 
This conception of "culture" does not reify it into some monolithic, determinate "thing" with defined contours that exists outside us and directs our behavior. In my view, culture is both "in" us and that which we are embedded within. It is a set of ideas or concepts that one shares with groups of people and that are used to construct, understand, and operate in a "world."

An ideational theory of culture can look at cultural knowledge as distributed within a social system, can take into account the variation between individuals' knowledge of and vantage points on the cultural heritage of their people. It can also view cultural knowledge as shaping and constraining, but not directly generating, social behavior. ${ }^{100}$

Individuals may be more or less a part of a culture, may be situated so as to affect cultural meaning more or less than others, ${ }^{101}$ and may be located in more than one culture or subculture. For example, as a law teacher, I am part of the legal subculture positioned to affect legal meanings more than a court bailiff and less than a Supreme Court Justice. But this hardly exhausts my cultural attachments. I am also a part of the general American culture. And, since I was raised in a family that is part of a living tradition with distinctive ways of understanding its world that go back to biblical times, I will always remain a part of that subculture in important ways that affect my understanding of my world.

The experientialist account of rationality explains how one individual can be a part of multiple social coherence systems of meaning without experiencing overwhelming cognitive dissonance or overload: Because the various "cultures" make use of the same basic raw materials, much of this differing cultural knowledge can, nevertheless, be coherent. Experientialism does not deny cultural conflict, but rather locates it in a larger human framework that makes communication and understanding possible for those who are willing to work at it. I shall

${ }^{100}$ Keesing, Models "Folk" and "Cultural": Paradigms Regained? in D. HoLLAND \& N. QUINN, supra note 1, at 371.

101 This is what Lakoff and Johnson mean when they claim that "people in power get to impose their metaphors." G. LAKOFF \& M. Johnson, supra note 1, at 157; see also Standing and Metaphor, supra note 1, at 1454-57 (giving a concrete historical example of this phenomenon - the process by which Justice Frankfurter successfully adapted the standing metaphor to implement Justice Brandeis' program of judicial restraint). In my forthcoming Legal Power and Narrative Meaning, supra note 4 , I discuss the interactive constraints that shape the process by which, to recast Jan Deutsch's felicitous phrase, cultural leaders "retail" meaning out of "wholesale" cultural practices. 
be focusing on that larger frame, stressing what is shared and continuous in our rationality. $\mathrm{My}$ hope is that a better understanding of the commonalities that structure our differences can ultimately lead to a better understanding and respect for those differences.

\section{B. Experientialism and its Empirical Bases}

The best way to explain experientialism is to present it in the empirical contexts that substantiate it. In this subsection, I provide an experientialist account of the cognitive process as revealed in three conceptual areas: (1) the formation of color categories; (2) the basic concepts of $u p$ and down and some of their metaphoric elaborations; and (3) the surprisingly imaginative, non-objectivist basis of most human categorization. By examining these phenomena, their experiential groundings, and their cognitive elaborations, we will be able more fully to understand that experientialism is neither objectivist and foundational nor radically relativist in a nihilist or "anything goes" sense. It is, rather, an approach to reason and knowledge that is simultaneously constrained, realist, and relativist.

Finally, examining these areas will provide an opportunity to demonstrate the workings of the key concepts of the experientialist epistemology: (1) the phenomenon of prototype effects; (2) the notion of an image-schema; (3) the function of metaphor; and (4) the operation of idealized cognitive models. These are the concepts that I employ in the last two parts of this essay to explicate some of the more elusive jurisprudential phenomena like indeterminacy, the structure of legal reasoning, and the meaning of rights.

\section{Color and Prototype Effects}

Color provides a useful empirical context for testing the agon between the objectivists and the radical relativists. For one thing, the stakes are not exceedingly high; few moral issues turn on how humans categorize the color spectrum. For another, the opposing relativist and objectivist positions are each supported both by common sense evidence and by widely shared intuitions. Yet substantial empirical evidence shows that neither the objectivist nor the relativist position captures the complex reality of human color categorization. Rather, the data suggest a more complex, multidimensional account.

The objectivists would argue that color is a demonstrable, language-neutral phenomenon subject to direct measurement. That is, we can measure the frequency and wavelength of the light waves that correspond to our perception of various colors regardless of our language 
categories. The relativists would point out, however, that the spectrum of light is a continuum and that different languages carve up the spectrum differently, recognizing radically different color categories. ${ }^{102}$ Thus, there seems to be scientific and linguistic evidence for and against both the objectivist and relativist theses concerning color categories.

\section{a. The neurophysiology of color perception}

The reality of color perception is more complex than supposed by the two dimensional debate between the objectivist and the relativist. Brent Berlin and Paul Kay have discovered surprising systematicity in human language categories for color. ${ }^{103}$ They studied the use of basic color terms ${ }^{104}$ in almost 100 languages. They found languages with as few as two basic terms, and others with as many as eleven. In all of the two-term systems, the terms correspond to "black" (encompassing the dark-cool colors,) and "white" (encompassing the bright-warm colors). In the most complex, eleven-term systems, the terms correspond to black, white, red, green, yellow, blue, brown, purple, pink, orange, and grey.

In the languages they studied, Berlin and Kay found only twentytwo different distribution patterns of the eleven basic color terms (of 2048 possible combinations). Moreover, they found that virtually all languages show the systematic progression:

(1) A two-term system will have black and white;

(2) a three-term system will add red;

(3) a four-term system will add either yellow or green;

(4) a five-term system will have added both green and yellow;

(5) a six-term system will add blue;

${ }^{102}$ For example, Octavio Paz has recently written that "from the physiological point of view, the experience of colors is the same for all races: the cells of the retina and of the optic nerve are the same in all humans; nonetheless differences in color perception . . . are a well-known, incontrovertible phenomenon." Paz, Edith Piaf Among the Pygmies, N.Y. Times, September 6, 1987 (Book Review), at 10-20.

${ }_{103}$ B. Berlin \& P. Kay, Basic Color Terms: Their Universality and Evolumion 1 (1969) ("The research reported here strongly indicates that semantic universals do exist in the domain of color vocabulary").

104 Berlin and Kay define a "basic color term" as a single term of general application that is salient to members of the language group, and whose meaning is neither derived from the meaning of its parts nor part of another color category. See id. at 5-6. Thus, salmon, blond, and mauve would not be basic color terms.

Later work revealed that the intuitive concept just described corresponds to a large extent with the neurophysiology of color perception. See infra text accompanying notes 109-115. 
(6) a seven-term system will add brown; and

(7) a language with eight or more terms will add purple, pink, orange, and grey in no particular order. ${ }^{105}$

Although different languages have different basic color terms, it does not follow that the speakers of diverse languages perceive color dissimilarly, relative to the categories that characterize their language. Berlin and Kay asked their subjects to identify the "best examples" of the color categories in their language. For each corresponding term, the speakers of different languages identified essentially the same focus on the color stimulus display as the best example, or prototype, of the respective color. Surprisingly, Berlin and Kay found greater variation in the selection of these "focal" colors as prototypes among speakers of the same language than between speakers of different languages. ${ }^{106}$

Subsequent empirical research shows that individuals whose cultures categorize colors differently from English nevertheless perceive the same colors, and identify the same prototypical, "focal" colors, that we do. For example, the Dani are an aboriginal culture of New Guinea that has only two colors - mili (all the dark-cool colors: black, green, blue) and mola (all the light-warm colors: white, red, yellow). When asked to select the best example of mili and of mola, different speakers of Dani chose different colors. But the colors they chose were all "focal" colors - e.g., "focal" white or "focal" red, not pinkishwhite or purple. ${ }^{107}$ Speakers of Tarahumara, a Uto-Aztecan language of Mexico that has a single word siyoname for the colors blue and green, do not choose turquoise as the prototype of siyoname even though it is the halfway point between blue and green on the color spectrum. Rather, they choose either "focal" green or "focal" blue as the best example of siyóname. ${ }^{108}$

108 See B. BERlin \& P. KAY, supra note 103, at 1-5. .

Of the 98 languages they studied, Berlin and Kay do discuss six cases that, on the basis of available historical evidence, may not fit their hypothesized evolutionary trajectory. See id. at 41-45. The small number of such problematic cases weighs against the pure relativist position.

${ }^{108}$ See id. at 10.

107 See G. LAKOFF, supra note 1 , at 40 . The Dani are perfectly capable of learning and memorizing colors not named in their language, but they have more success learning "focal" colors than "nonfocal" colors. See Rosch Heider, Universals in Color Naming and Memory, 93 J. EXPERIMental Psychology 10, 19 (1972); Rosch, Natural Categories, 4 Cognitive Psychology 328, 331 (1973). Rosch found similar results with 3-4 year old American children. When the children were asked to show a color to the experimenter, "focal" colors were more accurately matched and were more frequently chosen to represent the color name than non-focal colors. See Rosch Heider, "Focal" Color Areas and the Development of Color Names, 4 Developmental PsyCHOLOGY 447, 452-53 (1971).

108 See Kay \& Kempton, What is the Sapir-Whorf Hypothesis? 86 AM. AnTHRoPOLOGIST 65, 71 (1984); G. LAKoff, supra note 1, at 331-32. 
The salience of these "focal" colors is a function of neurophysiology. ${ }^{109}$ The receptor cells in the retina (rods and cones) are connected to the visual center in the brain by three types of paired neurons. Two types of these pairs are organized as opponent response cells; the neurons in each opponent response pair respond to wavelengths from opposite ends of the color spectrum. Thus, one pair responds to red (far long wavelength) and green (near short). The neurons in this pair are designated $+R-G$ and $+G-R$, respectively. The other pair, $+Y-B$ and $+B-Y$, responds to yellow (near long) and blue (far short). Neurons have a basal response rate - that is, a spontaneous rate of firing in the absence of stimulation. When stimulated by the color red, the $+R-G$ cell fires above its basal rate while its opponent cell, $+\mathrm{G}-\mathrm{R}$, is inhibited and correspondingly fires below its basal rate. The opposite set of responses transmits green. The opponent response cells for yellow and blue follow the same pattern.

The prototype phenomena relating to the four primary colors red, yellow, green, and blue - are a product of the way this neurological system functions. "Focal" blue occurs when the $+B-Y$ cell fires above its basal rate, the $+\mathrm{Y}-\mathrm{B}$ cell fires below its basal rate, and the $+R-G$ and $+G-R$ cells are both at their basal rates. "Focal" red, green, and yellow are the result of similar patterns. "In sum, the distinctive properties of the semantic categories red, yellow, green, and blue as discovered in semantic investigations correspond precisely to the properties of ... the opponent process model of the neural mechanisms that underlie color vision."110

The third type of paired neurons is linked to cones that respond to the entire color spectrum and determine brightness and darkness, respectively. They are non-opponent response cells; they can operate separately or together. Separately, they determine white and black. Together, they determine grey. Operating with the color sensitive opponent response cells, they determine the relative brightness of the particular hue. ${ }^{111}$

Nonprimary colors occur when these various color responses overlap. If the $+B-Y$ cell fires above its basal rate (inhibiting the $+Y-B$ cell), and the $+R-G$ cell also fires above its basal rate (inhibiting the $+\mathrm{G}-\mathrm{R}$ cell), the color purple results. In this way, brown is the overlap

109 The neurological account that follows is taken from Kay \& McDaniel, The Linguistic Significance of the Meanings of Basic Color Terms, 54 LANGUAGE 610, 617-26 (1978) (based on experiments with macaque monkeys, who have a visual system similar to that of humans).

110 Id. at 626.

111 See id. at 626-29. 
of the yellow and black responses; pink is the overlap of red and white; and orange is the overlap of red and yellow. These are "derived" colors, and according to Berlin and Kay, terms for these color categories develop later in the evolution of a language's color lexicon. ${ }^{\mathbf{1 1 2}}$

For early-stage languages with only two or three color terms, those terms are composites. ${ }^{113}$ Thus, in Dani, mili and mola are composites of the dark and light colors, respectively. ${ }^{114}$ These cultures name all their colors on a single axis of luminosity provided by the third type of paired neurons, the non-opponent response cells. The members of these cultures, nevertheless, have the same physiology as all other humans and are capable of perceiving and learning names for all of the colors used by English speakers. When they need to identify unnamed colors, they borrow directly from experience to express unnamed perceptions. Thus, Jale, a Stage 1 language of central New Guinea, has a term mut, which means "red soil" but is also used to refer to other red objects. Similarly, another Stage 1, New Guinean language has a term getega for green: the color of a fresh (get) leaf (ega). ${ }^{115}$

\section{b. The multidimensionality of color cognition}

What do these findings imply philosophically? First, they pose problems for the purely objectivist account. It is not sufficiently accurate to say that the colors are arrayed continuously along the light spectrum, yet are categorized discontinuously in language. Rather, some colors, the "focal" ones, are cognitively more "real" than others: more salient, more easily identified, and more easily learned. Thus, internal processes that are part of human physiological interactions with the environment are of central importance in determining what of our external reality is meaningful to us.

Secondly, these findings undermine the purely relativist position. Because we share the same biology, we have much more in common than the relativist supposes. Differences in language categories do not necessarily imply differences in color perception or in perception of color prototypes. Nor do these language differences suggest radical differences in cognitive processes; language development follows roughly the same progression given the relative stability of the human organism and the similarity of our environments.

112 See B. BerLin \& P. KAY, supra note 103, at 17-23; Kay \& McDaniel, supra note 109 , at $638-41$.

113 See Kay \& McDaniel, supra note 109, at 630-31.

114 See supra text accompanying note 107 for a fuller description of Dani and its color terms.

115 B. BERLIN \& P. KAX, supra note 103, at 23-25, 47. 
It is important to recognize, however, that this account does not suggest a "reobjectification" on the order of a Lockean empiricism that would simply define reality as "objective" relative to the human perceptual apparatus. Paul Kay and Willett Kempton designed an experiment to test the relativist insight concerning the effects of different language-systems on cognitive processes. ${ }^{116}$ They presented speakers of English and Tarahumara with three stimuli: two of which would be identified in English as green, and the other as blue. When measured in terms of wavelength, however, the blue and the first of the green stimuli were actually closer together than the two green stimuli. Nevertheless, English-speakers tended to perceive greater distance between the blue stimulus and the closer green stimulus than between the two green stimuli. Tarahumara-speakers - who group all three stimuli under the single color term siyoname - correctly judged the distances between the stimuli. Moreover, when the experimenter displayed the same stimuli two at a time, and characterized the intermediate stimulus as "greener" than one and "bluer" than the other, English speakers correctly identified the actual distance between the stimuli. ${ }^{117}$

The results of these color studies reveal that there is an interactive relationship between experience and the cognitive process: Although the conceptual system represented in a language is grounded in human experience, the acquisition of a particular language mediates further interactions with one's world. In sum, the empirical evidence suggests a three dimensional account that is simultaneously relativist and realist: Human color knowledge is an embodied process, which is shaped by (1) a shared physiology; and (2) a shared environment; nevertheless, it is also (3) subtly responsive to conceptual language systems. If this is true for basic level aspects of our experience, ${ }^{118}$ how do these epistemo-

116 See Kay \& Kempton, supra note 108, at 68-73.

${ }^{117}$ See id. at 73-75. Kay and Kempton identify the reason for this change as the inability of the English-speaking subjects to use a naming strategy to distinguish the stimuli. As they point out, the subject has already tacitly agreed with the nomenclature provided by the experimenter who has in effect identified the intermediate stimulus as both green and blue. Id. at 73 .

${ }_{118}$ "Basic level" categories are organized in terms of direct physical experience relative to observable attributes, human motor movements, and similarity in shape. See Rosch, Principles of Categorization, in Cognition and Categorization 27, 31 (E. Rosch \& B. Lloyd eds. 1978). Categorization at the basic level shows the greatest degree of stimulus commonality within the category, and of stimulus discontinuity between related categories, relative to human experience and purpose. For example, "dog" is a basic level category, "cocker spaniel" a subordinate level category, and "animal" a superordinate level category. "Animal" is less useful a classification because it includes creatures as varied as a golden retriever and a duckbilled platypus. Similarly, "cocker spaniel" is too specific for most everyday purposes such as pet food purchases and "Beware of the ..." signs.

Jay Feinman's otherwise superb piece on legal classification uses the term "basic 
logical insights play out for more abstract cognitive phenomena? We turn next to that question.

\section{Up-down and other Image-Schemata}

The concepts up and down are so fundamental that it is commonplace to take them as given. Quick reflection suggests some complications. Consider David Shapiro's tongue-in-cheek caricature of critical legal studies: ${ }^{119}$

Before Marx, before Hegel, and even before Vico, people were very dumb. And when it came to the question of up or down, they spoke their minds and let it go at that. For example, Heaven was "up" and Hell was "down," and that was just the way it was. And since Heaven was good, up was good, and since Hell was bad, down was bad. . . . People believed. . . .

When the idea occurred to someone that the world was round, the whole up-down business became a real mess. . . . In some ways, the discovery of gravity seemed to the more simple-minded to solve the dilemma. ${ }^{\mathbf{1 2 0}}$

Shapiro has some fun with the contextuality suggested by space travel; he notes that travel to the Sun would first involve going up-up-up but then, as one got closer to the Sun, down-down-down. ${ }^{121}$ But we cannot simply redefine up "objectively" as away from the center of a gravitational field. For this would not account for the orientations astronauts might impose on their space vehicle. Despite their weightlessness and their direction of movement, they are likely to describe the interior configuration of their vehicle in up-down terms - e.g., the bottom of the seats as down and the control panel as overhead.

level" in an idiosyncratic way. Thus, the one serious flaw in his piece is his assertion that: "Contract and tort are basic level categories." Feinman, supra note 2, at 703. To the contrary, categories like "contract" are superordinate level, highly abstract categories. Because they are not derived from the organism's direct experience in the same way as categories like "dog," legal categories have no corresponding "basic level" (although legal rules may use basic level categories like "dog"). Rather, as social and conceptual constructs, legal categories are organized quite differently. I describe this manner of organization and its application to legal categories in succeeding sections. (1984).

119 See Shapiro, The Death of the Up-Down Distinction, 36 Stan. L. Rev. 465

${ }^{120}$ Id. at 465. See also Lennie Bruce, Christ and Moses, on Live AT Carnegie Hali, February 4, 1961 (U.A. Records 1972) ("[H]eaven, I don't where it is; I know it's not up there, 'cause I believe that the earth revolves, man. And sometimes you can go to Heaven at 12:07 and go to Hell at 6:30, yeah. It'd be great name for a book, right: 'Hell is to the left.' Yeah, it may be, right now . . ..").

121 Shapiro, supra note 119 , at 466. 
a. The metaphorical structuring of abstract concepts

The concepts of $u p$ and down do refer to stable physical correlates of the real world, but those correlates are relative to human body orientation. More important, we use the up-down orientational structure to conceptualize a wide variety of nonphysical states. Consider the following common expressions and the metaphoric conceptualizations that make sense of them: ${ }^{122}$

$\begin{array}{ll}\text { things are looking up } & \text { Good is Up } \\ \text { wake up } & \text { Conscious is Up } \\ \text { she had the upper hand } & \text { Control is Up } \\ \text { cheer up } & \text { Happy is Up } \\ \text { he rose above his emotions } & \text { Rational is Up }\end{array}$

On this account, Shapiro gets it exactly backwards: Heaven is good is merely a conventional variant of Good is Up. Complementary formulations substantiate the systematicity of these expressions:

my job is going downhill Bad is Down

I fell asleep Unconscious is Down

I'm low man on the totem Being Controlled is Down pole

I feel low

Sad is Down

this essay is going downhill Nonrational is Down ${ }^{\mathbf{1 2 3}}$

These uses of up-down imagery are neither arbitrary nor completely contingent. As descendants of homo erectus, the experience of being upright in the world is inextricably related to consciousness (ever try to sleep standing?) and to control over many aspects of our environment (ever try to cook on your hands and knees?). For us, up is good. In experientially motivated cases like consciousness and control, that which we experience as pragmatically good and useful in our interac-

122 This discussion is taken from G. LAKOFF \& M. JoHNSoN, supra note 1 , at 14-17, which provides a much more thorough discussion of the extent of these up-down metaphors. Lakoff and Johnson also explain the experiential bases of, and conceptual interrelationships between, these different usages of the up-down schema. Id. at 14-21. I give only a partial account in the following text.

${ }^{123}$ Further examples include the following:

my income is $u p$

she's an upstanding citizen

he's cooking up a storm

More is Up

Virtue is Up

Activity is Up

Corresponding complementary examples would be:

my stocks fell

that's underhanded

I need some downtime
Less is Down

Depravity is Down

Rest is Down 
tions with the world is $u p$ in a basic, nonarbitrary sense. This is what motivates - makes sense of - our language and our way of conceptualizing these abstract experiences. ${ }^{124}$

To say that our way of conceptualizing is experientially motivated is not to say that it is objectively determined. Meaning is equally a matter of experiential grounding, metaphoric systematicity and cultural

124 A colleague reported that, while he changed his child's diaper, he said, "Stay down so Daddy can clean you up." He wondered whether the simultaneous use of contradictory terms might have confused his child, since "up" and "down" were two of the only words the child knew. I could have responded impishly that my colleague, who is a member of the critical legal studies movement, had just introduced his one-year old to the radical indeterminacy of the up-down distinction. Instead, I suggested that his statement was coherent in terms of the Control is Up metaphor: clean is control, so $u p$; baby is subject to control by Daddy, thus down. Rather than confusing his child, the incident was probably one of many that provided experiential grounding and motivation for these metaphors.

In this episode from lived experience we see that what seems like radical contingency in language when viewed against an objectivist standard is instead a case of metaphoric coherence. This phenomenon, in which objectivist assumptions make language appear more arbitrary than it is, is what I describe in Part III C infra as "indeterminacy of paradigm."

Consider also the apparent indeterminacy of divergent uses of the word "improved." See Fuller, Positivism and Fidelity to Law - A Reply to Professor Hart, 71 HARv. L. REv. 630, 664-66 (1958) (using the many meanings of the word "improvement" to illustrate the claim that meaning is contextual). When we say that our finances have "improved," we mean that the value of our assets has risen. Yet when we say that the crime rate has "improved," we mean that the crime rate has gone down.

In these cases, we have a more complex set of metaphoric coherences. "Improved" is understood in terms of a confluence of More is Up and Good is Up. In central cases like the financial case, more wealth is good and improvement is $u p$. In the crime case, however, these two metaphors interact with the Control is $U_{p}$ metaphor to produce a different set of coherences.

As more fully developed in Part IV A infra, we conceive "law" in part as restraint on and control of motion - as in "law and order." Crime is motion in disregard of legal restraint - e.g., when criminals are on the loose, we want them locked up. In our culture, then, the crime rate is understood as a function of the effectiveness of legal control. See Binder, supra note 74, at 894 ("Few seriously question that [imprisonment] 'protects society." "). Thus, when the crime rate is up (More is Up), it is because the level of control is down. Conversely, when the crime rate falls (Less is Down), it is because there is more effective legal control (or so we assume). Thus, the phrase "the crime rate has improved" involves the following metaphoric coherences:

down

crime is bad

crime should be controlled

we want less crime

Bad is Down

Being Controlled is Down

Less is Down

$u p$

control is good

more control $=$ less crime

Good is $U_{p}$
Control is Up
More is $U_{p}$

Because more control yields less crime and less crime is good, "improvement" is when control is up (More is $U p$ and Good is $U p$ ) and crime is down (Less is Down and Being Controlled is Down). 
coherence. In our culture, consciousness, rationality, control, and activity are good, and therefore $u p$. They need not be; in times of cultural ferment, shifts in values produce corresponding shifts in the uses of $u p$ and down. The sixties extolled altered consciousness; Conscious is Up was usurped by Good is Up and Happy is Up, as young people got high. Similarly, we could choose today to reward emotive approaches over coldly rational ones, and seek simplicity and quietude in the face of an increasingly despoiled and polluted world. ${ }^{125}$ For us, however, consciousness, rationality, control, and activity are virtues we seek in ourselves, our colleagues, and our students and therefore remain $u p$. These are our cultural metaphors; to understand their motivation and coherence is to understand how our way of making things "hang together" in fact "hangs together."126

These $u p$-down metaphors are equally conventional in law. If Control is Up, it follows that "[t]his Constitution, and the Laws . . . which shall be made in Pursuance thereof . . ., shall be the supreme Law of the Land."127 The Supreme Court is the highest court; its decisions bind lower courts. ${ }^{128}$ Pierre Schlag notes that the concept of judi-

${ }^{125}$ The group Talking Heads illustrates the robustness of our cultural values and the corresponding oddity to us of such alternative choices: "There was a factory/Now there are mountains and rivers/. . . There was a shopping mall/ Now it's all covered with flowers/If this is paradise/ I wish I had a lawnmower." Talking Heads, (Nothing But) Flowers, on NAKED (Sire Records 1988).

${ }^{126}$ See supra note 54 and accompanying text. Failure to appreciate the cognitive, nonarbitrary dimension of metaphor is fatal to the approaches of people as diverse as Richard Rorty and Steve Fuller. Fuller accepts a view of metaphor as "creative," and he identifies metaphor with "indeterminacy" and "free play." Fuller, supra note 2, at 557 n.18. Thus, it is no wonder that Fuller considers our cognitive capacities so inherently fallible; he does not understand how human rationality operates nonarbitrarily via metaphor. On the problems with Rorty's position, see Johnson, supra note 54, at 36-38 (Rorty fails to understand the continuity and metaphoric coherence in semantic change.).

${ }_{127}$ U.S. Const. art. VI, cl. 2 (emphasis added). "Supreme" derives from the Latin supremus, a variant of super ("over"). The latter is the source of the ubiquitous law review-ism "supra."

${ }^{128}$ Consider the Virginia Supreme Court's argument against the United States Supreme Court's review of state court judgments:

But, before one Court can dictate to another, the judgment it shall pronounce, it must bear, to that other, the relation of an appellate Court. The term appellate, however, necessarily includes the idea of superiority. But one Court cannot be correctly said to be superior to another, unless both of them belong to the same sovereignty.

Hunter v. Martin, 18 Va. (4 Munf.) 1, 12 (1814).

In rejecting this position, Justice Story was careful not to call state courts inferior. Nevertheless, he drew a powerful analogy to the relationship between the state legislatures and Congress, which he expressed with up-down metaphors:

When, therefore, the States are stripped of some of the highest attributes of sovereignty, and the same are given to the United States; when the legislatures of the states, are, in some respects, under the control of con- 
cial review is understood by means of this metaphor. In Marbury, Marshall observed: "The constitution is either a superior paramount law, unchangeable by ordinary means, or it is on a level with ordinary legislative acts." 129

\section{b. The function of image-schemata}

These simple examples illustrate how we structure abstract con-

gress, and in every case are, under the constitution, bound by the paramount authority of the United States; it is certainly difficult to support the argument that the appellate power over the decisions of State Courts is contrary to the genius of our institutions.

Martin v. Hunter's Lessee, 14 U.S. (1 Wheat.) 304, 343-44 (1816) (emphasis added). Later in the opinion, Story invoked the conventional $u p$-down metaphor directly, noting that "the present writ of error is founded upon the judgment of the court below." Id. at 353 (emphasis added).

The extraordinary power of the Control is $U p$ metaphor in legal thinking is strikingly revealed by Cover:

The extraordinary capacity of small shifts in membership of the Supreme Court to transform . . . the strategic significance of the entire federal judiciary, is testimony to the commitment of judges to the hierarchical ordering of authority first, and to interpretive integrity only later.

Cover, supra note 99 , at 58.

${ }_{128}$ Marbury v. Madison, 5 U.S. (1 Granch) 137, 176 (1803), quoted in Schlag, supra note 69, at 931 n. 8 (emphasis provided by Professor Schlag). In quoting the full passage, Schlag mistakenly characterizes Chief Justice Marshall's argument "[t]hat the people have an original right to establish, for their future government, such principles as, in their opinion, shall most conduce to their own happiness, is the basis on which the whole American fabric has been erected," Marbury, 5 U.S. at 175-76 (emphasis provided by Professor Schlag), as further examples of "the rhetorical force of the up/ down distinction." Schlag, supra note 69 , at $931 \mathrm{n} .8$. What Schlag misses is that this passage employs another conventional metaphor: Theories are Buildings. See G. LAKOFF \& M. JoHNSON, supra note 1 , at 46, 52-53.

Marshall's opinion is comprehensible to us because he uses three conventional metaphors: Control is Up; Theories are Buildings; and Rational Argument is War. See Standing and Metaphor, supra note 1, at 1410-12; infra text accompanying notes 404-14 (discussing the systematicity of Rational Argument is War in legal thought). Marshall argues that to allow an unconstitutional law to bind the courts, "would be to overthrow in fact what was established in theory. . . . This doctrine would subvert the very foundation of all written constitutions." Marbury, 5 U.S. at 177. To unpack the metaphors: The theory of constitutional supremacy is a foundation upon which the constitutional building has been established (Theories are Buildings); the argument of legislative supremancy would destroy that structure as in a coup (Rational Argument is War); it would overthrow (Control is Up) or subvert that which was established (Theories are Buildings).

The metaphors explain how we can understand Marshall despite almost two hundred years' difference in our social and historical circumstances. Contrary to Tushnet's suggestion, we do not "gain an interpretive understanding of the past by working from commonalities in the use of large abstractions to reach the unfamiliar particulars of what those abstractions really meant in the past." Tushnet, supra note 8, at 804 . Rather, the continuity of these metaphors in our culture and their comprehensibility in terms of experiential grounding makes the language in Marbury very much the same as our own. 
cepts indirectly by means of more directly experienced "concepts" such as up and down. Those basic concepts are meaningful because they are embodied - that is, because they arise from and are grounded in our preconceptual bodily experiences. Intermediate concepts such as updown are imaginative schemata that we derive from our daily interactions in the world. They are not determined by or immanent in the world. Rather, they are how we as humans make sense of it; how we make worlds. "A schema is a recurrent pattern, shape, and regularity in, or of, these ongoing ordering activities. These patterns emerge as meaningful structures for us chiefly at the level of our bodily movements through space, our manipulation of objects, and our perceptual interactions." 130

As we will see in the next subsection and in Part IV, some of the most important image-schemata that give rise to powerful metaphoric elaborations are the source-path-goal, container (with an in-out orientation), part-whole, front-back, center-periphery, and balance schemata. ${ }^{131}$ The use of legal metaphors derived from the balance schema, for example, is both familiar and ubiquitous. We use it every time we "weigh" competing arguments (and invoke the imagery of a scale when we express those arguments by contrasting statements made "on the one hand" with those made "on the other"). Similarly, we assess the "weight" of evidence, "balance" the competing interests, or apply the inevitable multipart balancing test. ${ }^{\mathbf{1 3 2}}$ Each of the various schemata and

130 M. Johnson, supra note 1, at 29 (emphasis deleted); see also id. at 79 ("If we are to experience our world as a connected and unified place that we can make sense of, then there must be repeatable pattern and structure in our experiences. Image schemata are those recurring structures.").

The idea of schemata as imaginative structures that are necessary to rationality comes from Kant. See id. at 29, 156-57. But the identification of these embodied schemata as mediating between direct experience and abstract thought does not solve the mind-body problem nor respond to the argument of infinite regress. See R. RoRTY, PHILOSOPHY, supra note 39, at 230-43. Some of the research done by "connectionists," however, may help provide the answer to the Cartesian dualism by providing a neurological account of metaphor and reasoning by means of idealized cognitive models. Their work suggests that the neural networks in the brain function by testing input against various known "hypotheses" until there is a "fit" with known information. See P. Churchland, supra note 48 , at 468 .

131 See G. LAKOFF, supra note 1, at 310, and supra note 96 (front-back schema); see Standing and Metaphor, supra note 1, at 1397-99 (part-whole schema); supra notes 92-95 (source-path-goal schema); infra text accompanying note 140 (center-periphery schema); infra text accompanying notes 141-43 (container schema); see also Schlag, supra note 69, at 932 n. 8 (discussing Marshall's use of the inside/outside distinction in Marbury, 5 U.S. at 178); see generally M. JoHNson, supra note 1, at 18-40; G. LAKOFF, supra note 1, at 271-75.

${ }^{132}$ For an extensive discussion of the balance schema, its experiential bases, and its metaphoric extension to structure concepts of ethics, rational argument, and art, see M. JoHNSON, supra note 1, at 74-100. I provide other examples of the centrality of the 
their metaphoric elaborations are familiar and indispensable aspects of our reasoning; they are the basic stuff that makes cognition and communication possible.

\section{Gategorization and Cognitive Models}

George Lakoff entitled his brilliant work on human categorization and cognition Women, Fire, and Dangerous Things. ${ }^{133}$ When I discuss the book with friends and colleagues, many of them interpolate the word "other" after the word "and." This reflects the underlying assumption of objectivist categorization that is a staple of legal reasoning: Items (e.g., fact patterns) are categorized together (e.g., subsumed under the same legal rule) because they share some common property. All things sharing property $\mathrm{P}$ are in the category; all things lacking property $\mathrm{P}$ - that is, $\sim \mathrm{P}$ (not-P) - are not members of the category. ${ }^{134}$ This objectivist approach to categorization is expressed by the conventional tautology of formal logic: "P or $P$."

In choosing his book's title, Lakoff was having a good laugh at the expense of the objectivists amongst us. The title refers to a real language with a category that includes both women and fire, but not, of course, because they are both considered dangerous. The category is balan in Dyirbal, an Australian aboriginal language. Balan also includes dangerous things, water, non-dangerous birds, unusual animals like the duckbilled platypus, and the sun. The explanation for this decidedly non-objectivist category is complex: in Dyirbal mythology, the moon and sun are husband and wife. The sun, being female, is balan. Fire is like the sun; water puts out fire; rivers are bodies of water. All these things are categorized together. Animals are generally classified with human males as bayi. Dangerous or unusual animals, however, are marked by placement in the opposing category, balan. According to Dyirbal myth, birds are the spirits of dead women; they are balan. Dangerous birds like the hawk, however, are marked as bayi. ${ }^{135}$

We cannot dismiss this nonobjectivist categorization as an artifact of some primitive culture. Much of our own categorization equally defies objectivist logic. Wittgenstein made this point for the category "game." He described this nonobjectivist kind of categorization by

balance schema in structuring narrative, morality, and legal reasoning in Legal Power and Narrative Meaning, supra note 4.

133 See G. LAKoff, supra note 1.

134 If this principle is taken as true for propositions, "P or " $P$ " yields the law of the excluded middle, because no alternatives other than $P$ and ${ }^{\top} \mathrm{P}$ exist.

${ }^{135}$ See G. LAKOFF, supra note 1, at 92-104. 
means of the metaphor of "family resemblance." of the modernist to the failure of objectivist classification is a relativist focus on context. As Whorf observes:

Take the word 'hand.' In 'his hand' it refers to a location on the human body, in 'hour hand' to a strikingly dissimilar object, in 'all hands on deck' to another reference, in 'a good hand at gardening' to another, in 'a good hand (at cards)' to another, whereas in 'he got the upper hand' it refers to nothing but is dissolved into a pattern of orientation. ${ }^{137}$

To Whorf's catalogue of expressions, we might add lend $a$ hand (assist) and give her a hand (applause).

Where the relativist sees contextualism, the objectivist sees homonymy: "different" words that sound the same but have disparate meanings. The experientialist, however, understands this to be polysemy: many usages for the same word that are related to each other by a common model or central case. Each usage for hand is related to our basic sense of the human limb. The hour hand is a metaphoric projection of the human body structure; we also refer to the clock's face. The upper hand is a an application of the up-down schema and the Control is $U p$ metaphor. It is grounded in the experience of physical fighting, in which gaining the advantage of gravity (literally the upper hand) is a prelude to achieving control. All hands on deck, a good hand at cards, lend $a$ hand, and give her $a$ hand are all metonymies. ${ }^{138}$ Like meta-

${ }^{136}$ Wittgenstein gives the examples of board-games, card-games, ball-games, Olympic games, and children's games. They have no common necessary and sufficient conditions; for example, "ring-a-ring-a-roses" has neither competition nor winners and losers. He concludes:

[W]e see a complicated network of similarities overlapping and criss-crossing: sometimes overall similarities, sometimes similarities of detail.

I can think of no better expression to characterize these similarities than "family resemblances"; for the various resemblances between members of a family: build, features, colour of eyes, gait, temperament, etc. etc. overlap and criss-cross in the same way.- And I shall say: 'games' form a family.

L. WITTGENSTEIN, supra note $44, \S 66$, at $31 \mathrm{e}-32 \mathrm{e}$.

As a second example, consider the category "salad." What are the necessary and sufficient properties of tossed salad, chef salad, Waldorf salad, fruit salad, tuna salad, potato salad, and bean salad? See Kanigel, How the Mind Sorts Things (Book Review), 21 Psychology Today, Sept. 1987, at 62 (reviewing G. LaKoff, supra note 1). The task of objectivist classification would be hard enough without also trying to account for Shakespeare's "salad days," W. Shakespeare, ANTony and Cleopatra, I.v.73 (G. Evans ed.), or Emerson, Lake \& Palmer's "Brain Salad Surgery." See Emerson, Lake, \& Palmer, Brain Salad Surgery (Atlantic Records 1973).

137 B. Whorf, Language, Mind, and Reality, in Language, Thought, and Reality: Selected Writings of BenJamin LeE WhoRf 260 (J. Carroll ed. 1956). 138 "Metonymic concepts allow us to conceptualize one thing by means of its rela- 
phors, metonymies are experientially grounded. Sailors work with their hands, we lend assistance or we applaud with our hands, and we hold our playing cards in our hands. Each metonymy is a natural extension of the central meaning of hand. ${ }^{139}$

The organization of the linguistic category hand can be understood as a radial category. It has a central case and certain conventionalized extensions. Each extension is related to the central case by means of an experientially-grounded metaphor or metonymy, although the various extensions may have little in common with each other besides their connection to the central case. The radial structure of the category is itself conceptualized metaphorically using the center-periphery schema. The use of this schema to organize and categorize our experiences has a powerful experiential grounding in our necessarily egocentric perception of the world around us. ${ }^{140}$

Objectivist categorization, it should be noted, is also a product of metaphoric reasoning. The dichotomous choice $\mathrm{P}$ or $\sim \mathrm{P}$ is an application of the container schema, as illustrated in Figure 1..Thus, it seems natural to say that "all things sharing property $\mathrm{P}$ are in the category." 141 The objectivist's use of common properties in categorizing conceives of categories as metaphoric containers in which all similarly

tion to something else." G. LAKoff \& M. Johnson, supra note 1, at 39. Lakoff and Johnson also include in their discussion of this cognitive process what rhetoricians call synecdoche, where the part stands for the whole. See id. at 36 (describing, for example, the use of "a set of wheels" to refer to an automobile).

139 Polysemy may also be a function of an idealized cognitive model.

[A] single idealized cognitive model can be the basis on which a collection of senses forms a single natural category expressed by a single lexical item. Window is a good example. In our cognitive model of a window there is both an opening in the wall and a glass-filled frame fitting into it. This correspondence provides motivation for using the same word to refer to both. In isolation, an opening in the wall doesn't have much if anything in common with a glass-filled frame. Independent of any knowledge about the way windows happen to work, there would be no objective reason to place these two very different kinds of things in the same category. The fact that the opening in the wall and the glass-filled frame have been brought together to fit one another physically and to correspond to one another in the same cognitive model seems to make them members of the same cognitive category ....

G. LAKoff, supra note 1, at 417; see also G. LAKoff \& M. JoHNSON, supra note 1, at 115-25 (discussing the problems with and limits of the homonymy view).

${ }_{140}$ As such, radial categories should be a cross-cultural phenomenon. In fact, they are. Balan in Dyirbal and hon in Japanese were the first two radial categories documented by Lakoff. See G. LAKoFf supra note 1, at 104-10 (analyzing the word hon); supra note 135 and accompanying text (describing Lakoff's study of balan). Lakoff and Brugman have also provided a thorough account of the English preposition over as a radial category. See G. LAKOFF, supra note 1, at 418-40.

${ }^{142}$ See supra text accompanying note 134 (emphasis added). 
situated items are located. ${ }^{142}$ This leads to the inference that categories have well defined boundaries. But the world does not come that way. Think of the category "tall people." The container schema of objectivist categorization is a construct we impose on the world. ${ }^{143}$

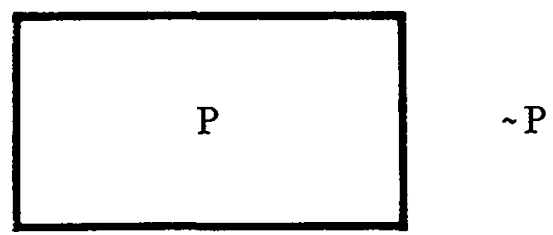

FIGURE 1

\section{Categorization as Container Metaphor}

Consider also the concept lie. A lie is not simply a false statement; the structure of the category lie is not $\mathrm{P}$ or ${ }^{\sim} \mathrm{P}$. Some false statements are exaggerations or jokes; others are great literature (fiction). Moreover, we distinguish between a prototypical lie, on the one hand, and social

142 Judge Posner recently noted this in explaining the logic of the classic syllogism: "All men are mortal; Socrates is a man; therefore, Socrates is mortal."

The first premise says, in effect, here is a box (labeled "all men") with a bunch of things in it, every one of which is "mortal." So anything we pluck out of the box will be "mortal." The second premise tells us that everything in the box is tagged with a name and that one of the tags says "Socrates." When we pluck Socrates out of the box we know that he is mortal because the only things in the box labeled "all men" are mortals. .. . Notice that we find the syllogism compelling by virtue of a metaphor, the metaphor of the box (odd that one should "prove" the truth of logic by a metaphor!).

Posner, The Jurisprudence of Skepticism, 86 Mich. L. REv. 827, 830-31 (1988). Of course, there is nothing odd about this at all, since logic is largely metaphorical.

143 The phenomenon of prototype effects, see supra text accompanying notes 10608; infra text accompanying notes 144-47, also indicates the falsity of the objectivist model of categorization. See also Standing \& Metaphor, supra note 1, at 1385-86 (noting prototype effects for the categories bird and mother).

The logic of objectivist categorization posits that membership in a category is premised on a shared characteristic, so every member should be the same with regard to the relevant trait. $C f$. Posner, supra note 142, at 830-31 (all things placed in the same category by definition share the same property). Yet Rosch found prototype effects in a wide variety of domains aside from color. See, e.g., Rosch, supra note 118, at 31-34 (discussing the categories of furniture and vehicles). According to objectivist logic, this should not be: since all category members share the defining property, they should all be equally good examples of the category.

It is important to recognize that the use of the center-periphery schema to elaborate radial categories does not state an objective truth about the world either. Like the container schema, it, too, is a construct we impose on the world. The difference, however, is that the concept of radial categories better captures the way that humans construct categories. It therefore reflects a better "fit," not with the world, but with the cognitive process by which we apprehend the world. 
lies, white lies, fibs, oversimplifications, tall tales, fantasies, and mistakes, on the other. Linda Coleman and Paul Kay found that, although subjects defined a lie as a false statement, factual falsity was the least important of three criteria used to identify statements as lies.

A consistent pattern was found: falsity of belief is the most important element of the prototype of lie, intended deception is the next most important element, and factual falsity is the least important.

.. . [S]ubjects fairly easily and reliably assign the word lie to reported speech acts in a more-or-less, rather than allor-none, fashion; and ... subjects agree fairly generally on the relative weights of the elements . . . ${ }^{\mathbf{1 4 4}}$

In short, the concept lie is structured in a way that produces prototype effects. Some lies are prototypical; others are graded members of the category. These findings cannot be explained by the category structure $\mathrm{P}$ or $\mathrm{P}$; the objectivist theory of categorization cannot account for these prototype effects. Moreover, the consistency Coleman and Kay found among their subjects indicates that this category structure must be generally shared.

The concept of an idealized cognitive model ("ICM") satisfies these empirical requirements for category structure. An ICM is a "folk" theory or cultural model that we create and use to organize our knowledge. ${ }^{145}$ It relates many concepts that are inferentially connected by means of a single conceptual structure that is experientially meaningful as a whole. For example, our understanding of the words "buy," "sell," "cost," "goods," "advertise," "credit," and the like, are made meaningful by an ICM of a commercial transaction that relates them together as a structured activity. ${ }^{146}$ The use of any of these words individually evokes the entire picture or model, the ICM - a sort of holistic, standardized account.

144 Coleman \& Kay, Prototype Semantics: The English Word Lie, 57 Language 26, 43 (1981).

145 The concept of an idealized cognitive model is related to that of a "stock story" as used by Gerry Lopez and that of a "paradigm" as used by Jay Feinman. See Lopez, supra note 2, at 5-9 ; Feinman, supra note 2, at 699-700. Lopez draws on much of the same social science work as experientialism. Compare Lopez, supra note 2, at $5 \mathrm{n}$. 244, 16 n. 30, \& 17 n. 38 (referring to the work of Roger Schank \& Robert Abelson, Eleanor Rosch, Amos Tversky, George Lakoff, and Mark Johnson) with G. LAKoFf, supra note 1 , at 39-57, 78, 89-90, \& 271-73 (same). Lopez draws on the research available as of approximately 1980; Feinman uses Rosch's 1970's work as a "suggestive metaphor." Feinman, supra note 2, at 702-03 n.150. Lakoff's approach, however, is premised on further empirical and theoretical work since that time.

${ }_{146}$ See Fillmore, Frame Semantics in Linguistics in the Morning Galm 111, 116-17 (Linguistic Society of Korea, 1982). 
An ICM's typical constituent features include:

- ontological entities (including actors, objects, places, events, states, actions, etc.)

- properties of those entities

- temporal sequences of events and actions

- internal structures of events

- causal relations between events

- other patterns of inferences and relations among the entities of the model

An ICM is idealized because it does not "fit" actual, lived situations in a 1:1 correspondence. For example, the concept of

bachelor is defined with respect to an ICM in which there is a human society with (typically monogamous) marriage, and a typical marriageable age. . . .

This idealized model, however, does not fit the world very precisely. It is oversimplified in its background assumptions. There are some segments of society where the idealized model fits reasonably well, and when an unmarried adult man might well be called a bachelor. But the ICM does not fit the case of the pope or people abandoned in the jungle, like Tarzan. . . . ${ }^{147}$

A prototype effect is a consequence of this idealized structure: Some cases will fit the model better than others, and we feel that such cases are prototypical or "right."

Eve Sweetser applied this approach to explain the Coleman-Kay findings. ${ }^{148}$ The use of lie is motivated by two cognitive models. The first is the ICM of ordinary knowledge. Very few of us have direct knowledge of most of what we "know" - like the world being round. Most of us, most of the time, say we "know" when we have adequate

147 G. LAKOFF, supra note 1 , at 70 (discussing Fillmore, Towards a Descriptive Framework for Spatial Deixis, in SPEECH, Place, AND Action 31, 34 (R. Harvella \& W. Klein eds. 1982). Ronald Dworkin refers to this phenomenon of prototype effects as a "paradigm," although he mistakenly distinguishes bachelor as an objectivist $\mathrm{P}$ or $\mathrm{P}$ definition: "bachelorhood holds of unmarried men." LAw's EMPIRE, supra note 8, at 72.

148 See Sweetser, The definition of lie: An Examination of the Folk Models Underlying a Semantic Prototype, in D. Holland \& N. QuinN, supra note 1, at 43. Sweetser's paper was originally done in 1984. The account of Sweetser's work that follows is modified slightly to reflect the subsequent discussion of her work in $G$. LAKOFF, supra note 1 , at 71-74. I have also made two further changes. First, I have reformulated the terms of the ICMs slightly to make the account a little more clear to nonlinguists. Second, I have used the concepts of metonymy and radial categories to explain additional aspects of Sweetser's account. 
reason to believe something to be true. Thus, the ICM of ordinary knowledge posits that:

(1) People have adequate reasons for their beliefs.

(2) Adequately justified beliefs are true.

(3) Then, beliefs are true (i.e., are knowledge).

(3) Something that is false is not believed.

The second ICM is that of ordinary conversation, which assumes that the following conditions are true:

(4) Truthful information is helpful.

(5) The speaker has information; the listener needs/wants that information.

(6) The speaker intends to help the listener by sharing that information.

(6) The speaker who intentionally shares false information intends to harm the listener.

These two ICMs account both for the Coleman-Kay data and the variety of linguistic expressions for false statements. Coleman and Kay found that subjects identified lies in terms of three unconscious, ranked criteria: (a) falsity of belief, the most important criterion; (b) intended deception, the next most important; and (c) factual falsity, the least important. ${ }^{149}$ A prototypical lie meets all three criteria. They found that other false statements were more or less lies depending on which of the ranked criteria applied.

Thus, the concept lie is understood in relation to social conditions in which the ICM of ordinary conversation is expected to apply. The listener assumes that the speaker intends to be helpful. One is helpful if one conveys truthful information. Given the ICM of ordinary knowledge, truth entails belief. A lie violates these social expectations and assumptions. The salient aspect of the lie is not that the speaker conveyed false information, but that the speaker did not believe her own statement ( $3^{\prime}$ and $\left.6^{\prime}\right)$. This is the single most important factor because, in the ICM of conversation, falsity of belief entails a breach of the fundamental normative assumption of an intention to be helpful. It also meets Coleman and Kay's second most important criterion: intention to deceive $\left(\left(6^{\circ}\right)\right.$ sharing information the speaker believes is false).

These ICMs also yield the conventional "definition" of lie that focuses on factual falsity, notwithstanding the fact that it is the least determinative criterion. In the ICM of knowledge, factual falsity entails

149 See Coleman \& Kay, supra note 144, at 43. 
falsity of belief $\left(3^{\prime}\right)$. Given the ICM of conversation, falsity of belief in turn entails intent to deceive (that is, $\left(6^{\circ}\right)$ intent to harm rather than to help). Thus, the conventional definition is a metonymic device for the more complex concept lie. It is a natural choice as the metonym because it is the simplest: What is a lie? A lie is "a false statement."150 The conventional definition is a cognitively more useful way to remember and store the more complicated ICMs that structure the concept lie. ${ }^{151}$

Another way to describe Sweetser's data is to say that the concept lie is a radial category whose central case is defined in terms of the two ICMs for conversation and knowledge. Other false statements share some but not all of the conditions of the prototypical lie. ${ }^{162}$ As indicated

${ }^{150}$ Any other formulation would be longer, for example, "a statement the speaker does not believe"; "a statement the speaker does not intend to be helpful." Economy in encoding information, as it turns out, is one of the most difficult problems faced by those working in artificial intelligence; a computer cannot store enough information to approximate the vast amount of common sense knowledge that the average human utilizes daily. See Holland \& Quinn, Culture and Cognition, in D. Holland \& N. QuinN, supra note 1, at 19.

${ }_{151}$ These models also explain the variant terms listed above. Terms like "joke," "tall tale," and "fiction" indicate that the ICM of conversation is not operating. In these cases, conditions (5) and (6) are otherwise operative and have been complied with because the frame assumes other purposes for the communication, such as humor. Similarly, the term "social lie" - e.g., telling the host "that was a lovely .party" when, in fact, it was a dud - assumes a communication frame in which politeness is more helpful than information. The terms "white lie" and "fib" assume a frame in which information isn't terribly important. The terms "fantasy," "exaggeration," and "mistake" (as well as hedges, e.g., "for all I know") assume that the ICM of ordinary conversation is fully operative but that of knowledge is not. The listener does not depend on the speaker's belief for "truth." "Oversimplification" or a hedge like "to the best of my knowledge" assumes that the ICM of knowledge is operative but that the acceptable "truth" conditions have been altered as specified.

${ }^{162}$ A slightly expanded account of the idealized cognitive model underlying lie also explains the moral ambiguity of two familiar cases: (a) the altruistic person who lies to the Nazis to protect the Jews hiding in the attic; and (b) the doctor who, believing it to be in the patient's best interest, lies to the patient about her condition. Some people would consider both of these to be justified lies; others would think the first justified but not the second; still others would dispute the designation of the first situation as a "lie." See generally S. BoK, Lying: Moral Choice in Public and PRIVATE LIFE 141-53 (1979) (discussing lying to one's enemies); id. at 232-55 (discussing lies to the sick and dying).

Condition (5) of the ICM of ordinary conversation (conveying information) actually entails certain assumptions about the power relationships between speaker and listener. In "the simplified world in which the credulous hearer depends on the speaker for some crucial information, ... . falsehood constitutes a deliberate use of authority to harm someone in a weaker, dependent informational position." Sweetser, supra note 148, at 59; of. Standing and Metaphor, supra note 1, at 1494 n.687 (discussing the related cultural metaphors Ideas are a Physical Force and Knowledge is Power). Together with conditions (4) and (6) relating to truthfulness and helpfulness, this entailment explains the ambiguity of cases (a) and (b).

In (a), the power relationships do not fit the model. The speaker may have information the Nazi wants and, thus, a measure of power, but the Nazi is substantially 
in Figure 2, they are distributed around the core of the concept lie along the axes that mark out the inapplicable conditions.

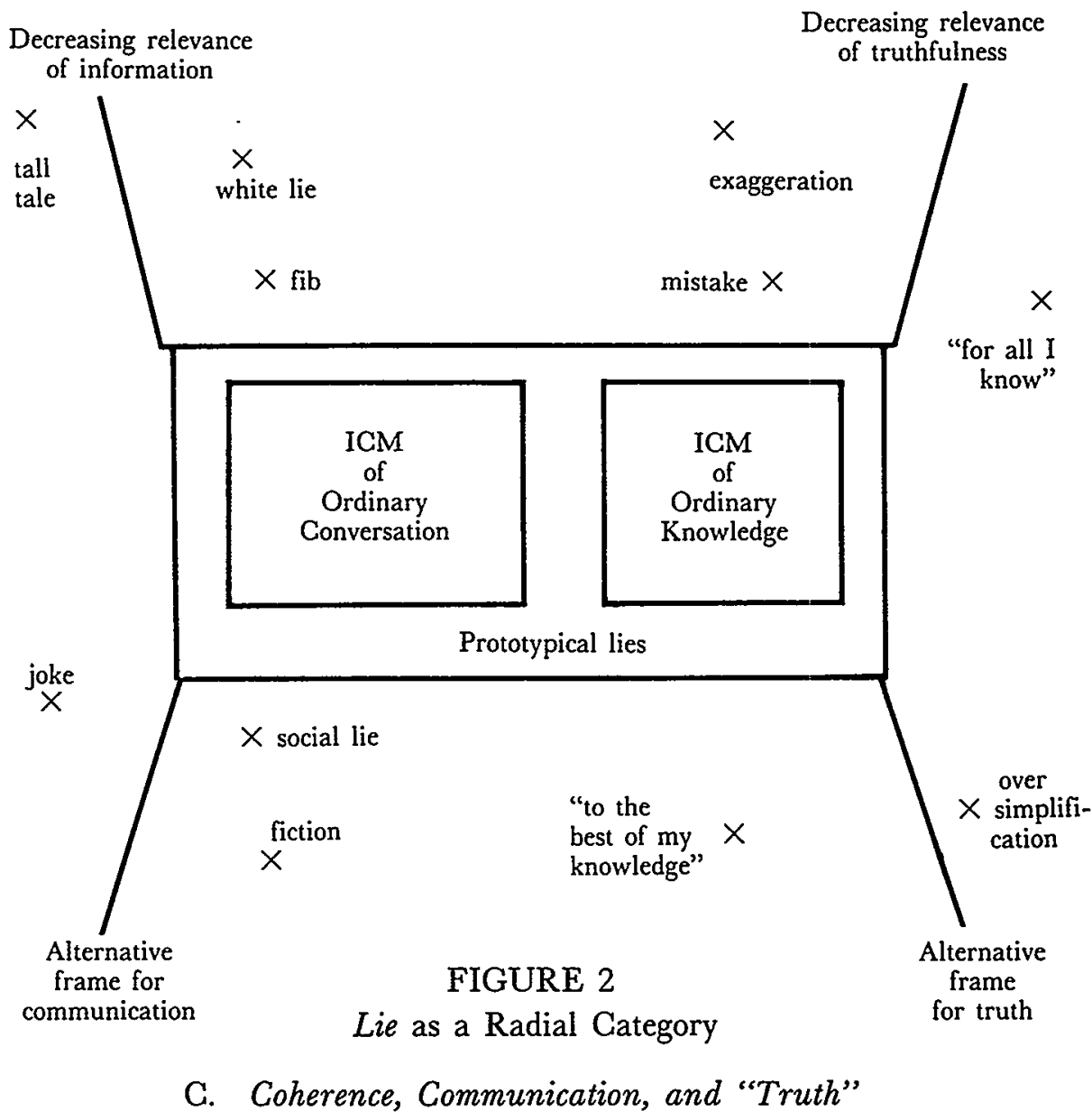

The empirical data concerning human categorization show that

more powerful than the altruist. Moreover, the altruist appears to violate conditions (4) and $(6)$ in the conversation with the Nazi, but the intended helpfulness of the speaker's comments is to the third party she is protecting. The entire situation is in some ways close to the ICM of lie, but it is sufficiently divergent in important particulars to create ambiguity.

Similarly, case (b) is close to but not sufficiently coherent with the ICM to be a prototypical lie. The doctor has a lot of (informational) power over the patient; the false statement appears to be a serious abuse of that power. Nevertheless, it is not a prototypical lie because the situation diverges sharply from conditions (4) and (6): the doctor decides to deceive the patient precisely because she believes (although perhaps wrongly) that deception will be helpful to the patient. 
people do not in fact employ the objectivist categorization of $\mathrm{P}$ or $\sim \mathrm{P}$ in their daily interactions. Categorization is not a function of objectivist logic; it is, rather, an imaginative, cognitive process. Categories are not, however, ad hoc or subjective. Rather, they show substantial systematicity in organization and regularity in extension. Similarly, the empirical work on language shows that metaphor - usually thought to be subjective and wildly contingent - is in fact grounded in human experience and is orderly and systematic in operation. Color categorization, thought to be the most arbitrary of all, turns out to be both regular and related to neurophysiology. In sum, whether we are objectivists or skeptics like Rorty, most of what we think we "know" about meaning and rationality turns out to be the mistaken assumptions of $a$ priori theorizing.

The balance of this essay takes up some of the implications for law of this approach to cognition and categorization. I present evidence that legal categories are neither organized according to the objectivist principle of $\mathrm{P}$ or $\sim \mathrm{P}$, nor radically indeterminate. ${ }^{153}$ Rather, most legal doctrines are radial categories structured in terms of idealized cognitive models. To see this, we need to understand that meaning is not a purely subjective phenomenon, but arises out of direct bodily experiences in the world that all humans share. Although this "grounding" makes language and communication possible, it must not be mistaken for "foundations." Natural motivations of word meanings and of basic level categories are not equivalent to an order immanent in the world itself. At the basic level, they are relative to how we as humans interact with our environment. At more abstract levels, meaning and category structure are a function of human cognitive capacities: They are imaginative, social constructions rather than "rational" deductions from "objective" reality.

Cognitive science indicates that language is not a mysterious, autonomous "creature," but is rather a product of a human cognition that arises from having real bodies and real experiences in real social and

163 The significance to law of the recent scholarship on categorization cannot be overemphasized. Kenneth Vandevelde has noted the pervasiveness of the outmoded $\mathrm{P}$ or "P structure in legal thinking:

Legal thought is, in essence, the process of categorization. The lawyer is taught to place phenomena into categories such as fact or law, substance or process, public or private, contract or tort, and foreseeable or unforeseeable, to name but a few. Categoriz[ation of] phenomena determines how they will be treated by the legal system.

Vandevelde, The New Property of the Nineteenth Century: The Development of the Modern Concept of Property, 29 Buffalo L. Rev. 325, 327 (1980); see also Feinman, supra note 2 , at 664-65. 
physical environments: Color categories are related to neurophysiology; ${ }^{154}$ the many uses of $u p$ and down are motivated by human body structure and its experiential consequences; ${ }^{155}$ and the use and meaning of the term lie and its cognates are structured in terms of social experiences and assumptions. ${ }^{156}$ In none of these cases is the use of language a function of purely arbitrary social conventions. In each case, it is a reflection of how we as embodied and socially-situated humans understand our world by making imaginative use of more directly experienced realities. These imaginative structures are what make a language "hang together" and therefore capable of being shared. At the same time, they introduce an inevitable degree of indeterminacy that can be described and predicted.

This experientialist understanding of language allows us to modify and adapt two of Rorty's important nonobjectivist insights: First, "truth" is a characteristic of language, and language is a human creation; ${ }^{157}$ second, there are some areas of human concern that can be domesticated (reduced to a normal science) and others that will intractably resist domestication. Rorty cites as contrasting examples the prevention of violence, on the one hand, and the search for a just society, on the other. ${ }^{158}$

"Truth" is a function of an understanding that is dependent on the experientially grounded, but imaginatively elaborated cognitive process. In the experientialist view, Rorty's second insight is not only related to, but in fact follows from the first. "Because . . . truth cannot be characterized simply as correspondence to a physical reality, we must recognize truth as a human concept, subject to the laws of human thought. It should come as no surprise that it is structured the way other human concepts are structured." 159 "Truth" is a radial category;

154 See supra notes $109-15$ and accompanying text.

${ }^{165}$ See supra notes $122-29$ and accompanying text.

${ }^{156}$ See supra notes $144-52$ and accompanying text.

157 See supra text accompanying notes 42-46; R. RORTY, ConTINGENCY, supra note 6 , at 21 .

108 See supra text accompanying note 71 . Rorty often expresses this insight in terms of dichotomous distinctions, see R. RORTY, ConsequenCES, supra note 5, at 162,164 . Nevertheless, his insight can be reformulated as revolving around central cases of correspondence. Compare id. at 165 ("The way in which the properlyprogrammed speaker cannot help believing that the patch before him is red has no analogy for the more interesting and controversial beliefs which provoke epistemological reflection.") with G. LAKOFF, supra note 1, at 296-97 ("Here are some examples of central truths: I am writing this. There are three pens and a telephone on my desk. . . . These sentences (like many of the example sentences in the philosophical literature) have a decidedly Dick-and-Jane quality about them. They are very different from the other sentences in this book, most of which I hope you will find true. . . .").

159 G. LAKOFF, supra note 1, at 296. 
we experience central, verifiable truths that are a product of the relative stability of the ways in which our perceptual/conceptual systems "fit" our direct experience of the world at the "basic level." But there are many more non-central truths that are understood indirectly, and, therefore, display a high degree of relativity across cultures.

With Rorty, we can appreciate that the radial structure of our understanding imposes limits on what we can hope to "settle" in highly abstract, normative areas such as social and political theory or philosophy. We can agree upon what it takes to prevent violence in concrete circumstances, but we have difficulty agreeing on how to do so in the abstract (that is, at the level of social policy). Moreover, we are unlikely ever to know the Platonic "essence" of the just society.

Rorty concludes: "If what you are interested in is philosophy, you certainly will not get [agreement]."160 Here, we can both agree and disagree. Rorty is correct that we will not resolve the ultimate problems of philosophy that mark the peripheries of radial constructions such as "Truth," "Beauty," "Goodness," and the like. But there is much at the experiential core of our being that begs to be understood. This too is a kind of philosophy.

But this sort of philosophy is not an a priori discipline pontificating grandly to the rest of science; it is in the swim with the rest of science and hence stands to be corrected as empirical discovery proceeds.

So it is that the brain investigates the brain, theorizing about what brains do when they theorize, finding out what brains do when they find out, and being changed forever by the knowledge. ${ }^{161}$

\title{
III. Metaphoric Reasoning: "Relativity's Laws" In The "Fields" OF PRECEDENT
}

\begin{abstract}
'It is altogether likely that metaphoric 'reasoning' cuts across, indeed rolls right over, the subtleties of ratio decidendi." ${ }^{162}$
\end{abstract}

In a series of four subsections, this Part explores the implications of experientialism for the debate about determinacy and objectivity in

\footnotetext{
${ }^{100}$ R. RoRty, Consequences, supra note 5, at xlii.

161 P. CHURCHLAND, supra note 48 , at 482 .

${ }^{102}$ Leff, Law and, 87 Yale L.J. 989, 1007 n.45 (1978).
} 
traditional legal analysis. I examine several classic and familiar legal texts that discuss the process of legal analysis, and offer an explanation in terms of experientialist cognitive theory. The first two texts are Felix Cohen's Transcendental Nonsense and the Functional Approach ${ }^{\mathbf{1 6 3}}$ and his Field Theory and Judicial Logic. ${ }^{164}$

I start with Cohen's Transcendental Nonsense because it is a classic example of legal realist analysis that disparages the use of metaphor as a distortion of thought which interferes with the rationality associated with law. ${ }^{165}$ Gohen begins his famous article by recounting Von Jhering's satirical longing to meet the transcendental spirits of legal formalisms, the Platonic essences of legal concepts such as "property, possession, laches, and rights in rem."168 Cohen treats these and other legal fictions and metaphors as "transcendental nonsense." This is the realist attack on metaphor as a formalist or rhetorical trope that distorts legal thinking. ${ }^{167}$

I shall show that beneath the surface of its rational pragmatism, Cohen's argument for his "functional approach" displays the same powerful and systematic process of metaphoric reasoning as the decisions he criticizes. I will demonstrate that a single set of metaphors is central both to his initial critique and his later efforts at reconstruction.

16335 Colum. L. Rev. 809 (1935).

18459 YALE L.J. 238 (1950). These legal realist works have inspired many associated with the critical legal studies movement. See, e.g., Kennedy, Form and Substance in Private Law Adjudication, 89 HARv. L. Rev. 1685, 1732 n.108 \& 109 (1976) (citing numerous articles by Cohen); Hutchinson \& Monahan, The "Rights" Stuff: Roberto Unger and Beyond, 62 TEX. L. REv. 1477, 1485 n.42 (1984) (relating Cohen's "early sighting of 'thingification'" to the critical legal studies critique of law as "reification"); Peller, The Metaphysics of American Law, 73 CAL. L. REV. 1151, 1226$32,1238-40$ \& 1245-54 (1985) (describing Cohen's "deconstructionist" versus his "constructive" and "scientific" tendencies); Boyle, The Politics of Reason: Critical Legal Theory and Local Social Thought, 133 U. PA. L. REv. 685, 693 n.18 (1985) (noting that an article by Cohen encapsulated so many of the realist themes); see also Stick, supra note 20 , at 333 n. 6 (noting that "[t]he legal realists most often cited by critical legal scholars are Felix Cohen, Jerome Frank, and Karl Llewellyn.").

165 See Cohen, supra note 163, at 810-12.

${ }^{168} I d$. at 809.

${ }^{167}$ Here, again, the use of categorical labels like "realist" is potentially misleading. Cohen was a legal realist but, in point of fact, his philosophical position changed over time from pragmatism to a scientific form of relativism. Compare Cohen, supra note 163, at 822-34 (identifying the "functional approach" with the pragmatism of Peirce, Dewey, and James) with Cohen, The Relativity of Philosophical Systems and the Method of Systematic Relativism, 36 J. PHIL. 57 (1939), reprinted in F. CoHEN, THE Legal CONSCIENCE 95, 96-97 (L. Cohen ed. 1960) (abandoning pure pragmatism for a "systematic relativism"); Cohen, supra note 164, at 242-44 (applying to law a notion of "translatability" between conceptual systems taken from Einstein's theory of relativity) and Cohen, The Vocabulary of Prejudice, 19 Fellowship MAG. 5 (Nov. 1953), reprinted in $\mathrm{F}$. COHEN, supra, at 429,435 (applying this technique to a semantic analysis of prejudice). Needless to say, the experientialist approach to metaphor is quite different from that articulated by Felix Cohen in Transcendental Nonsense. 
I contrast these efforts with parallel articles and decisions that take up related metaphors as their means of analysis. In making this analysis, I wish to go beyond the obvious point regarding the ubiquity and necessity of metaphor in human thought. Rather, I intend to demonstrate how an appreciation of the cognitive dimension of metaphor can help us construct a framework for a more realistic concept of law.

In the second subsection, I examine the famous exchange between H.L.A. Hart and Lon Fuller concerning the interpretation of a rule that prohibits the use of vehicles in a park. ${ }^{168}$ To a surprising degree, Hart's approach to legal meaning anticipates the linguistic insights of the experientialist epistemology. ${ }^{169}$ I will examine the counterarguments raised by Fuller and show that they are substantially answered by cognitive theory. Notwithstanding Hart's prescience, I will discuss both the gap in and the limits of his position. I will explain how the concept of idealized cognitive models simultaneously fills that gap, incorporates what is most important about Fuller's critique, and makes untenable Hart's ultimate positivist claim.

The third subsection elaborates an experientialist approach to the indeterminacy critique. Understanding the role of metaphor and idealized cognitive models in legal reasoning will enable us to account for, and more accurately describe, the experience and process of legal analysis. It will enable us to locate and describe three different kinds of indeterminacy: one that is intrinsic to human rationality; a second that is an avoidable consequence of the traditional approach to legal reasoning; and $a$ third that is merely the obverse of law's contribution to social organization and development.

In the fourth subsection, I illustrate the aptness of an experientialist understanding of legal analysis by examining the majority opinion in NLRB v. Jones \& Laughlin Steel Corp. ${ }^{170}$ Chief Justice Hughes' opinions generally are distinguished by a sensitivity to the unreality of legal metaphors like the "situs" of an intangible debt. ${ }^{171}$ Accordingly,

${ }^{168}$ Hart, Positivism and the Separation of Law and Morals, 71 HaRv. L. REv. 593 (1958); Fuller, supra note 124.

169 The relationship between Hart's linguistic position and the later experientialist epistemology can be traced to the influence of J.L. Austin, who was at Oxford during the same years as Hart. See N. MacCormick, H.L.A. Hart 14-19 (1981); H.L.A. HART, The ConCEPT OF LAW (1961) (Preface) (acknowledging the influence of Austin's work). Austin's PhIlosophical PAPERs (1961), which was written in 1940 , later influenced the development of the experientialist approach. See G. LAKOFF, supra note 1 , at $17-21$. Gudridge.

170301 U.S. 1 (1937). My interest in this text was sparked by my colleague Pat

${ }^{171}$ See, e.g., New York ex rel. Whitney v. Graves, 299 U.S. 366, 372 (1937) ("When we speak of a 'business situs' of intangible property in the taxing State we are indulging in a metaphor."); Liverpool \& London \& Globe Ins. Go. v. Board of Asses- 
the Jones $\mathcal{E}^{2}$ Laughlin opinion is usually read as displaying skepticism toward the Court's dependence on metaphor in its "stream of commerce" precedents.

Hughes' Jones \& Laughlin opinion, however, displays precisely the opposite phenomenon. Hughes rejects the petitioners' propositional, categorical argument, and instead, elaborates a systematic set of metaphors that suggests the naturalness and necessity of an expanded federal role in the modern American economic system. I will show that the rejected categorical distinction and the newly elaborated position are each metaphorically structured relative to a different cognitive model for commerce clause analysis. Thus, the Jones $\mathcal{E}$ Laughlin opinion demonstrates the way that law changes by means of a shift from one idealized cognitive model to another - a shift that then motivates the elaboration of a different set of metaphors.

\section{A. What's a Metaphor For?}

Much legal thought assumes that metaphors distort and that only propositions and rigorous logic are proper bases of legal reason. ${ }^{\mathbf{1 7 2}}$ Richard Rorty expresses similar sentiments in his argument against objectivist epistemology: "It is pictures rather than propositions, metaphors rather than statements, which determine most of our philosophical convictions."173 Felix Cohen makes a related point in attacking what he calls transcendental nonsense in law. "When the vivid fictions

sors, 221 U.S. 346, 354 (1911) ("When it is said that intangible property, such as credits on open account, have their situs at the creditor's domicile, the metaphor does not aid. Being incorporeal, they can have no actual situs."); but see Graves v. Elliott, 307 U.S. 383, 390 (1939) (Hughes, C.J., dissenting) ("This general rule proceeds in the view that intangibles, as such, are incapable of an actual physical location and that to attribute to them a 'situs' is to indulge in a metaphor. Still, in certain circumstances the use of the metaphor is appropriate." (citation omitted)).

${ }^{172}$ Despite his unusual rhetorical gift, Justice Cardozo was a frequent critic of legal metaphor. In criticizing the phraseology used in legal tests concerning "piercing the corporate veil" he wrote: "Metaphors in law are to be narrowly watched, for though starting as devices to liberate thought, they end often by enslaving it." Berkey v. Third Ave. Ry. Co., 244 N.Y. 84, 94, 155 N.E. 58, 61 (1926); see also B. Cardozo, What Medicine Can Do for Law, in LAw AND Lirerature 100 (1930) (What is meant [by 'sudden impulse' sufficient to defeat a finding of 'malice aforethought'], as I understand it, is that the impulse must be the product of an emotion or passion so swift and overmastering as to sweep the mind from its moorings. A metaphor, however, is, to say the least, a shifting test whereby to measure degrees of guilt that mean the difference between life and death.").

${ }_{173}$ R. RORTy, Philosophy, supra note 39, at 12. This is Rorty's attack on the mind as mirror metaphor. As noted above, supra note 54, Rorty has adopted Davidson's view that metaphors have no meaning or cognitive content, comparing a metaphor to a tic, malapropism, or grimace. See R. RORTY, CoNTINGENCY, supra note 6, at 14, 18 (discussing Davidson's view). 
and metaphors of traditional jurisprudence are thought of as reasons for decisions, rather than poetical or mnemonic devices . . . [,] then [one] . . . is apt to forget the social forces which mold the law."174

Cohen's critique of legal metaphor comes at the close of his discussion of Cardozo's opinion in Tauza v. Susquehanna Coal Co. ${ }^{175}$ The New York Court of Appeals upheld the assertion of jurisdiction over a Pennsylvania company with a sales office, eight salespersons, and a bank account in New York. It did so on the ground that the company was doing business in the state and, thus, that "its business is such that it is here."176 Cohen's biting criticism of the opinion focuses on the court's reasoning process.

Instead of addressing itself to such economic, sociological, political, or ethical questions as a competent legislature might have faced, the court addressed itself to the question, 'Where is a corporation?' Was this corporation really in Pennsylvania or New York, or could it be in two places at once?

Clearly the question of where a corporation is, when it incorporates in one state and has agents transacting corporate business in another state, is not a question that can be answered by empirical observation. . . .

.. . Nobody has ever seen a corporation. What right have we to believe in corporations if we don't believe in angels? To be sure, some of us have seen corporate funds, corporate transactions, etc. (just as some of us have seen angelic deeds, angelic countenances, etc.). But this does not give us the right to hypostatize, to "thingify," the corporation, and to assume that it travels about from State to State as mortal men travel. . . .

[I]t is exactly in these terms of transcendental nonsense that the Court of Appeals approached the question. . . . "The essential thing," said Judge Gardozo. . . "is that the corporation shall have come into the State." Why this journey is essential, or how it is possible, we are not informed. The opinion notes that the corporation has an office in the State, with eight salesmen and eleven desks, and concludes that the corporation is really "in" New York State. From this inference it easily follows that since a person who is in New York can be sued here, and since a corporation is a 
person, the Susquehanna Coal Company is subject to suit in a New York court. ${ }^{177}$

What do we make of Cohen's critique? Certainly, it captures a flow in the court's reasoning that is simultaneously bizarre and logical in a common sense way. Cohen is correct that corporations cannot be "here" in any literalist sense. On the other hand, talk about the "presence" of the corporation is conventional in our language (Is that ABC over there on Sixth Avenue? Do you have an A \& $P$ here?). ${ }^{178}$ Moreover, Cohen may be wrong about "thingification"; the court does not "thingify" the corporation so much as personify it. Cohen recognizes this in his complaint that the court treats the corporation as if "it travels about from State to State as mortal men travel."179 Again, though, such personification is conventional in our language (Has Exxon raised its prices again? Did USX declare a dividend this quarter?). ${ }^{\mathbf{1 8 0}}$ And, even if it is only a heuristic device, the personification works exceedingly well. It captures a sense of balance and fairness in making a corporation that does business in (and thus extracts profits from) a state, amenable to that state's adjudicatory power. If the corporation has "come into" the state to do business, then it is "in" the state for jurisdictional purposes, too.

Cohen does acknowledge some role for the "poetical or mnemonic devices." "The law is not a science but a practical activity, and myths may impress the imagination and memory where more exact discourse would leave minds cold." 181 His complaint is merely that such devices should not be mistaken for the "reasons for decisions." happens when the courts attempt self-consciously to acknowledge the figurative discourse that clothes practical decisionmaking? Experientialist epistemology suggests that the courts will not function in a substantially different manner: They will not be able to purge metaphors from their analyses, but will be driven to other metaphors. And in fact, that is what we find.

Ten years after Cohen's critique of Tauza, the New Deal Court

177 Cohen, supra note 163, at 810-11 (quoting Tauza, 220 N.Y. at 268-69, 115 N.E. at 918) (footnotes omitted).

${ }^{278}$ The discerning reader will note that these two examples also employ metonymy. See supra text accompanying notes 138-39.

${ }_{179}$ Cohen, supra note 163, at 811.

180 The word "corporation" signifies personification; it derives from the Latin corporatus, which means "to furnish with a body." See A LATIN Dictionary Founded on ANDREw's Edition of Freund's Latin Dictionary 492 (C. Lewis \& C. short eds. 1955).

181 Cohen, supra note 163 , at 812 .

182 Id. 
revamped the exercise of state long arm jurisdiction over foreign corporations. In International Shoe Co. $v$. Washington, ${ }^{183}$ Chief Justice Stone introduced the discourse that still dominates modern determinations of jurisdiction. Acknowledging Cohen's critique, he argued:

Since the corporate personality is a fiction, although a fiction intended to be acted upon as though it were a fact[,]. . . it is clear that unlike an individual its "presence" without, as well as within, the state of its origin can be manifested only by activities carried on in its behalf by those who are authorized to act for it. ${ }^{184}$

Stone had not abandoned the figurative discourse of Tauza. Corporate presence was now recognized as a fiction, but "a fiction intended to be acted upon as though it were a fact." In fact, Stone cited Tauza in support of the Court's decision in International Shoe. ${ }^{185}$

The sole accomplishment was the recognition of the metaphor of corporate presence with quotation marks: "[T]he terms 'present' or 'presence' are used merely to symbolize those activities of the corporation's agent within the state which courts will deem to be sufficient to satisfy the demands of due process." 188 The Court interposed none of Cohen's desired economic, sociological, political, or ethical discussions between the symbolic or mnemonic label of "presence" and its practical conclusion. It merely substituted one "thingification," one metaphor of objectification, for another:

[D]ue process requires only that in order to subject a defendant to a judgment in personam, if he be not present within the territory of the forum, he have certain minimum contacts with it such that the maintenance of the suit does not offend "traditional notions of fair play and substantial justice."187

Under the new regime of International Shoe, the courts were to look not for the "presence" of the personified corporation, but rather for the "contacts" of one object (the corporation) with another (the forum state). The analysis had not been advanced at all; indeed, commentators and the Court still struggle to determine which "contacts" count. ${ }^{188}$

183326 U.S. 310 (1945).

184 Id. at 316 (citation omitted).

185 See id. at 318.

186 Id. at 316-17.

187 Id. at 316 (quoting Milliken v. Meyer, 311 U.S. 457, 463 (1940)); see also id. at 317 ( requiring "such contacts of the corporation with the state of the forum as make it reasonable. . . to require the corporation to defend the particular suit").

${ }^{188}$ See, e.g., Asahi Metal Indus. Co. v. Superior Court, 480 U.S. 102, 112 (1987) 
There are two ways to look at the lesson of International Shoe. First, Cohen could be right: The Court failed to advance analysis because we cannot improve legal analysis without abjuring metaphor. Cohen argues for a realist, functional jurisprudence that focuses on empirical and social facts - precisely what the Court failed to provide. ${ }^{188}$ On the other hand, the experientialist epistemology could be correct: Metaphor is inevitable in legal analysis because it is central to human rationality; it is a primary mode of comprehension and reasoning. On the latter view, Cohen's genius is not in his disparagement of the Court's mode of analysis, but in his explication of how legal reasoning works. It depends, first, on "thingifications" and, second, on exploiting inferences suggested by metaphoric projection. Cohen himself suggests the naturalness of the inference arising from personifying a corporation: "[I]t easily follows, that since a person who is in New York can be sued here, and since a corporation is a person, the Susquehanna Coal Company is subject to suit in a New York court."180

I want to test this new reading of Cohen's critique against his own work. Cohen has two prescriptions for reading precedents, for "substitut[ing] a realistic, rational, scientific account of legal happenings for the classical theological jurisprudence of concepts." risprudence of empirical fact: "Any word that cannot pay up in the currency of fact, upon demand, is to be declared bankrupt, and we are to have no further dealings with it." ${ }^{192}$ The second is a jurisprudence of sociological realities:

Creative legal thought will more and more look behind the pretty array of "correct" cases to the actual facts of judicial behavior, will make increasing use of statistical methods in the scientific description and prediction of judicial behavior, will more and more seek to map the hidden springs of judicial decision and to weigh the social forces which are repre-

(plurality opinion) (Jurisdiction based on minimum contacts should require "an action of the defendant purposefully directed toward the forum state."); Brilmayer, How Contacts Count: Due Process Limitations on State Court Jurisdiction, 1980 SuP. CT. REv. 77, 82-83 (arguing that the "contacts" which count should be those that establish the cause of action).

${ }^{180}$ But see, e.g., Gray v. American Radiator \& Standard Sanitary Corp., 22 Ill.2d $432,441-42,176$ N.E.2d 761, 765-66 (1961) (emphasizing the fact of "the increasing nationalization of commerce" in support of long arm jurisdiction). Gray's survival is in doubt, however, in light of World-Wide Volkswagen Corp. v. Woodson, 444 U.S. 286, 293, 298 (1980), and the plurality opinion in Asahi, 480 U.S. at 109-12, both limiting jurisdiction despite the increasing economic interdependence of the States.

190 Cohen, supra note 163 , at 811 .

191 Id. at 821 .

192 Id. at 823. 
sented on the bench. ${ }^{193}$

Let us count the metaphors. First, Words are Market Phenomena (pay up in the currency of fact, or face bankruptcy). Second, Judicial Decisions are Geological Phenomena (judicial decisions come from hidden springs which legal thought should map). ${ }^{194}$ Third, Law is an Object (the pretty array of cases, which we should look behind). In this last metaphor, Cohen stoops to his own "thingification" of law. He explicitly describes law as a social phenomenon "no different from other social institutions or physical objects."185 Fourth, like other objects, law responds to physical forces, so Legal Theory is Physics. Cohen can thus reject legal science qua transcendental logic yet argue for "the scientific description" of judicial behavior that will "weigh the social forces which are represented on the bench."198

This fourth set of metaphoric inferences is particularly important to Cohen's position. He invokes the social force metaphor consistently ${ }^{197}$ and casts it in a pivotal role as he adumbrates his central claim for the functional method's empirical component. Cohen first rejects the subjectivist approach (which he associates with realists like Jerome Frank and Judge Hutcheson) that attributes judicial decisionmaking to the judge's intuition or imagination. ${ }^{198}$ Second, he claims that the study of law should be the study of the sociological meaning of judicial decisions; he argues for a new science of law that follows the functional method of empirical study and practical consequence. He elaborates on Legal Theory is Physics, asking: "What are legal decisions made of?"

Just as every physical object may be analyzed as a complex

193 Id. at 833 .

194 See id. Cohen uses the structural metaphors Knowing is Seeing and Intellectual Investigation is Exploration. The specific metaphors of "mapping hidden springs" is an entailment of these more conventional general metaphors.

195 Id. at 844 n.84 (emphasis added).

198 Id. at 833 (emphasis added).

197 He uses this metaphor no fewer than five times: in his criticism that metaphor makes us "apt to forget the social forces that mold the law ...," id. at 812 (emphasis added); in his prescription for creative legal thought, see id. at 833; in his characterization of the role of social policy in decisionmaking, see id. at 840; in his description of the nature of legal thought, see id. at 839; and in his theory of legal decision, see id. at 842-43.

198 See id. at 843 n.81 (citing J. Frank, Law and the Modern Mind (1930) and Hutcheson, The Judgment Intuitive: The Function of the "Hunch" in Judicial Decisions, 14 CoRNell L.Q. 274, $277-78$ (1929)).

I do not read Judge Hutcheson to have advocated such a solipsistic view of judicial decisionmaking. See infra note 255. Rather, it was Felix Frankfurter who acknowledged the role of what he called "the interplay of the subjective element in any judgment and the objective criteria by which it professes to be guided . . . ." Frankfurter, Foreword, 9 RuTGers L. REv. 355, 355 (1954). Ironically, Frankfurter made this remark in his eulogy for Felix Cohen. See id. 
of positive and negative electrons, so every legal institution, every legal rule or concept may be analyzed as a complex of plaintiff decisions and defendant decisions. But simplicity is relative to the level of analysis. For the chemist, the atom is the lowest term of analysis. But the physicist cannot stop the process of analysis with the atom or even the electron. . . . Unfortunately, certain advocates of realistic jurisprudence, after using the functional method to break down rules and concepts into atomic decisions, refuse to go any further with the analytic process. They are willing to look upon decisions as simple unanalyzable products of judicial hunches or indigestion.

. . Those who have advanced this viewpoint have performed a real service in indicating the large realm of uncertainty in the actual law. But actual experience does reveal $a$ significant body of predictable uniformity in the behavior of courts. Law is not a mass of unrelated decisions nor a product of judicial bellyaches. . . . The decision that is "peculiar" suffers erosion -- unless it represents the first salient manifestation of a new social force....

A truly realistic theory of judicial decisions must conceive every decision as something more than an expression of individual personality, as concomitantly and even more importantly a function of social forces, that is to say, as a product of social determinants and an index of social consequences. A judicial decision . . . is an intersection of social forces: Behind the decision are social forces that play upon it to give it a resultant momentum and direction; beyond the decision are human activities affected by it. . . . Only by probing behind the decision to the forces which it reflects, or projecting beyond the decision the lines of its force upon the future, do we come to an understanding of the meaning of the decision itself. ${ }^{189}$

In Transcendental Nonsense, Cohen also invokes a force field metaphor to argue for the role of social policy in judicial decisionmaking: "Social policy' will be comprehended not as an emergency factor in legal argument but rather as the gravitational field that gives weight to any rule or precedent."200 Cohen elaborates on that insight in

198 Cohen, supra note 163, at 842-43 (emphasis added) (footnote omitted).

${ }^{200}$ Id. at 834 (emphasis added). 
his 1950 article Field Theory and Judicial Logic, referring to Einstein's theory of relativity and the concept of the field to describe the operation of precedent. He writes:

According to traditional judicial logic, every precedent moves in a straight line, imparting its direction to every case that gets in its way. In fact, however, we find that the force and direction of a precedent vary with the field in which it is observed. We are not now, and probably never will be, able to predict the path of a precedent with absolute certainty. No more can we always, with complete assurance, predict the path of a merely physical object. But at least we know that information about the weight of the object and its direction and velocity at a given point would be relevant to our prediction. So, too, we know something about the relevant factors in plotting the path of a precedent. We know that the line of motion of any precedent is subjected to a special pull that skews it whenever it passes near a point of high value tension. A series of precedents that shows a straight line when the judgments range from $\$ 1,000$ to $\$ 100,000$ may swerve pretty sharply when a case involves a twenty million dollar judgment against a government or other public institution that cannot make such a payment without serious public repercussions. Precedents that point to the protection of civil liberties may suddenly dwindle in times of public hysteria, but after the hysteria subsides they may resume their original force and direction. ${ }^{201}$

In this passage, Cohen uses the force field metaphor several ways. First, by elaborating Legal Theory is Physics, Cohen privileges his argument by implying that his assertions about law must be true because they are premised on a new scientific discovery: force fields. Second, the metaphor provides an effective means of communicating the experience of both constraint and pliability in applying precedent. Third, the metaphor accounts for observed aberrations without vitiating a theory of predictability in judicial decisionmaking: As an astronomer discovers a new planet because it is the only explanation for the seemingly irrational movement of a known one, the legal scientist can account for and predict distortions in areas of high political charge or "high value tension."

The metaphor may also be working in a fourth way. The con-

201 Cohen, supra note 164, at 249 (footnote omitted). 
tinuity of the metaphor may mask a change both in how Cohen uses the metaphor and in what he uses it to say. In 1935, Cohen argued that we should replace formalistic legal reasoning with realistic, empirical analysis of social fact and policy. He criticized the dominant jurisprudence for failing to account for the real reasons of decision, portraying social policy as "the gravitational field that gives weight to any rule or precedent." 202 But in 1950, Cohen invoked the force field metaphor both to acknowledge how precedent shapes subsequent decisions and to capture the subtle relationship between that vector and the force exerted by a decisionmaker's value system. Propositional legal rules have an ascertainable, directive effect on judicial decisionmaking. ${ }^{203}$ If we don't know how much of an effect, it is because in law, as in the physical sciences, we are still learning to understand our world. ${ }^{204}$

In Field Theory, Gohen attempts to interpolate insights from Einstein's relativity theory into his own previously pragmatist assessment of the judicial process. Here, he aims for greater precision and predictability in evaluating the use of precedent. ${ }^{205}$ To Cohen, variations in different observers' descriptions suggest not a lack of essential objectivity to the underlying phenomenon, but rather merely different perspectives or value-fields. ${ }^{206}$ This view leads Cohen to use the force field

${ }^{202}$ Cohen, supra note 163 , at 834 .

${ }^{203}$ In Cohen's words, "[a] series of precedent ... shows a straight line"; "[p]recedents . . . point." Cohen, supra note 164, at 249.

204 "We are not now, and probably never will be, able to predict the path of a precedent with absolute certainty. No more can we always, with complete assurance, predict the path of a merely physical object." Id.

20s "[T]he real question is not whether judges should follow precedent (or logic or the law of gravitation or anything else that they cannot help following, whether they know it or not). It is, rather, how they should follow precedent. . . " Id. at 245 (footnote omitted).

${ }^{208}$ Cohen puts this most strongly in his The Relativity of Philosophical Systems, supra note 167, at 95-110, and in THE LeGal Conscience, supra note 167, at 11820 ("If what Aristotle had to say about law, what St. Thomas, Hobbes, Bentham, Austin, and Holmes have had to say about law, was, as I believe, worth saying, then the substance of each of these great contributions to jurisprudence must be capable of translation into every other jurisprudential tongue. . . .").

Cohen derived this model of translatability from relativity theory, an analogy he took quite seriously:

The real importance of Einstein is his development of formulae by which many different accounts of the same physical event may be correlated with each other, so that from the position and direction of an event in any physical system we can calculate its position and direction in any other system. . . .

What is needed in law, if law is to become more scientific in the future than it has been in the past, is a body of learning from which we can predict that what looks like a straight story or a straight sale from one standpoint will look like a crooked story or a crooked sale from another. ... 
metaphor to change his account of how legal rules are used to decide cases. Thus, in.Field Theory, gravitational force is no longer something that accounts for a rule and makes it work (i.e., that gives it weight). Rather, gravity becomes an additional force that acts upon the normal operation of a rule: the extra-legal factor of values now exerts "a special pull that skews" the ordinary "line of motion of any precedent."207

The continuity of the force field metaphor, however, enables Gohen to recognize some order and determinacy to legal reasoning and still recapitulate his prior critique. He repeats the atomic metaphor to reject Jerome Frank's "bellyache" theory and uses the force field metaphor to explain why Judge Frank felt so constrained by precedent. ${ }^{208}$ $\mathrm{He}$ also uses the metaphor to defend against the charge of nihilism frequently leveled at legal realism (as it is now at critical legal studies): "It is enough to see that we can reject the old idea of straight lines of precedent filling absolute legal space, without surrendering to chaos or impressionism. Relativity also has its laws, its certainties, and its demanding quests for verifiable fact."208

If this section has seemed critical of Cohen, it is not so intended. Like Karl Llewellyn, ${ }^{\mathbf{2 1 0}}$ Cohen was sensing and pursuing some very important cognitive phenomena. Cohen, however, died before he had an opportunity to explicate "relativity's laws" further. In subsection C, I extend Cohen's analysis by reinvigorating his first set of force metaphors with his later field analysis. To do so, however, I will need to enrich our discussion, first, with a famous jurisprudential debate and, second, with the work of one of Cohen's successors.

Similarly, we should be able to predict that what Justice $\mathrm{X}$ will view as "judicial protection of fundamental constitutional liberties" will be viewed by Justice $\mathrm{Y}$ as "federal interference with the constitutional freedom of the states to experiment in the solution of their own social problems."

Cohen, supra note 164, at 243 (footnote omitted). Thus, Cohen's notion of relativity was (paradoxically) objectivist: He assumed a mind-independent reality composed of objects whose essences remain constant despite differences in perspective and description, and he believed that a formula could "translate" between these apparent differences. For a discussion that demonstrates similar objectivist assumptions behind the relativism of Benjamin Lee Whorf, see G. LAKoff, supra note 1, at 324.

207 Cohen, supra note 164 , at 249.

${ }^{208}$ See id. at 250-51 ("[T] he man who dons the judicial robe with the greatest contempt for precedent finds that the pressure of his office-space compels him to follow paths that, from outside the office-space, once appeared absurd."); see also supra notes 198-99 and accompanying text (discussing Cohen's initial rejection of the subjectivist approach).

${ }^{200}$ Cohen, supra note 164 , at 251.

${ }^{210}$ See Legal Power and Narrative Meaning, supra note 4, at 43-47 (discussing Llewellyn's concept of "situation-sense" in his later work). 


\section{B. The Hart/Fuller Debate, or "When Is a Vehicle a Vehicle?"}

In 1958, H.L.A. Hart and Lon Fuller debated the structure of a rule that prohibits vehicles in a park. ${ }^{211}$ In the course of defending the positivist distinction between law (the "is") and morals (the "ought"), Hart characterizes as "usually illuminating" the legal realists' critique of judicial decisionmaking. He understands their basic insight as follows:

A legal rule forbids you to take a vehicle into the public park. Plainly this forbids an automobile, but what about bicycles, roller skates, toy automobiles? What about airplanes? Are these, as we say, to be called "vehicles" for the purpose of the rule or not? If we are to communicate with each other at all, ... then the general words we use . . . must have some standard instance in which no doubts are felt about its application. There must be a core of settled meaning, but there will be, as well, a penumbra of debatable cases in which words are neither obviously applicable nor obviously ruled out. These cases will each have some features in common with the standard case; they will lack others or be accompanied by features not present in the standard case. . . .

We may call the problems which arise outside the hard core of standard instances or settled meaning "problems of the penumbra"; they are always with us whether in relation to such trivial things as the regulation of the use of the public park or in relation to the multidimensional generalities of a constitution. If a penumbra of uncertainty must surround all legal rules, then their application to specific cases in the penumbral area cannot be a matter of logical deduction, and so deductive reasoning, which for generations has been cherished as the very perfection of human reasoning, cannot serve as a model for what judges, or indeed anyone, should do ......212

211 See Hart, supra note 168; Fuller, supra note 124.

212 Hart, supra note 168, at 606-08. The sources of the penumbra metaphor in law, which goes back to mid-nineteenth century Holmes, are traced in Henly, "Penumbra": The Roots of a Legal Metaphor, 15 HAstings Const. L.Q. 81 (1987). Although Henly shows sensitivity to the function of metaphor, he does not apply the more systematic experientialist approach described in this essay. Accordingly, he misses the fact that the metaphor of "penumbra" (a penumbra is an area between light and shadow) is a variant of the conventional Ideas are Light metaphor. See G. Lakoff \& M. JoHnson, supra note 1, at 48; Standing and Metaphor, supra note 1 , at $1494 \mathrm{n}$. 687. This conventional metaphor is precisely what motivates Justice Douglas' use of the penumbra metaphor in the famous passage from Griswold v. Connecticut, 381 U.S. 
Fuller responds with a three-step attack. First, he disagrees with Hart's characterization of the legal process. Fuller argues that legal interpretations rarely turn on individual words and that the central engine of legal interpretation is the identification of purpose. ${ }^{213}$

Second, Fuller attempts to illustrate the centrality of purpose, and thus disprove Hart's core/penumbra analysis, with two counterexamples. Fuller asks: Would the rule prohibiting "vehicles" forbid the mounting of a working World War II truck on a pedestal in the park as a veterans' memorial? What about a rule prohibiting "sleeping" in the train station? Could it properly be invoked to sanction the traveller who dozes off while waiting for a late train? Would it not be invoked to punish the person stretched out on a bench for the night but arrested before falling asleep? "Which of these cases presents the 'standard instance' of the word 'sleep'?"214

Third, he attributes Hart's jurisprudential position to a general theory of language that he calls "the pointer theory of meaning." Fuller, Hart's whole position turns on there being a "standard instance," or fixed meaning, to the word "vehicle." But, Fuller argues, Wittgenstein and Bertrand Russell have shown words to depend on context and purpose for their meanings. ${ }^{216}$

While Fuller's critique seems powerful, it is only partially correct. This will perhaps be clearest if we take his third claim first. For contrary to Fuller's assertion, Hart does not adopt a correspondence view of meaning. ${ }^{217}$ Rather, Hart sees meaning as experientially based and consensually elaborated:

In all fields of experience, not only that of rules, there is a

479 (1965): "[The] specific guarantees in the Bill of Rights have penumbras, formed by emanations from those guarantees. . . . [The Connecticut] law cannot stand in light of the familiar principle. . . that . . . state regulation may not be achieved by means which sweep unnecessarily broadly . . .' Id. at 484-85 (quoting NAACP v. Alabama, 377 U.S. 288, 307 (1964)) (emphasis added).

213 "Even in the case of statutes, we commonly have to assign meaning, not to a single word, but to a sentence, a paragraph, or a whole page or more of text." Fuller, supra note 124, at 663. "If the rule excluding vehicles from parks seems easy to apply in some cases, I submit this is because we can see clearly enough what the rule is aiming at in general." "Id.

214 Id. at 663-64.

215 Id. at 668 (footnote omitted).

216 See id. at 669.

217 Despite his argument that Hart's position depends upon a correspondence view, even Fuller recognizes that this is not Hart's actual position. In a footnote, he acknowledges that Hart had previously rejected a correspondence view for a functional view of meaning. See id. at 668 n.40. Instead of dealing with this more complex situation, Fuller limits his critique to "the linguistic theory that seems to be implied in the essay under discussion here." Id. 
limit ... to the guidance which general language can provide. There will indeed be plain cases constantly recurring in similar contexts to which general expressions are clearly applicable. ... The plain case, where the general terms seem to need no interpretation and where the recognition of instances seems unproblematic or "automatic", are only the familiar ones, constantly recurring in similar contexts, where there is general agreement. ${ }^{218}$

This passage indicates that Hart's notion of "standard instance" does not imply an intrinsic, objectivist meaning. ${ }^{218}$ Rather, it is an early sighting of the phenomenon of prototype effects arising from the experientially grounded and culturally shared nature of cognitive models. ${ }^{220}$ Hart's insight that words have "core" meanings and "penumbral" cases describes the radial structure of word-categories that we saw in the cases of lie and hand in Part II above.

Once we recharacterize Hart's description of interpretation in this way, the gap between him and Fuller narrows substantially, and the counterexamples in Fuller's second argument lose much of their force. Fuller's working-truck-on-a-pedestal provides little problem for Hart's core/penumbra analysis. The rule prohibiting "vehicles" connotes a "standard instance" premised on an experientially based cognitive model that entails mobility; once the truck is a statue it will no longer be understood to fall within the core meaning of the statute. The core of the word "vehicle" is not a 1:1 correspondence to determinate objects in the world, but rather an idealized conception of an experienced, con-

218 H.L.A. HART, supra note 169, at 123 (emphasis added).

219 See also Hart, supra note 168, at 607 ("Fact situations do not await us neatly labeled, creased, and folded, nor is their legal classification written on them to be simply read off by judges.").

${ }^{220}$ Hart appears also to have shared with experientialism the insight about the role of embodiment in human cognition:

The world in which we live, and we who live in it, may one day change in many different ways; and if this change were radical enough not only would certain statements of fact now true be false and vice versa, but whole ways of thinking and talking which constitute our present conceptual apparatus, through which we see the world and each other, would lapse. We have only to consider how the whole of our social, moral, and legal life, as we understand it now, depends on the contingent fact that though our bodies do change in shape, size, and other physical properties they do not do this so drastically nor with such quicksilver rapidity and irregularity that we cannot identify each other as the same persistent individual over considerable spans of time. Though this is but a contingent fact which may one day be different, on it at present rest huge structures of our thought and principles of action and social life.

Id. at 622 (emphasis added); see also id. at 623 (describing how Hobbesian political theory would be different if we had the armored bodies of land crabs). 
textual gestalt. "[T]he language of the rule seems now only to mark out an authoritative example, namely that constituted by the plain case."221 Similarly, the power of Fuller's train station example depends upon attributing objectivist meaning to Hart's "standard instance." For Fuller, the "standard instance" of the word "sleep" would have to be the physiological state of sleep. ${ }^{222}$ In this view, Fuller implies that Hart's reasoning is not merely wrong but perverse: The nice (presumedly middle class) traveller would be punished for dozing off while the person stretched out on the bench would escape punishment. ${ }^{223}$ But Fuller's own analysis nicely illustrates Hart's point about a "standard instance" or, more precisely, the experientialist point about image-based cognitive models:

[W]e are likely at once to call to mind the picture of a disheveled tramp, spread out in an ungainly fashion on one of the benches of the station, keeping weary passengers on their feet and filling their ears with raucous and alcoholic snores. This vision may fairly be said to represent the "obvious instance" contemplated by the statute. ${ }^{224}$

Hart might well agree that this image is close to the "standard" or "obvious instance." On this reading, the "core" is not the objective, physiological state of sleep, but rather an idealized conception like "deliberately to go to bed for the night" - an experiential gestalt less tainted by Fuller's overtly class-biased stereotype. Once the objectivist's literal reading is shown not to be the only possible occupant of the statute's "core," the gap between Fuller and Hart is narrowed: They differ only on the issue of whether one is looking for "the standard instance of the word 'sleep" "versus "the standard instance of the statute." But this difference is trivial because, in this case, the outcome of the interpretive process would be very nearly the same.

What remains of Fuller's criticism that lawyers typically interpret not words, but statutes, is his point that they do so by reference to purpose. Here, Hart and Fuller appear to exchange roles. Up to this point in the debate, Fuller has taken instrumentalist positions and Hart positivist ones. On the question of the relevance of statutory purpose, however, Hart adopts a nakedly utilitarian position and accuses Fuller of reification.

221 H.L.A. HART, supra note 169, at 124.

222 See Fuller, supra note 124, at 664.

${ }^{223}$ Even on its own terms, Fuller's argument is less than compelling. The person going to sleep for the night could be prosecuted for an attempt, the traveller exonerated for lack of mens rea.

224 Fuller, supra note 124, at 664. 
Hart implicitly criticizes Fuller's purposivist approach to legal interpretation: "[W]e shall say that the social policies which guide the judges' choice are in a sense there for them to discover; the judges are only 'drawing out' of the rule what, if it is properly understood, is 'latent' within it." ${ }^{225}$ In a later elaboration, Hart also argued that relative indeterminacy of purpose is inevitable. In enacting a statute, the legislature focuses on specific problems to be solved; it cannot possibly anticipate all future situations and applications. ${ }^{22 B}$

Hart's apparent switch when confronted with Fuller's purposivist critique is even more problematic when contrasted with Hart's criticism of Holmes for not being purposivist enough in McBoyle v. United States. ${ }^{227}$ Although Hart begins with a paean to Holmes, he belittles Holmes' opinion. McBoyle concerned the theft of an airplane; the question was the applicability of a 1919 federal statute prohibiting the interstate theft of a "vehicle." Holmes concluded that Congress did not intend airplanes to come within the scope of the statute because "in everyday speech 'vehicle' calls up the picture of a thing moving on land."228 Hart criticizes this analysis, in part, because "[i]nstead of choosing in the light of social aims," Holmes "takes the meaning that the word most obviously suggests in its ordinary nonlegal context to ordinary men."229 In this critique, Hart appears to abandon his position that the standard instance of a word resides in the "core of settled meaning" that is the product of "general agreement."

Hart attempts to resolve the dissonance of these conflicting positions by invoking his distinction between core and penumbra. Hart thinks $M c B o y l e$ is wrong because Holmes treated it as a core case ${ }^{\mathbf{2 3 0}}$ to

${ }^{225}$ Hart, supra note 168, at 612; see also id. at 614 ("We are invited to include in the 'rule' the various aims and policies. . . . But though an invitation cannot be refuted, it may be refused." (emphasis added)). As if to underline the danger of this type of reification, the latent purpose that Fuller extracts from the statute prohibiting sleeping in the train station is expressed in blatantly class-biased terms.

${ }^{226}$ See H.L.A. HART, supra note 169, at 125-26.

227283 U.S. 25 (1931); see Hart, supra note 168, at 593, 610-11.

${ }^{228} \mathrm{McBoyle}, 283$ U.S. at 26. Here, again, we have an illustration of the experientialist point about image-based cognitive models. As Steve Diamond pointed out to me, Holmes' prototypical image was probably a horse drawn carriage: For Holmes, the quintessential nineteenth century gentleman, a car was probably a peripheral case of the word "vehicle." (personal communication to the author).

${ }^{228}$ Hart, supra note 168 , at $610-11$. Hart does give Holmes a little more credit than this; he recognizes that "the interpretation . . . resulted from the conviction that it is fairer in a criminal statute to take a meaning which would jump to the mind of the ordinary man at the cost even of defeating other values, and this itself is a social policy (though possibly a bad one)." Id. at 611 .

${ }_{230}$ There is another way to understand Holmes' analysis, however. In Hart's view, Holmes mistook the periphery for the core. It is more likely, I think, that Holmes consciously invoked a reduction-to-prototype effect for the policy reason identified by 
be decided by reference to common usage, ${ }^{231}$ whereas Hart sees it as a penumbral case to be determined by reference to policy. ${ }^{232}$ Because he insists on the separation of the "is" from the "ought" - of law from morals - Hart is forced to restrict policy to the periphery "to emphasize that the hard core of settled meaning is law in some centrally important sense."233 Only by dichotomizing in this way can Hart simultaneously acknowledge both the subjectivity of human purpose and the reliability of intersubjective communication so central to his positivist conception of law.

Hart's position has two problems. First, he has no coherent approach to linguistic meaning by which to accommodate the apparent dichotomy between subjectivist purpose and the reality of intersubjective communication; he is forced to draw on the core/penumbra distinction in order to accommodate this tension. Second, the viability of this distinction depends entirely on having a reliable way of differentiating core questions from penumbral ones. ${ }^{234}$ But Hart has no firm description of what occupies the core of meaning, just an affirmation that there must be something. ${ }^{235}$ It is this undefined "something-which-must-beat-the-core" that led Fuller to describe Hart's position as dependent on an objectivist theory of meaning.

Glose analysis of Hart's position reveals that he has rejected each

Hart. See supra note 229. By reduction-to-prototype effect, I refer to a cognitive process by which an entire category is reduced to and considered coextensive with the central or prototypical case. See Standing and Metaphor, supra note 1, at 1385-86. An example would be the museum-goer who insists that "that modern stuff just isn't Art."

I think the reduction-to-prototype explanation is the more likely for three reasons. First, it provides an account of the decision that assumes Holmes knew what he was doing (a more likely, although not inevitable, assumption). It does not, therefore, need to downplay (as Hart does) the obvious policy considerations. Second, the reduction-toprototype move is a common and familiar aspect of legal reasoning. See id. at 1459-65, 1471-74 ("[S]tanding law is a self-conscious effort to limit adjudication to cases that fit the prototype."). Third, this explanation is consistent with a theory of motivation which holds that people accommodate their purposes, not arbitrarily and unpredictably, but rather by means of predictable cognitive processes.

${ }^{231}$ In McBoyle, Holmes would presumably argue that, at least in 1919 when Congress wrote the statute, the core of the notion "vehicle" would not have included the recently invented airplane.

${ }^{232}$ "[L]aws are incurably incomplete and we must decide the penumbral cases rationally by reference to social aims." Hart, supra note 168, at 614 .

${ }^{233}$ Id.

${ }^{234}$ See, e.g., id. ("[E]ven if there are borderlines, there must first be lines.").

${ }^{235}$ As Hart insists:

It is to assert that there is [a] central element of actual law to be seen in the core of central meaning which rules have, that there is [something] in the nature of a legal rule inconsistent with all questions being open to reconsideration in the light of social policy.

Id. at 615; see also id. at 607 ("There must be a core of settled meaning"). 
of the obvious candidates for that "something-which-must-be-at-thecore." He rejects Fuller's reified notion of statutory purpose, Holmes' deference to common usage, and the objectivist identification of "certain features ... as always necessary and always sufficient conditions for the use in all contexts of the word." ${ }^{\text {"236 }}$ Having thus rejected subjectivist purpose, relativist coherence, and objectivist correspondence, Hart is left with an empty "core."

Here, I think, the holistic, experientialist approach to human reasoning helps fill the gap. In The Concept of Law, Hart reaches for an incomplete, experiential description of the core. The plain cases, the agreed upon prototypes, "are only the familiar ones, constantly recurring in similar contexts, where there is general agreement."237 But the concept of culturally shared cognitive models, unconsciously used to structure language and thought, gives us a better way both to describe Hart's perception of a core and to integrate it with Fuller's point about statutory purpose.

The notion of an ICM integrates the possibility of potentially variable purpose with the reality of meaningful intersubjective communication. We all experience vehicles in much the same way; the concept vehicle is structured relative to human purpose and use. Vehicles carry us and our goods at greater speed and with less expenditure of energy than walking. "Vehicleness" entails mobility, transportability, and an energy source. In historical human experience, vehicles vary from rickshaws to chariots to Conestoga wagons to cars; the energy sources range from other humans to animals to the internal combustion engine and beyond. In a given culture at a given moment, however, there are only a few conventional (common and recurrent) modes of transportation. These will inevitably share the conditions of the ICM of vehicle that is a function of human body structure and experience. A rule prohibiting vehicles in the park presents no great difficulties because our commonly grounded ICM allows us to discuss "vehicles" with relative consistency. The "purpose" of the rule need not be abstracted as a reified entity because our common experience with vehicles and their respective hazards informs us immediately what the concern is likely to be. ${ }^{238}$ Of course, the target will be different in Victorian England than in 1958, but no person of those respective eras would miss the reference.

The "purpose" of the statute will therefore be evident from its

${ }^{236} I d$. at 611 .

${ }^{237}$ H.L.A. HART, supra note 169, at 123.

${ }^{238}$ Fuller concedes as much. See Fuller, supra note 124, at 663 ("[T] cluding vehicles from parks seems easy. . . because we can see clearly enough what the rule 'is aiming at in general'."). 
language terms. It will be evident because "vehicle" has neither a fixed objectivist meaning nor a purely contextual and radically indeterminate meaning. It will be evident because "vehicle" is not just a word, but part of a cognitive process that evokes an experiential, embodied model. As a structure of thought, that model will identify an experiential gestalt: an object, its purposes, the manner of its use, and its concomitant hazards. The same will be true of the word "park": not any area of grass and trees, but one put aside for certain kinds of uses by embodied humans. Because all of these entailments will be built into one's understanding of these ICMs, the purpose of the statute will be clear from its language terms.

Let me conclude this section by summarizing what I have tried to do, my reasons for doing it, and the tentative conclusions we might draw. I have defended Hart's description of law as structured such that it has core areas of clarity and peripheral areas of indeterminacy. $\mathrm{My}$ purpose has not been to salvage any positivist insight about LAw, ${ }^{239}$ but rather to illustrate how experientialist linguistics provides powerful explanations for familiar legal problems. By exploring Hart's position from this epistemological approach, I have demonstrated how ordinary legal discourse about a simple rule prohibiting vehicles in a park is structured in terms of radial categories, idealized cognitive models, and experientially grounded reason.

There are two conclusions that we may draw, one congenial to Hart and the other not. The first follows naturally from this experientialist account. With Hart, we can see that "deductive reasoning, which for generations has been cherished as the very perfection of human reasoning, cannot serve as a model for what judges, or indeed anyone, should do."240

The second will require some further exposition in the subsections that follow, but can usefully be stated at this point: Positivism is an

230 I use the capitalized format for the word LAW when I mean to signify the concept with all its deepest psychological resonance. This is in the tradition of Robert Cover, who understood that:

The word "law," itself, is always a primary object of contention. People argue and fight over "what is law" because the very term is a valuable resource in the enterprises that lead people to think and talk about law in the first place. "Law" evokes the law given on Sinai, Solon's legislative enterprise, Kant's categorical imperative. On a political level it connotes legitimacy in the exercise of coercion and in the organization of authority and privilege. On a philosophical plane it connotes universality and objectivity.

Cover, The Folktales of Justice: Tales of Jurisdiction, 14 CAP. U.L. REv. 179, 180 (1985).

${ }^{240}$ Hart, supra note 168, at 607-08. 
inherently incomplete legal theory. It requires a linguistic theory that allows for a high degree of constancy in communication. Cognitive theory is a useful candidate; we have seen how ICMs can structure a simple legal command like a rule prohibiting vehicles in the park. But an ICM is an experiential gestalt identified by a culture because it is a useful, but not objective way to organize experience. In this way, meaning is allied with, although not solely defined by, purpose and social agreement. The recognition that intersubjective meaning is dependent on this alliance, however, is fatal to positivism. As we move from simple terms like vehicle to the more complex, socially-constructed data typically encountered in legal rules, we find more and more of the "ought" already immanent in the very terms of communication: An ICM often entails socially contingent, normative accounts of experience, as in the case of lie or bachelor or mother. ${ }^{241}$ When it can speak only in the normative language of the culture, LAw can neither be explained as the command of the sovereign nor separated from the "ought" in any meaningful sense.

\section{Structured Indeterminacy, or "Duncan Kennedy Meets H.L.A. Hart"}

In a recent article, Duncan Kennedy uses the force field metaphor to express his sense of both pliability and constraint in the use of precedents. ${ }^{242} \mathrm{He}$ employs a phenomenological methodology to explore the dilemma of a hypothetical pro-labor judge deciding an employer's suit to enjoin striking bus drivers who intend to lie-in and prevent nonunion replacements from successfully taking their places. ${ }^{243}$ The hypothetical judge works through the precedents, their opposition to his desired outcome, and the possible recharacterizations that could turn the workers' actions into an exercise of a first amendment right. ${ }^{244} \mathrm{He}$ conceptualizes the pro-employer cases and the first amendment precedents as cre-

241 For a discussion of lie, see supra text accompanying notes 144-52. For a discussion of bachelor, see supra text accompanying note 147. For a discussion of mother, see Standing and Metaphor, supra note 1, at 1385-86 \& n.78.

${ }^{242}$ See Kennedy, Freedom and Constraint in Adjudication: A Critical Phenomenology, 36 J. LEGAL EDUc. 518 (1986). Kennedy describes his work as a continuation "of the legal realist project as exemplified" by Cohen, The Ethical Basis of Legal Criticism, 41 Y ALE L.J. 201 (1931). See Kennedy, supra, at 518 n.1. He attributes his use of the force field metaphor, however, to works in psychology by Wolfgang Kohler, Kurt Lewin, and Jean Piaget. Id. Kennedy does not cite Cohen's Transcendental Nonsense or Field Theory articles, which actually employ the force field metaphor. See Cohen, supra note 163, at 843-44; Cohen, supra note 164, at 265-66.

${ }^{243}$ See Kennedy, supra note 242, at 519-20.

244 See id. at 523-35. 
ating fields with a central focus:

We can represent the process of arranging cases in a field, and the process of fixing a boundary between permitted and forbidden acts, in terms of this imagery of vectors and balancing. . . .

As we move from fact-situation to fact-situation across the field, the speech policy gets weaker, and the property policy stronger, until at the boundary they are in equilibrium. At this point a very small change in the relative forces of the policies produces a dramatic change in result. . . .

What this means is that we have to add to our model of the field of law the notion that, at every point in the field, contradictory policies exert different levels of force. Boundary lines in the field represent points of equilibrium of opposing forces. At points not on boundaries, one or another set of policies predominates. The policies are to be understood as gradients; they are strongest in the "core," where a given general rule seems utterly obvious in its application and also utterly "appropriate as a matter of social policy." The argument set supporting the general rule diminishes in force as we move from the core outward toward the periphery, and ultimately to a boundary with another general rule. ${ }^{245}$

Here, as in Cohen's Field Theory, the force field metaphor sustains an intuitively powerful insight that appears to represent a substantial change in position. Kennedy seems to drop his previous arguments that legal rules ${ }^{246}$ are radically indeterminate because of the dialectical structure of the pairs of available doctrinal and policy argu-

245 Id. at 535.

${ }^{248}$ I use "rules" here because, as between rules and standards, rules are generally thought to be more determinate. My point, however, is intended to apply to both.

In Form and Substance, Duncan Kennedy identified a structural affinity between rules and individualism, on one hand, and standards and altruism, on the other. See Kennedy, supra note 164, at 1737-51; $i d$. at 1776-78. Recent scholarship has questioned those structural relationships. See M. Kelman, A Guide to Critical Legal STUDIES 15-63 (1987) (criticizing Kennedy's work to the extent that it plays a predictive role); Fischl, Some Realism About Critical Legal Studies, 41 U. MIAMI L. REv. $505,518 \mathrm{n} .48$ (1987) ("The point is that the respective 'biases' of the legal arguments involved depend upon the nature of the background legal regime rather than upon anything inherent in the arguments themselves."); Schlag, Rules and Standards, 33 UCLA L. REv. 379, 383 (1985) ("This dialectic [of rules versus standards] doesn't go anywhere. It is an arrested dialectic: There is no moment of synthesis."); see also Rose, Crystals and Mud in Property Law, 40 StaN. L. Rev. 577, 577-80 (1988) (describing the cyclical process by which property law alternates between rules and standards). I think there is more to the original insight than the critics allow. An adequate discussion, however, is beyond the scope of this essay. 
ments for and against every legal position. ${ }^{247}$ Instead, he acknowledges a kind of determinacy or constraint at the "core" even if there may be dialectical equilibrium and, therefore, judicial freedom at the boundaries. $^{248}$

Kennedy describes this experience of freedom and constraint in rule application both in terms of the "imagery of vectors and balancing"249 and by means of the center-periphery schema. The structure of the rule's force field is a radial category. ${ }^{250}$ This suggests an important correlation among the epistemological questions discussed in Part II of this essay, the linguistic dimensions of legal phenomena explored in the last subsection, and the problem of the indeterminacy of legal rules. Since law, like language, is a human creation, we should expect to experience a similar radial structure throughout the legal enterprise.

What we found with individual words ("vehicle") and simple legal contexts (a rule barring vehicles from a park) should also appear in the complex analytic contexts of the "large" issues of law. There will be core areas, well-structured by legal concepts and principles; there will be peripheral areas displaying substantial indeterminacy. Kennedy describes just this phenomenon in his labor/first amendment hypothetical. He describes a force field with a "core" occupied by a powerful social policy that "seems utterly obvious in its application and also utterly 'appropriate." "251 This use of the force field metaphor yields an insight that sounds remarkably like our synthesis of H.L.A. Hart and Lon Fuller in terms of experientialist cognitive theory.

What structures these experiences of core "certainty" and peripheral "indeterminacy" are our ICMs. When the facts of a case display a good fit with the particular ICM motivating the precedent or legal principle, most legally trained observers committed to applying the rule will experience the rule as having sufficient structure to constrain deci-

247 See Kennedy, supra note 164 , at 1712-13. For an application of the dialectical approach that thoughtfully grounds this style of legal argument in everyday experience, see Paul, A Bedtime Story, 74 VA. L. Rev. 915, 928-34 (1988). See also Kennedy, supra note 14, at 211-13,354-55 (ascribing the indeterminacy of legal doctrine to the "fundamental contradiction" in our need for and fear of others). But see Gabel \& Kennedy, supra note 69, at 15-16, 36-37 (renouncing the "fundamental contradiction").

${ }_{248}$ Kennedy and Cohen's use of the force field metaphor is coherent with a notion that at the boundaries, where the force fields of the relevant rules or precedents are equally balanced, cases are resolved by the arbitrary use of judicial (or social) power.

24 Kennedy, supra note 242, at 535.

280 I have discussed the concept of adjudication, including the constitutional "case or controversy" requirement, as a radial category. See Standing and Metaphor, supra note 1, at 1412; see also K. Llewellyn, The Common Law Tradition: Deciding APPEALs 263 (1960) (describing the "shaping and joining of complementary hubs and spokes and rims to form a doctrinal wheel").

${ }^{251}$ Kennedy, supra note 242, at 535. 
sion. ${ }^{252}$ As the facts vary from the idealized model, however, there will be increasing indeterminacy. The degree of fit is not an objective given, but rather is a function of the available model or models. The model, thus, has an ontological effect: "there are [no] inputs which are not themselves to some extent shaped by our concepts."253 Multiple models will create greater pliability and indeterminacy.

To sustain this account, we need to deal with two important questions. First, how are these ICMs developed? Second, how do we distinguish ICMs and choose a particular model for a particular case? With respect to the first question, I suggest that the "large" ICMs of constitutional law - like the "small" ones of rules prohibiting vehicles in parks - are grounded in the particular social experiences of our culture. Thus, their "core" areas will reflect the experience of these particular historical contingencies in ways that will "render[] some problems easier to see and solve, others more opaque or less obvious." 254 The "cores" of these ICMs will be sustained by these experiences and the social consensus they engender; their penumbras will include the metaphoric extensions of those idealized experiences; their peripheries will bump up against the force fields of other legal/cultural ICMs.

With respect to the second question, I suggest that choice among available models is not radically indeterminate. Subjectivist purpose can and will affect the choice of a particular model for a particular case, but the experiential grounding of the models constrains the usefulness or "fit" of the models for a given case. Similarly, the available metaphors conventional in the culture both create and constrain the possible extensions of the available models.

Some scholars in critical legal studies aver that there are always competing doctrinal models. There often are. In Standing and Metaphor, I argued that this is a necessary operational condition if the legal system is successfully to map onto our complex social reality. ${ }^{258}$ But

${ }^{252}$ The reader will note that I deliberately refrain from making any claim of determinacy. I reject any such claim much as I reject psychological behaviorism as an adequate model of human behavior or positivism as an accurate description of legal/ political organization. No matter what one's jurisprudential stance, it should be common ground that people, not rules, decide cases. The question is only about the degree of meaningful structure that the rules provide. Even where decisionmaking is understood as highly structured, it is a human process involving human agents, human will, and human commitment to an ideal called LAw. See infra text accompanying notes 360-67, 433-61. Any other view would be the worst kind of "thingification."

${ }^{253} \mathrm{H}$. PutnaM, supra note 38, at 54 (emphasis deleted).

254 Powell, Parchment Matters: A Meditation on the Constitution as Text, 71 Iowa L. REv. 1427, 1430 (1986) (discussing material from G. LAKOFF \& M. JoHNsoN, supra note 1, at 101).

${ }_{255}$ Thus, in Standing and Metaphor, my critique was that the modern "case or 
these scholars hold it as a matter of faith, rather than of sustained theory or systematic empirical demonstration, that there are always divergent models that can be made to fit. ${ }^{256}$ Similarly, it is a matter of commitment that the plasticity of legal doctrine is the consequence of fundamental contradictions inherent in legal thought. ${ }^{267}$

Both of these insights require a belief that language terms are completely plastic, ungrounded coherence data always open to manipulation in light of subjectivist purpose - a sort of words as widgets phenomenon. ${ }^{258}$ Work in cognitive linguistics, some of which I have

controversy" doctrine uses only a single, individualist model. That model, however, does not map onto the interdependent nature of much of our social experience without very substantial distortions. See Standing and Metaphor, supra note 1, at 1500-03.

This idea, that we use multiple models to fit complex experience, is at the heart of what Judge Hutcheson was trying to convey in his discussion of the role of the "hunch" in judicial decisionmaking. See Hutcheson, supra note 198, at 278. Confronted with the factual assertions and legal arguments of the parties, the judge is faced with choosing an appropriate model (perspective, category, theory, or legal principle) which will yield a cognitive fit with the data: "I, after canvassing all the available material at my command, . . . give my imagination play, and brooding over the cause, wait for the feeling, the hunch - that intuitive flash of understanding which makes the jump-spark connection between question and decision." Id.; see also id. at 281 (analogizing judicial decisionmaking to a scientist's "flash of a luminous hypothesis") (quoting B. CARDozo, supra note 3 , at 59). I provide a concrete example of this phenomenon in the conclusion of this article. See infra text accompanying notes 457-61.

${ }^{256}$ See Hutchinson \& Monahan, supra note 164, at 1508-09:

The demonstration of particular indeterminacies is used to prove a general indeterminacy throughout legal doctrine. But this crucial maneuver demands a leap of faith. Any successfully generalized claims about indeterminacy can be sustained only through some overarching background theory of skeptical epistemology. To date, no such theory has appeared; the offerings have been polemical and visceral. Commitment has clouded construction.

Id. (footnotes omitted). The claim of general indeterminacy made by Mark Tushnet is explicitly justified by just such an intuitive assertion, although it is also partially sustained by a coherence theory of meaning. See infra notes 295-300 and accompanying text.

${ }^{267}$ The structuralist position mentioned in the text produces its own internal contradiction. It simultaneously asserts that legal materials are radically indeterminate and that this is because they have a determinate, dialectic structure. $C f$. Boyle, supra note 164 , at $779-80$ (discussing "the bleak determinism of external structures"). But, if this is so, then the critique itself must be both infinitely manipulable and radically indeterminate because of its own internal contradiction. It is not clear whether this characteristic of the critique renders it self-validating or ultimately unpersuasive.

${ }^{258}$ As Powell writes:

Those who are impressed above all by the opaqueness and malleability of the text maintain that its emptiness, not its concreteness, creates the possibility of change. According to the disbelievers in language, the words of the equal protection clause, for example, have permitted judges to effect modern notions of equality precisely because the words are essentially devoid of meaning. I disagree. During the long, sad decades of Jim Crow, the text bore mute witness to the nation's prior recognition of the evil of racism. And in the end, the residual, common sense meaning of a phrase 
summarized, demonstrates that this is not true of words. It is also not true of grounded legal concepts. In this subsection, I present a sketch of the radial, experientially-grounded structure of modern first amendment law. I do not intend to "justify" or provide "foundations" for this area of the law, nor to demonstrate the correctness of this account in any "objective" or absolute sense. ${ }^{258}$ Rather, I hope to show that it is possible to envision a doctrinal area as neither propositional and dependent on mediating principles, à la Fiss, nor radically indeterminate (thus inherently dangerous), à la Tushnet.

In his critique-of-rights essay, Mark Tushnet invokes first amendment doctrine to illustrate how manipulability interacts with the concept of rights to injure the "party of humanity."260 To do so, however, Tushnet deliberately "invert[s] the usual approach to first amendment doctrine"261 and takes the peripheral areas first. The inversion allows

like "the equal protection of the laws," read against the backdrop of a civil war fought in part to end a racial caste system, empowered judges, lawmakers, and ordinary citizens to question and then to overthrow that caste system.

Powell, supra note 254, at 1433.

${ }^{259}$ It is not clear how one could "prove" such a thesis, since the theory itself denies that there is only one objective account independent of all conceptual assumptions. The legal materials will always be amenable to another characterization - by definition there will always be the conventional syllogistic version. Rather, the value of a theory must lie in its explanatory power. What I hope to do in the first amendment discussion is to provide an explanation in terms of the experientialist epistemology, and the empirical evidence upon which it is based, that both fits and accounts for the legal data in a way that is elegant and unforced. This account will still be "relative," but not in the sense that it is dependent upon underlying political assumptions about society or the legal system; it is, rather, relative to a particular theory of mind.

I want to emphasize that this account is merely descriptive and not a normative statement of what I believe freedom of speech is or should be. On this point, I share some sympathies both with Tushnet and Fiss. With Tushnet, I view first amendment doctrine as underprotective in important areas of speech by individuals, and overprotective of corporate "speech." See infra text accompanying notes 262-64. With Fiss, I share a sense that the focus of free speech doctrine is skewed by the underlying model, which does not map well onto the social circumstances of late twentieth century America. See Fiss, supra note 8, at 793-94; Fiss, supra note 9, at 1408, 1425. A significant value of the experientialist approach to law is that by unearthing the idealized cognitive models that unconsciously structure standard legal thinking, we are consciously empowered to reconstruct those models in more productive ways. See supra note 86.

I have not attempted to give an exhaustive account of the first amendment in terms of this cognitive theory, although that would be preferable. I already have provided such an account, however, for Article III. See generally Standing and Metaphor, supra note 1. For an account of the complexities of takings clause jurisprudence that makes excellent use of the underlying cognitive models of property, see Paul, The Hidden Structure of Takings Law (forthcoming 1989) (manuscript on file with the author).

${ }^{260}$ Tushnet, An Essay on Rights, 62 Tex. L. Rev. 1363, 1364 (1984).

${ }^{281}$ Id. at 1389. 
him to portray first amendment doctrine as pernicious when manipulated to protect corporations, wealthy contributors to political campaigns, and large utilities. ${ }^{262} \mathrm{He}$ next turns to core first amendment doctrine and again proceeds from the outside in, examining first the nonpublic and quasi-public forum doctrines. ${ }^{263}$ Only at the close does he acknowledge "a public forum doctrine that unequivocally protects access ... to the streets and parks." 264

If we approach first amendment doctrine in the conventional manner, we start not with rampant indeterminacy but with distinctive core areas of clarity: People can use the streets and parks for peaceful protest, ${ }^{265}$ and newspapers cannot be censored (except when they directly jeopardize the government's conduct of a war). ${ }^{266}$ These are the prototypes of a rudimentary first amendment model, which centers on two images: (1) an "individual mount[ed on] a soapbox on a corner in some large city . . . criticiz[ing] government policy,"267 and (2) a basement

${ }^{262}$ See id. at 1387 (discussing First Nat'l Bank v. Bellotti, 435 U.S. 765 (1978)) (corporations); id. at 1387 (discussing Buckley v. Valeo, 424 U.S. 1 (1976)) (campaign contributions); id. at 1387-88 (discussing Central Hudson Gas \& Elec. Corp. v. Public Serv. Comm'n, 447 U.S. 557 (1980)) (utilities).

${ }_{263}$ See id. at 1389-90 (discussing Perry Educ. Ass'n v. Perry Local Educators' Ass'n, 460 U.S. 37 (1983), and Brown v. Louisiana, 383 U.S. 131 (1966)).

${ }^{264}$ Id. at 1390 . Tushnet characterizes this protection as "only" applying to streets and parks. To the extent that this is intended to suggest that this degree of protection is insufficient, I agree. My point, however, is that Tushnet has it backwards - rather like complaining that there isn't much use for the coconut because the outside is hairy and inedible.

In his most recent account of these materials, Tushnet retreats slightly from his claim of complete indeterminacy in first amendment doctrine. Instead, he observes that first amendment law is biased in favor of what he calls "instrumental rationality," a term that appears to correlate with a mixture of pragmatism and what $I$ have identified as objectivist logic. See M. TuSHNET, supra note 17, at 277-78. Interestingly, his more recent account also contains a discussion of first amendment doctrine as structured in terms of what cognitive theory has identified as prototype effects: "[W]e are to determine the degree of protection that a category of speech gets by considering paradigmatic examples of speech in that category, not by considering unusual or merely possible examples." Id. at 307. Ultimately, however, Tushnet proclaims this approach "analytically unsatisfying" and "likely to be manipulated." Id. at 309.

${ }^{285}$ See Cox v. Louisiana, 379 U.S. 536, 558 (1965); Edwards v. South Carolina, 372 U.S. 229, 237 (1963). As Justice Roberts stated in Hague v. G.I.O., 307 U.S. 496, 515 (1939): "[S]treets and parks . . . have immemoriably been held in trust for the use of the public and, time out of mind, have been used for purposes of assembly, communicating thoughts between citizens, and discussing public questions." David Kairys correctly argues that Hague's history is overly idealized. See Kairys, Freedom of Speech, in D. KaIRYS, supra note 17 , at 144. But Kairys' own history is biased in the opposite direction, failing to consider the social experiences that led to the adoption of the first amendment. See infra text accompanying notes 268-71.

${ }^{266}$ See, e.g., Near v. Minnesota, 283 U.S. 697, 716 (1931) ("No one would question but that a government might prevent ... the publication of the sailing dates of transports or the number and location of troops.").

${ }^{287}$ Fiss, supra note 9, at 1408. 
press cranking out seditious leaflets. ${ }^{268}$ The model is grounded in a very particular set of social and historical experiences. It represents a powerful set of social values and conventions rooted, first, in the experience of English pamphleteers in the 17th and 18th centuries ${ }^{269}$ and the history of the American Revolution ${ }^{270}$ and, later, in the labor movement and civil rights struggle. ${ }^{271}$

This rudimentary model is neither arbitrary, nor completely contingent on power; but neither is it an objective truth about the world or the constitutional text.

[I]t is rather contingent in the sense that it is rooted in the particularity of a concrete, lived experience, and determinate in the sense that it is expressive only of the existential quality of this experience, as this quality might be realized in its universality through an infinite number of particular, historical instances. ${ }^{272}$

The core of this rudimentary model has an experienced social meaning that is neither endlessly manipulable nor very generalizable. Indeed, I call this two-part model "rudimentary" because it is not rich enough in structure to motivate or sustain the kinds of extensions typical of the ICMs we have explored.

${ }^{268}$ See, e.g., Schenck v. United States, 249 U.S. 47, 52 (1919) (upholding conviction for printing of anti-war leaflets); Abrams v. United States, 250 U.S. 616, 619 (1919) (same).

${ }_{269}$ Some of this history, which was also central to the development of the fourth amendment, is recounted in Blasi, The Checking Value in First Amendment Theory, 1977 AM. B. Found. Res. J. 521, 529-38, and Schnapper, Unreasonable Searches and Seizures of Papers, 71 VA. L. REv. 869, 875-915 (1985).

270 "The press along with pulpit, platform, and parliamentary forum, became an enormously effective vehicle for advertising the Whig position, and so long as England maintained control of the situation, the revolutionary journalists, whose newspapers doubled in number between 1763 and 1775, unceasingly urged the value of open debate." L. Levy, Emergence of a Free Press 62 (1985). 59.

${ }^{271}$ See Kairys, Freedom of Speech, in D. KAIRYS, supra note 17, at 149-53, 156-

${ }^{272}$ Gabel, The Phenomenology of Rights-Consciousness and the Pact of the Withdrawn Selves, 62 Tex. L. Rev. 1563, 1590 (1984). My quote from Gabel may be misleading. He prefaces this passage with the assertion that rights-consciousness arising from empowering social movements is good because it is disalienating, in part because these movements are not "requesting recognition of their meaning from the hallucinatory projection we call 'the State'." Id. at 1589. He asserts that "[i]t is for this reason that the meaning of these rights is neither reified, nor indeterminate." Id. at 1589-90. I disagree with Gabel about the quest for recognition and the role of reification. Nevertheless, I think that the passage from Gabel exactly characterizes the creation of legal meaning and the possibility of its communication. The key lies in the concept of disalienation and the relationship between reification (objectification), on one hand, and the processes of motivation and idealization, on the other. See infra notes 422-49 and accompanying text. 
Even so, it is important to see that the model's central meaning is expressed not by propositional rules or mediating principles - such as, "reasonable time, place and manner" restrictions, or the "autonomy" or "public debate" principles - but rather by metaphor. The fundamental rule of the first amendment is that against prior restraints. At its inception in the mid-17th century, Milton expressed this rule with an extended metaphor: "Truth is compar'd in Scripture to a streaming fountain; if her waters flow not in a perpetuall progression, they sick'n into a muddy pool of conformity and tradition."273 During its early stages, the first amendment merely ensured the free flow of ideas by protecting against prior restraint. ${ }^{274}$ The direct experience of unhealthy, stagnant waters motivated a view of the evil to be avoided as something halting intellectual progress toward "truth." Accordingly, ideas, once communicated, were not protected automatically, but were vulnerable to coercive governmental action if they did not contribute to that progress. This was clearly the case with the Alien and Sedition Acts adopted not long after the amendment itself. ${ }^{275}$

The development of the modern first amendment had to wait for a richer ICM. That came in Holmes' World War I opinions. Dissenting in Abrams $v$. United States, ${ }^{276}$ Holmes argued that "the ultimate good desired is better reached by free trade in ideas, -- that the best test of truth is the power of the thought to get itself accepted in the competition of the market." ${ }^{277}$ This passage has provided the critical metaphor

${ }^{273}$ Milton, Areopagitica (1644), in The Prose of John Milton 265, 310 (J.M. Patrick ed. 1967): "This speech is widely regarded as the first comprehensive analysis of the arguments underlying free expression." 1 N. DORSEN, P. BENDER \& B. Neuborne, Emerson, Haber, \& Dorsen's Political and Givil Rights in the UNITED STATES 1 n.a (4th ed. 1976) (referring to the quoted passage from Milton).

The structural metaphor Knowledge is Water is systematically used in the Bible. I discuss its experiential grounding and cultural specificity in Standing and Metaphor, supra note 1, at 1494 n.687.

274 See L. LevY, supra note 270 , at 65.

${ }^{275}$ See An Act Concerning Aliens, 1 Stat. 570 (June 25, 1798) (expired by its own terms two years later); An Act in Addition to the Act, Entitled "An Act for the Punishment of Certian Crimes Against the United States," 1 Stat. 596 (July 14, 1798) (expired by its own terms, 1801). In New York Times Co. v. Sullivan, 376 U.S. 254 (1964), the Court relied on Leonard Levy's earlier work on the historical meaning and development of the first amendment, see id. at 273 (citing L. Levy, LEGACY of SupPRESSION (1960)), and concluded that: "Although the Sedition Act was never tested in this Court, the attack upon its validity has carried the day in the court of history." Id. at 276 (footnote omitted).

For a more recent example, see Chaplinsky v. New York, 315 U.S. 568, 572 (1942) (permitting suppression of "fighting words" because "such utterances are no essential part of any exposition of ideas, and are of such slight social value as a step to truth").

276250 U.S. 616 (1919).

${ }^{277}$ Id. at 630 (Holmes, J., dissenting). 
for the twentieth century ICM of the first amendment: the marketplace of ideas. ${ }^{278}$

One of the interesting aspects of Holmes' metaphor is that it is more conventional than it is "creative." 279 It is related to several conventional metaphors for mind and ideas:

The Mind is a Machine - She just grinds out those papers; I got a lot of writing done this morning but then I ran out of steam; he had a nervous breakdown.

Ideas are Products - that's a good hypothesis, but we need to refine it; she is our most productive writer.

Ideas are Commodities - Her idea is valuable, but yours is worthless; it just won't sell. ${ }^{280}$

The marketplace of ideas metaphor joins these cultural metaphors with the ICM of a commercial transaction into a new ICM for the first amendment. The obvious entailments are that persuasion is like selling, acceptance is like buying, and truth results from the test of competition - a "folk" version of the relativist view of meaning.

This experientialist account of the development of the twentieth century first amendment provides two explanations why the idea of free speech held by Milton and the framers could not be the same as that later articulated by Holmes. First, as long as "truth" was understood in strong objectivist terms, one could trust after-the-fact judgments to sort out the false and unprotected from the true and protected. Within this framework, a first amendment that prohibited only prior restraint made sense. The rise of classical liberalism in the late nineteenth century, however, led to the notion that, at least in some intellectual domains, there can be many competing "truths."281 Thus, post hoc epistemological tolerance will be necessary if an unpopular "truth" is to be given a

278 For a thoughtful development of the role of the market metaphor in the growth of the modern first amendment, see Cole, Agon at Agora: Creative Misreadings in the First Amendment Tradition, 95 YALE L.J. 857 (1986). Cole, however, views the metaphor as "abstract," id. at 903, and its imaginative extensions as "misreadings," id. at $887-904$, characterizations that I obviously do not share.

${ }^{279}$ Felix Cohen invoked a variant, Words are Market Phenomena, supra text accompanying notes $192-94$, as did Rorty, see supra text accompanying note 77 , and Milton, although for contrary purposes. See infra note 282.

280 See G. LAKoff \& M. Johnson, supra note 1, at 27-28, 47-48.

281 "Neither freedom of speech nor freedom of the press could become a civil liberty until people believed that the truth of their opinions, especially their religious opinions, was relative rather than absolute." L. LEVY, supra note 270 , at 5 . A first step along this road was the realization of human fallibility. See, e.g., J.S. MrLL, ON LIBERTY 21-22 (C.V. Shields ed. 1956) ("To refuse a hearing to an opinion because they are sure that it is false is to assume that their certainty is the same thing as absolute certainty. All silencing of discussion is an assumption of infallibility."). 
fair chance at general acceptance in the "market." Second, Milton and Holmes did not have the same experiences available to them as models for their respective metaphors for free speech. In Areopagitica, Milton specifically rejected the idea of the market as a model for laws having to do with speech. ${ }^{282}$ Milton lived in an era of imperial mercantilism; seventeenth century market practices would have supported licensing. Holmes, however, wrote in a period of laissez-faire capitalism. If it was no longer universally accepted that "truth" is the inexorable outcome of the forward motion of ideas, the concept of the market provided a meaningful alternative model for the notion that "truth" - like economic well-being - could be the product of human competition. ${ }^{283}$

In this view, first amendment law is entirely socially contingent; modern free speech doctrine was not possible before the development of the modern experiences and beliefs that give it meaning. In fashioning modern first amendment doctrine, Holmes acted in a socially contingent way that drew upon conventional metaphors, cultural knowledge, and everyday economic experience. By doing so, he was able to evoke an experienced gestalt that entails both the autonomy and public debate ideas (principles that Fiss, in contrast, sees as warring for the soul of the amendment). The complex cognitive entailments of the market metaphor provide a rich understanding of, and a solid ground for, the modern first amendment. ${ }^{284}$

In this sense, our modern understanding of the first amendment is dependent upon the use of the market metaphor. The metaphor carries over from the source domain of economic experience certain normative, cultural assumptions about the usefulness and value of autonomy and free trade and applies them to the target domain of free speech. As long as the social consensus regarding economic autonomy remains stable, so will the core of our first amendment ICM. This stability will not elimi-

282 See Milton, supra note 273, at 303-04 ("Truth and understanding are not such wares as to be monopoliz'd and traded in by tickets and statutes and standards. We must not think to make a staple commodity of all knowledge in the Land, to mark and licence it like our broad cloath, and wooll packs."). Milton's arguments against licensing dissuaded neither Parliament from passing the licensing act nor Milton himself from working as a licensor and censor. L. LEVY, supra note 270 , at 95 .

${ }^{283}$ On the natural relationship between the first amendment concept of autonomy and the concept of economic autonomy, see Fiss, supra note 8, at 782-83 (arguing that the autonomy principle in first amendment doctrine provides colorable constitutional support to those on the right arguing for free market principles).

${ }^{284}$ For example, Rorty writes: 'Milton's 'free and open encounter,' in' which truth is bound to prevail, must itself be described in terms of examples rather than principles - it is to be more like the Athenian market-place than the council-chamber of the Great King." R. RORTY, ConseQuences, supra note 5, at 173 (referring to Milton, supra note 273, at 327 ("Let her and falsehod grapple; who ever knew Truth put to the wors, in a free and open encounter.")). 
nate indeterminacy, however, it will only locate it. As we move from the core, we will experience all the familiar distortions and increasing indeterminacy of standard first amendment doctrine. Peripheral indeterminacy occurs because our ability to extend the first amendment ICM is both dependent upon and limited by the metaphor that motivates it. Thus, for example, the quasi-public forum doctrine, which allows content but not viewpoint censorship, reflects the limits of an amendment structured in terms of the market metaphor: Speech is only expected to be "unhibited, robust, and wide-open"28s in the freewheeling space of the public forum; in more limited contexts, one expects more limited space for speech. ${ }^{286}$ Similarly, the doctrine that provides less protection to "speech mixed with conduct"287 is a reflection of the limits of the Ideas are Products entailment of that metaphor: When "pure" speech is contaminated by action, it moves from the domain of the market, where Ideas are Products to be bought and sold freely, to the domain of behavior, where Actions are Motions subject to the control and constraint of law. ${ }^{288}$

Modern first amendment doctrine also displays prototype effects. Consider the rule against prior restraints. Its traditional application to newspapers has been fairly broad. Not only is the government forbidden from enjoining publication of an offending story, ${ }^{289}$ but it can

${ }^{285}$ New York Times v. Sullivan, 376 U.S. 254, 270 (1964).

${ }^{286}$ See, e.g., Perry Educ. Ass'n v. Perry Local Educators' Ass'n, 460 U.S. 37, 5253 (1983) ("The Court of Appeals would have been correct if a public forum were involved here. But the internal mail system is not a public forum." (emphasis added)); Federal Communications Comm'n. v. Pacifica Foundation, 438 U.S. 726, 750-51 (1978) ([W]hen . . . a pig has entered the parlor, the exercise of . . . regulatory power does not depend on proof that the pig is obscene."); Greer v. Spock, 424 U.S. 828, 838 (1976) ("The notion that federal military reservations, like municipal streets and parks, have traditionally served as a place for free public assembly and communication of thoughts by private citizens is thus historically and constitutionally false." (emphasis added)); see also Consolidated Edison Co. v. Public Serv. Comm'n, 447 U.S. 530, 54445 (1980) ("Any student of history who has been reprimanded for talking about the World Series during a class discussion of the First Amendment knows that it is incorrect to state that a 'time, place, or manner restriction may not be based upon either the content or subject matter of speech." (Stevens, J., concurring (quoting majority opinion))).

${ }^{287}$ See, e.g., Broadrick v. Oklahoma, 413 U.S. 601, 615 (1973) (doctrine of facial overbreadth "attenuates as the otherwise unprotected behavior that it forbids the State to sanction moves from 'pure speech' toward conduct"); International Bhd. of Teamsters, Local 695 v. Vogt, Inc., 354 U.S. 284, 294 (1957) (state may enjoin picketing); Giboney v. Empire Storage \& Ice Co., 336 U.S. 490, 497-98 (1949) (speech used as integral part of validly prohibited conduct is unprotected).

${ }^{288}$ For an analogous discussion of the structural effects on standing doctrine of the related Ideas are Objects metaphor, see Standing and Metaphor, supra note 1, at 1496-97. The systematicity of the metaphors Actions are Motions and Law is a Constraint on Motion is discussed infra, text accompanying notes 385-403.

${ }^{289}$ See New York Times Co. v. United States, 403 U.S. 713, 714 (1971) (the Pentagon Papers case) ("heavy presumption" against prior restraint's validity). 
neither require a "right of reply"280 nor tax the print media differentially. ${ }^{201}$ When we move away from prototypical papers, however, the rule against prior restraints is relaxed substantially. High school newspapers are not prototypical papers; they are not part of the core ICM of the first amendment, but rather part of the core curriculum. ${ }^{292}$ Similarly, non-print media have been subject to constraints such as the fairness doctrine ${ }^{293}$ and censorship of nonobscene language. ${ }^{294}$ These decisions are problematic in terms of the doctrinal rules, but understandable as products of the radial structure of the categories used in first amendment analysis.

Tushnet would be quick to ask: "How solid is the core itself?" If the first amendment prohibits prior restraints only in peacetime, can't we play games with categories like "peacetime" and "war"? National security? A police action? The Cold War? Some games are possible. But Tushnet sustains his sense of infinite manipulability by intuitive "assumptions about language and social life that seem simply to be true."295 To the extent that he relies on a coherence theory of meaning, ${ }^{286}$ he has little or no empirical evidence with which to back his claim. In contrast, I claim that "peace" and "war" have central meanings that are stable and accessible, not because they are objectively given, but because peace and war are experiential gestalts that we share. We have a central meaning of peace and war even if there is a

${ }^{290}$ See Miami Herald Pub. Co. v. Tornillo, 418 U.S. 241, 256 (1974) (statute requiring newpaper to offer "equal space" to criticized politician "operates as a command in the same sense as a statute or regulation forbidding [the newspaper] to publish specified matter. . . . The Florida statute exacts a penalty on the basis of the content of the newspaper.")(citation omitted).

201 See Minneapolis Star \& Tribune Co. v. Minnesota Comm'r of Revenue, 460 U.S. 575, 591-92 (1983) (tax burdening small group of newspapers held invalid).

${ }^{202}$ See Hazelwood School Dist. v. Kuhlmeier, 108 S. Ct. 562, 569-70 (1988) ("[School-sponsored publications] may fairly be characterized as part of the school curriculum."). In my view, the Court did not so much mischaracterize the paper as assimilate it to an alternative ICM in a reduction-to-prototype effect. See supra note 230.

${ }^{283}$ See Red Lion Broadcasting Co. v. FCG, 395 U.S. 367, 396 (1969) (requiring broadcasters to give reply time to answer personal attacks and political editorials). The notorious doctrinal problems posed by Red Lion have only been aggravated now that cable has ended airwave scarcity.

${ }^{294}$ See FGC v. Pacifica Found., 438 U.S. 726, 747-51 (1978) ("seven dirty words" case) ("offensive" language may constitutionally be prohibited in medium that broadcasts into the home).

${ }^{295}$ Tushnet, supra note 260 , at 1381 . Tushnet supports his intuition only by citing Kennedy, Critical Labor Law Theory: A Comment, 4 Indus. Rel. L.J. 503, 506 (1981) ("liberal rights theory . . . is wrong and incoherent. This is just true, as far as I can tell, and no amount of lamenting the consequences of his fall can put Humpty Dumpty back together again.").

${ }_{296}$ See supra note 18 and accompanying text. 
no-man's-land in between. The wartime exception specified by dictum in Near v. Minnesota ${ }^{\mathbf{2 9 7}}$ is not likely to encompass just any governmental claim of national security, as the Pentagon Papers case demonstrates. ${ }^{298}$ Unless. Unless the social consensus is so radically changed that the society experiences peacetime as war. In that event, however, society does not alter its central meaning of "peace." Rather, it uses its concept of war to structure a peripheral experience of political and ideological conflict. Predictably, the new social consensus will be expressed by metaphors projecting wartime experience onto peacetime conflict. It will be a Cold War. In which case, Dennis v. United States ${ }^{289}$ cannot be far behind.

Legal reasoning is socially contingent in just this way. Legal concepts are unstable over time; history demonstrates as much. But Tushnet's claim - that rights are irrelevant because "to specify a particularized right in some localized area, . . . we have committed ourselves to a description of an entire social order"300 — does not follow. Rights are structured relative to idealized cognitive models that exhibit differing degrees of stability. Rights-talk is thus both meaningful and manipulable; the what and how of meaning and manipulation all depend on where and when.

This is what I think Felix Cohen meant by "relativity's laws." He used the Legal Theory is Physics metaphor to capture and explain the nonobjective, not quite determinative reality of legal reasoning. "Behind [a judicial] decision are social forces that play upon it to give it a resultant momentum and direction."301 Ordinarily, those social forces impart a linear direction. But areas of strong policy value or times of high political charge can skew the trajectory. In this sense, Dennis is not so much a change "in" or "manipulation of" first amendment doctrine (notice the container and object metaphors). Rather it is a social perception that, in the weltanschauung of 1951, communists were seen as precisely the kind of people who might falsely shout fire in a crowded

297283 U.S. 697, 716 (1931) (permitting prior restraint of wartime publication of troop movements).

288 See New York Times v. United States, 403 U.S. 713, 719 (1971).

209341 U.S. 494, 517 (1951) (upholding Smith Act prosecutions of communist party members).

${ }^{300}$ Tushnet, supra note 260 , at 1379 . This claim is a product of Tushnet's reliance on a social coherence theory of meaning. See supra note 18 and accompanying text.

301 Cohen, supra note 163, at 843. Or, to use Cohen's other force metaphor, social policy is "the gravitational field that gives weight to any rule or precedent." Id. at 834; see also Cover, supra note 99, at 9-10 ("Law is a force, like gravity, through which our worlds exercise an influence upon one another, a force that affects the courses of these worlds through normative space."). 
theater. ${ }^{302}$ "[B] $[\mathrm{Bt}$ after the hysteria subsides," 303 the precedents can return to the original trajectory and Brandenburg $v$. Ohio ${ }^{304}$ is possible.

The particular force field of a doctrinal ICM does not exist in a vacuum, but in a legal universe occupied by other doctrinal ICMs. Other powerful social forces are also manifested in doctrinal ICMs, and these competing fields exert their strongest pull on cases peripheral to a neighboring ICM. ${ }^{305}$ Accordingly, there is something a little naive in the critique of the peripheral areas of first amendment doctrine as cases of simple manipulation. For example, the first amendment protection provided to large aggregates of wealth, which Tushnet identifies as a product of indeterminacy, ${ }^{308}$ may simply be a predictable effect of the greater power of the ICM of property in our culture. ${ }^{307}$ It is powerfully reflected in the fact that the central metaphor of the first

${ }^{302}$ Compare Schenck v. United States, 249 U.S. 47, 52 (1919) ("The most stringent protection of free speech would not protect a man in falsely shouting fire in a theatre and causing a panic."), with Dennis, 341 U.S. at 510 ("The formation by petitioners of such a highly organized conspiracy, with rigidly disciplined members subject to call when the leaders . . . felt that the time had come for action, coupled with the inflammable nature of world conditions, . . . convince us that their convictions were justified on this score.") (emphasis added).

${ }^{303}$ Cohen, supra note 164, at 249.

304395 U.S. 444 (1969). For a different description of the discontinuities between Dennis and Brandenburg, see Tushnet, supra note 8, at 816.

30s See Holland \& Quinn, Culture and Cognition, in D. Holland \& N. QuinN, supra note 1 , at 10-11, 34-35 (competing cultural models do not simply alternate with the task, but rather display systematicity and structural linkages).

${ }^{306}$ See supra text accompanying notes 262-64.

307 See, e.g., Adderley v. Florida, 385 U.S. 39, 47 (1966) (A state, "no less than a private owner of property, has power to preserve the property under its control for the use to which it is lawfully dedicated.'), reh'g denied, 385 U.S. 1020 (1967); see generally Paul, supra note 259.

Robert Cover provides another such example in his explanation of the Court's decision in NLRB v. Catholic Bishops, 440 U.S. 490 (1979). The Court in Catholic Bishops held that the labor laws did not apply to lay teachers in a parochial school. Id. at 507. The Court's reading avoided a potential conflict between the ICM of the labor laws and the ICM of the free exercise clause. As Cover puts it:

The central thrust of the redemptive story of the struggle for the protection of labor's rights of organization and bargaining seemed to the Court to involve a religious school only marginally, whereas the Court perceived the norms of educational autonomy to be centrally related to the narratives of free exercise.

Cover, supra note 99, at 63 (emphasis added). Cover's account includes each aspect of the experientialist explanation of the structure of legal reasoning. His notion of a "story" or "narrative" grounded in the labor struggle corresponds with my identification of legal ICMs grounded in social experience; his notion of a "central thrust" and a "margin" corresponds with my description of legal rules as radial categories whose directional force is greatest at the core and weakest and most indeterminate at the periphery. For further discussion of the relationship between Cover's notion of "redemptive stories," the concept of legal ICMs, and the role of narrative in law, see Legal Power and Narrative Meaning, supra note 4, at 40-47. 
amendment - the marketplace of ideas - is itself expressed in property terms. First amendment cases privileging wealth may be products of the general cultural metaphor money talks. ${ }^{308}$ It is too simplistic to portray such decisions as purposeful, self-interested manipulations of doctrine by powerful individuals. Rather, the protections afforded wealth by current first amendment doctrine may be part of the interest that accrues to the wealthy in a society that values wealth and power and invokes them as the source domain for potent cultural models and metaphors.

Historical doctrinal change is similarly a product of socio-cultural forces. If the competing social forces are strong enough, a precedent hurtling through "absolute legal space" will be captured in a new gravitational field. That field will restructure the idealized cognitive model at the core of the precedent. A new precedent will be born. The new ICM will be expressed by a new set of metaphors. And the paradigm shift of the new ICM" I09 $^{30}$ will mean that "other precedents in many other fields of law will thenceforth cease to be precedents." 310

This account is not intended to deny indeterminacy in legal reasoning. Quite the contrary. It is intended to explicate the kinds of, degrees of, and reasons for the relative indeterminacy that we experience in working with legal materials. I shall categorize these indeterminacies as indeterminacy of extension, indeterminacy of paradigm, and substantive indeterminacy. Indeterminacy of extension results from the lack of fixed, generative rules or principles that determine the mode of extension from the central case of an ICM. Indeterminacy of paradigm results from the law's commitment to objectivist logic and classical categorization. Substantive indeterminacy refers to both how old doctrines evolve and how new doctrine is made where none existed before.

${ }^{308}$ Strikingly, this was Tushnet's argument in 1982. See Tushnet, Corporations and Free Speech, in D. KaIRYs, supra note 17, at 253. Tushnet noted that a "deep structure of capitalist ideology" treats "all products of human activity as commodities. . . subject to trade in markets." Id. at 254 . He identified first amendment protection of corporate speech as natural products of three metaphors: "(1) the corporation as person; (2) the free marketplace of ideas; and (3) money talks." Id. at 255. Moreover, Tushnet concluded that "[a] simple instrumental explanation. . . . must be augmented by emphasizing the sense of naturalness that the significant metaphors have." Id. at 260. Tushnet's recent treatments of the same doctrinal material, see M. TusHNET, supra note 17; Tushnet, supra note 260 , omit these earlier observations.

309 The notion of intellectual "progress" as a shift in ICMs and an accompanying shift in metaphors (as opposed to straight-line progress in objective understanding) is closely related to Kuhn's notion of paradigm-shift in scientific development. See generally $\mathrm{T}$. KuHN, supra note 61 . The experientialist cognitive theory developed by Lakoff and Johnson was, in fact, strongly influenced by Kuhn.

310 Cohen, supra note 164 , at 248-49 (footnote omitted) (referring to NLRB v. Jones \& Laughlin Steel Corp., 301 U.S. 1 (1937), discussed infra in subsection III D). 
Indeterminacy of extension is a function of the radial structure of thought. This radial structure is what produces the areas of peripheral indeterminacy that both Hart and Kennedy identify. "[T]he authoritative general language in which a rule is expressed may guide only in an uncertain way much as an authoritative example does."311 This passage nicely illustrates the phenomenon of prototype effects, which are the products of categorization by means of idealized cognitive models. Because ICMs "characterize the nerve [center] of . . . reasoning," "312 a legal category is never capable of determinate extensions beyond the core of unproblematic, prototypical cases. "[T]he language of the rule will enable us simply to pick out easily the recognizable instances."

We experience a high degree of indeterminacy of extension in our daily teaching, brief writing, and scholarly pursuits. ${ }^{314}$ But as Hart observed, this is merely the flip-side of the relative degree of determinacy at the core of legal analysis. ${ }^{315}$ Little of the content of the appellate reports, and even less of that of casebooks and law reviews, is about core areas of doctrine. Core areas do not present substantially difficult legal and doctrinal questions. The materials we work with are, therefore, overdetermined toward indeterminacy. The cases in which doctrine works reasonably well are those that don't get litigated; those that, if litigated, settle; and those that, if decided, don't get reported. This means, however, that although LAw is hard at work much of the time, it cannot do what we most want to depend on it for: To decide the difficult, controversial cases.

The lack of determinacy of extension does not connote arbitrariness of extension. Rather, there are motivating structures that constrain-but-do-not-determine both the extension of ICMs and their initial formulation. This, in part, accounts for indeterminacy of paradigm. Indeterminacy of paradigm arises out of the disparity between the objectivist model of legal discourse and the cognitive model of human rationality. The rules proposed by the objectivist present themselves as propositional and syllogistic; but human rationality is neither. Propositional legal rules promise determinate answers; the imaginative and metaphoric structure of thought yields a different pattern of decisionmaking. This lack of fit between the professed and the experienced is perceived as indeterminacy. The superimposition of propositional legal

311 H.L.A. HART, supra note 169, at 124.

312 Id.

313 Id.

s14 See Hart, supra note 168 , at 615 ("[I]t is good to be occupied with the penumbra. Its problems are rightly the daily diet of the law schools.").

s1s See H.L.A. HART, supra note 169, at 132; Posner, supra note 142, at 840. 
doctrines and syllogistic arguments upon an imaginative and largely metaphoric reasoning process is what makes indeterminacy "seem simply to be true."

Indeterminacy of paradigm is exacerbated because the objectivist paradigm not only conflicts with the normal process of human reasoning, but also distorts it in particular, predictable ways. Conventional legal reasoning creates greater indeterminacy because it seeks propositional principles, syllogistic rules, and determinative factual statements as necessary and sufficient criteria. It thereby abstracts and simplifies a complex experience; its very partiality falsifies what it tries to capture. ${ }^{316}$ For example, Fiss' view of the first amendment as torn between the autonomy and public debate principles ${ }^{317}$ is a typical objectivist dissection of a single experiential gestalt better captured by the market metaphor. To see the first amendment as protecting either autonomy or public debate is to miss important parts of what is real about the ICM of free speech. ${ }^{318}$

Substantive indeterminacy results from the social contingency of the idealized cognitive models that underlie legal principles. Doctrines can fluctuate widely when social forces conflict or when there is substantial social change. We have seen how a traditional doctrinal area like the first amendment can change substantively as a function of social change in apparently unrelated areas of experience. This is good as well as bad. After all, how many of us share with the New Right an excitement about returning to doctrines of economic substantive due process? Who would go back to "separate but equal"? The language of law is not a surrogate for political discourse; it is a form of political discourse. Because the law is grounded in the same cultural ICMs, it is contingent on general cultural conflict and change. One of the costs of this contingency is that legal decisions made in times of social conflict cannot expect to command universal social assent solely on the basis of methodology. One of the benefits, on the other hand, is that to understand that law is socially grounded is to enable us to harness the transformative power of law as a means of social construction, temporary institutionalization, and collective recovery ${ }^{319}$ - a point I shall return

${ }^{316}$ See supra note 69. I use "partial" in a literalist sense, but it may be just this sense that motivates the metaphoric idea of partiality as bias.

${ }^{317}$ See Fiss, supra note 8, at 785-87.

318 This is, in essence, a version of the familiar reification critique of critical legal studies. See, e.g., Freeman, Legitimizing Racial Discrimination Through Antidiscrimination Law: A Critical Review of Supreme Court Doctrine, 62 MINN. L. REv. $1049,1062-79$ (1978) (describing and criticizing the different "neutral principles" that can be derived from Brown); see discussion infra notes 435-39 and accompanying text. ${ }^{319}$ Cf. Cornell, supra note 23, at 1204-09 (describing as "recollective imagina- 
to in Part IV B below.

This perspective suggests that there can be no meaningful claim either of total objectivity or of total indeterminacy for law. The interesting question is one of typology, a question that Duncan Kennedy has been bold enough fruitfully to explore. ${ }^{320}$ But the current debate over whether law is radically indeterminate, and thus illegitimate, or ascertainable via deduction or interpretation, and therefore ethically defensible, simply misses the point.

Our problems with law are products of human rationality. Because it is LAw, it pretends to clothe itself in objectivity and invites us to expect more than human rationality can deliver. Disillusioned, some overreact and proclaim loudly that the emperor has no clothes at all. Understanding the cognitive structure of law itself may help us redress our very human dilemma. We are not entirely naked, but the threads we wear are surely woven by human hands. We need to know that, and to take it into account in assessing our predicament. Some urge us to go further and replace law with something else, such as a frankly political discourse. But that would not ameliorate our predicament. We will still be who we are.

tion" the social process of reconstructing principle by interpreting the "should be" and the "might have been" of history and past practice and observing that this process is dependent on the reality of Sittlichkeit).

${ }^{320}$ In Critical Phenomenology, supra note 242, at 538-42, Kennedy describes six "typical field configurations": (1) the impacted field with "long straight boundaries, reenforced at regular intervals with precedents" that are difficult to manipulate; (2) the case of first impression, traditionally viewed as a "kind of clearing of freedom in the endless forest of constraint"; (3) the unrationalized field, in which the existing precedents are scattered in chaotic fashion, yielding maximum freedom to the decisionmaker; (4) the contradictory field, in which there are "rapid fluctuations along a contorted boundary" and, therefore, "[e]very point not occupied by a recent precedent is contestable"; (5) the collapsed field, like state action doctrine after Shelley v. Kraemer, 334 U.S. 1, 20 (1948) (judicial enforcement of racially restrictive covenant constitutes state action), in which there is "no coherent argument for a line that would hold against the collapsing argument"; and (6) the loopified field, in which the core areas of opposing precedents are more alike than their peripheries. An example suggested by Kennedy is the familial prerogative of childrearing, which is both constitutionally protected as private, see, e.g., Wisconsin v. Yoder, 406 U.S. 205, 234 (1972) (first amendment religion clauses bar state from compelling children to attend formal high school), and extensively regulated by the states under the guise of family law.

Kennedy's typology, however, is just a typology and not a map. He concludes his piece with the assertion that there is no way to know in advance when a body of precedent will yield a particular field structure. Moreover, he asserts that, even after the fact, there is no way of knowing whether one missed "the catch that releases the secret panel" that would allow a different characterization. Id. at 561. In contrast, my argument is that general cultural knowledge will be useful in predicting much of this typology in advance. 


\section{Metaphor Makes Its Move}

I want to concretize my analysis by considering a specific case: NLRB v. Jones $\&$ Laughlin Steel Corp. ${ }^{321}$ The case marks a watershed in commerce clause analysis, reflecting a major shift in the legal/ social consensus on the constitutional status of New Deal regulatory programs. ${ }^{322}$ It is the case Felix Cohen identifies as a major paradigm shift, affecting "precedents in many other fields of law." ${ }^{\text {"323 }}$ It is, thus, a perfect case to illustrate how metaphoric reasoning operates in legal analysis.

As in International Shoe and Holmes' Abrams dissent, landmark cases can be expected to exhibit important changes in the use of the conventional legal metaphors. In International Shoe, Chief Justice Stone supplanted one "thingification" with another. ${ }^{324}$ In Abrams, Holmes elaborated on conventional metaphors to reconstruct the first amendment. ${ }^{325}$ In Jones $\mathcal{E}$ Laughlin, Hughes reorganized the cognitive model for interstate commerce issues. In doing so, he did not operate free-form, as a subjectivist might have it. Rather, he worked with the metaphoric material already in the cases to refashion commerce clause doctrine in a manner that was neither predetermined by the materials nor completely arbitrary.

Hughes accomplished this in three moves. First, he rejected the rigid, objectivist categorization of the precedents that ordinarily dominates the surface of legal analysis. Second, he sliced through the conventional stream of commerce metaphor ${ }^{326}$ to its underlying source-

321301 U.S. 1 (1937). Jones \& Laughlin arose after the National Labor Relations Board determined that a steel manufacturer had coerced, intimidated, and discriminated against its employees in an effort to prevent unionization. See id. at 22.

${ }^{322}$ See B. ACKerman, Reconstructing AMERICAN LAw 6-11 (1984); Ackerman, The Storrs Lectures: Discovering the Constitution, 93 YALE L.J. 1013, 1053-57 (1984).

${ }^{323}$ Cohen, supra note 164 , at 249 n.12.

324 See supra notes $183-88$ and accompanying text.

${ }^{325}$ See supra notes $276-84$ and accompanying text.

326 The stream of commerce metaphor dates to a 1905 Holmes opinion, which uses the phrase "current of commerce." Swift \& Co. v. United States, 196 U.S. 375, 399 (1905). Prior to that, the streams referred to in commerce clause cases were quite literal. As the Court observed in Gibbons v. Ogden:

The commerce of the United States with foreign nations is that of the whole United States. Every district has a right to participate in it. The deep streams which penetrate our country in every direction, pass through the interior of almost every State in the Union, and furnish the means of exercising this right.

22 U.S. (9 Wheat.) 1, 195 (1824). Before the advent of the railroads in the nineteenth century and of trucks in the twentieth, ships were the primary vehicles of commerce. Thus, the stream of commerce metaphor had a grounding in day-to-day experience. 
path-goal schema. Third, he used that schema to reelaborate the metaphors for commerce in a way that both radically changed the question and substantially determined a new constitutional answer.

The primary question in Jones $\mathcal{E}$ Laughlin was jurisdictional: Could the federal government, under the commerce clause, regulate labor relations in manufacturing? The drafters of the National Labor Relations Act had determined that interference with the right to organize and to bargain collectively has

the necessary effect of burdening or obstructing commerce by (a) impairing the efficiency, safety, or operation of the instrumentalities of commerce; (b) occurring in the current of commerce; (c) materially affecting, restraining, or controlling the flow of raw materials or manufactured or processed goods from or into the channels of commerce. . .; or (d) causing diminution of employment and wages in such volume as substantially to impair or disrupt the market for goods flowing from or into the channels of commerce. ${ }^{\mathbf{3 2 z}}$

The drafters used fluid metaphors (amongst others) to express the applicability and relevance of Congress's commerce clause power to labor relations.

In contrast, the steel manufacturer's "argument rest[ed] upon the proposition that manufacturing . . . is not commerce."328 This objectivist argument treats the distinction between manufacturing and commerce according to the rigors of the essentialist categorization of $\mathrm{P}$ or $\sim \mathrm{P}$. This position was firmly rooted in nineteenth century precedent, ${ }^{\mathbf{3 2 9}}$ and had been mirrored in the circuit court's approach to the federalism

327 29 U.S.C. $\S 151$ (1982) (emphasis added) (congressional findings in $\S 1$ of the Act). They further declared it to be "the policy of the United States to eliminate the causes of certain substantial obstructions to the free flow of commerce. . . by encouraging the practice and procedure of collective bargaining." Id. The sections that I have quoted in the text and in this footnote are from the first and fourth paragraphs of the preamble, respectively. These portions focused on the more traditional grounds for congressional power, and reflect the position taken by Charles Wyzanski. The second paragraph introduced a constitutionally more novel justification premised on economic theory; it included an attack on economic substantive due process. See Casebeer, Holder of the Pen: An Interview with Leon Keyserling on Drafting the Wagner Act, $42 \mathrm{U}$. Miami L. REv. 285, 308-12 (1987). These latter positions were not addressed by Hughes in Jones $\mathcal{E}^{2}$ Laughlin.

${ }^{328}$ Jones $\mathcal{E}$ Laughlin, 301 U.S. at 34 (citations omitted).

${ }^{320}$ See, e.g., Kidd v. Pearson, 128 U.S. 1, 20 (1888) ("No distinction is more . . . clearly expressed in economic and political literature, than that between manufactures and commerce."); United States v. E.C. Knight Co., 156 U.S. 1, 12 (1895) ("Commerce succeeds to manufacture, and is not a part of it."). 
question.

One who produces or manufactures a commodity, subsequently sold and shipped by him in interstate commerce, . . . has engaged in two distinct and separate activities. So far as he produces or manufactures a commodity, his business is purely local. So far as he sells and ships ... the commodity to customers in another state, he engages in interstate commerce. In respect of the former, he is subject only to regulation by the state; in respect of the latter, to regulation only by the federal government. ${ }^{330}$

The use of the container schema for categorization fits well with the geopolitical structure of federalism: since manufacturing "is purely local," it "is subject only to regulation by the state." Thus, everything had only a single essence: either commerce or manufacturer; either federal or state; either $\mathrm{P}$ or ${ }^{\sim} \mathrm{P}$; either in the container (manufacturing = within state borders) or across its boundaries (commerce $=$ federal power). The Jones $\&$ Laughlin dissent, moreover, added Schechter Poultry's further categorical distinction between direct and indirect effects on commerce, a fuzzy distinction that it defended with an unshakeable objectivist faith: "The precise line can be drawn only as individual cases arise, but the distinction is clear in principle."331

Both the Board and the Solicitor General, on the other hand, stayed within the statute's metaphoric paradigm as they argued in support of congressional power. In its opinion, the Board invoked the conventional personification metaphor for a corporation and elaborated on its fluid entailment, held in common with the statute, by invoking a cardiovascular analogy. It likened steel plants

to the heart of a self-contained, highly integrated body. They draw in the raw materials from Michigan, Minnesota, West Virginia, Pennsylvania in part through arteries and by means controlled by the respondent; they transform the materials and then pump them out to all parts of the nation through the vast mechanism which the respondent has

sso Jones \& Laughlin, 301 U.S. at 79 (McReynolds, J., dissenting) (quoting NLRB v. Jones \& Laughlin Steel Corp., 83 F.2d 998, 998 (5th Cir. 1936)(citations omitted)).

${ }^{331}$ Id. at 96 (quoting Schechter Poultry Corp. v. United States, 295 U.S. 495, 546 (1935)). The notion of a "precise line" implicates underlying objectivist assumptions. In contrast, one can understand the reference to the distinction as "clear in principle" as a suggestion that "direct" and "indirect" are structured radially with clear cores and indistinct peripheries. 
elaborated..$^{332}$

Similarly, the Solicitor General's argument in defense of the Board observed that the steel company's "activities constitute a 'stream' or 'flow' of commerce, of which the ... manufacturing plant is the focal point." "sss $\mathrm{He}$ relied on stream of commerce precedents such as Stafford v. Wallace," ins which the "Court found that the stockyards were but a 'throat' through which the current of commerce flowed and the transactions which there occurred could not be separated from that movement."3ss

These quotations are taken from Hughes' opinion. Hughes' designation of metaphors such as stream, flow, and throat in quotation marks suggests his self-conscious stance toward metaphor, reminiscent of Stone's in International Shoe. But, in fact, Hughes was neither solicitous of the steel company's propositional arguments nor disdainful of the government's metaphors. His classic response instead elaborated and extended those metaphors.

We do not find it necessary to determine whether these features of defendant's business dispose of the asserted analogy to the "stream of commerce" cases. The instances in which that metaphor has been used are but particular, and not exclusive, illustrations of the protective power which the government invokes in support of the present Act. The congressional authority to protect interstate commerce from burdens and obstructions is not limited to transactions which can be deemed to be an essential part of a "flow" of interstate or foreign commerce. Burdens and obstructions may be due to injurious action springing from other sources. The fundamental principle is that the power to regulate commerce is the power to enact "all appropriate legislation" for its "protection and advancement" . . . "and it is primarily for Congress to consider and decide the fact of the danger and to meet it."'338

Trained as legal objectivists, we are prone to misread Hughes' stance as dismissing the stream of commerce metaphor in favor of a

${ }^{332}$ Jones $\mathcal{E}$ Laughlin, 301 U.S. at 27 (emphasis added). On the conventional use of the personification metaphor to structure our understanding of a "corporation," see supra text accompanying notes 178-80.

${ }^{333}$ Id. at 35.

334258 U.S. 495 (1922).

33 Jones $\mathbb{E}$ Laughlin, 301 U.S. at 35.

${ }^{336}$ Id. at 36-37 (quoting The Daniel Ball, 77 U.S. (10 Wall.) 557, 564 (1870), and Stafford v. Wallace, 258 U.S. 495, 521 (1922)). 
realistic assessment of congressional power over commerce. A closer look, however, suggests the opposite: What Hughes rejects is the steel manufacturer's objectivist distinctions. Manufacturing may be different from commerce, but Hughes treats that essentialist approach to categorization as beside the point. ${ }^{337}$

Hughes' primary concern is for what motivates the stream of commerce metaphor. In prior opinions, Hughes self-consciously rejected legal metaphor as figurative. ${ }^{338} \mathrm{Here}$, in contrast, he treats the metaphor as "but [a] particular, and not exclusive, illustration." trates is an underlying image-schema. The stream of commerce image is merely one particular metaphor motivated by the source-path-goal schema. In effect, Hughes returns to the schematic level of cognition and from there elaborates other metaphoric entailments. Suppose commerce is conceptualized not as a stream but, in the government's metaphor, as "a great movement of iron ore, coal and limestone along welldefined paths." ${ }^{340}$ If commerce is movement along a path, then it can be personified as a traveler. In that case, we would not want undue burdens to delay it or obstructions to impede its progress. Most important, we would not want it to be waylaid from ambush by the side of the road - i.e., harmed "due to injurious action springing from other sources." start on its journey. As Hughes asks rhetorically: "[O]f what avail is it to protect the facility of transportation, if interstate commerce is throttled with respect to the commodities to be transported!"342

These metaphors for commerce lead to two conclusions. First, Congress must be empowered to consider matters outside the "flow" of commerce, because that is where danger is most likely to lurk. Second, someone must protect commerce from these dangers. Who but Congress? The fundamental principle then becomes that Congress is charged with the "protection and advancement" of commerce. "[A]nd it is primarily for Congress to consider . . . the danger and to meet it. ${ }^{3343}$

By this point in his opinion, Hughes has thoroughly reorganized

s37 "We do not find it necessary to determine whether these features of defendant's business dispose of the asserted analogy to the 'stream of commerce' cases. . . . [C]ongressional authority . . . is not limited to transactions which can be deemed to be an essential part of the "flow' of . . . commerce." Id. at 36.

s38 See supra note 171.

${ }^{339}$ Jones $\mathcal{E}$ Laughlin, 301 U.S. at 36 (emphasis added).

340 Id. at 34-35 (emphasis added).

341 Id. at 36 (emphasis added).

342 Id. at 42 (emphasis added).

${ }^{343} I d$. at 37 (emphasis added). 
the ICM of the commerce power to one structured by a metaphor that entails a radically different conception of the federal role. The older model was premised on a stream metaphor that entailed a quite limited congressional role: If commerce is a stream, then Congress's job is to regulate its flow and protect it from obstructions. ${ }^{344}$ Hughes' model, premised on the much richer journey metaphor, yields more wide ranging entailments. If commerce is a traveler on a journey, then the potential sources of interference are much more widespread. The focus now becomes not mere obstructions, but harms of many sorts such as throttling, danger, injurious action springing from other sources. The correlative congressional power shifts from regulation to protection and advancement. Congress is now the interstate police protecting the always vulnerable traveler and expediting her journey. Hughes dramatically extends the congressional commerce power by a subtle, almost imperceptible shift from the stream to the journey metaphor,

This, however, does not quite get Hughes where he needs to go. As the dissent observes, it is a long way from the discharge of a single union organizer to a significant danger to the advancement of commerce. ${ }^{345}$ Hughes' response to that argument draws on the natural elaborations of the metaphors he has been subtly revising. He starts with the obstruction entailment common to both the stream and journey metaphors, but elaborates on the danger and protection entailments of the latter. "[T]he fact remains that the stoppage of those [manufacturing] operations by industrial strife would have a most serious effect on interstate commerce." ${ }^{\text {346 }}$ Having thus invoked the local danger to the

344 In traditional commerce clause analysis, the chief fear seems to have been that of balkanization. See, e.g., H. P. Hood \& Sons v. Du Mond, 336 U.S. 525, 539 (1949) ("Our system is that every farmer and every craftsman shall be encouraged to produce ... [ [and that] no foreign state will by customs duties or regulations exclude them."). On this view, Congress and the federal courts had only to watch the stream, make sure that it continued to flow, and remove any local obstructions. During the Great Depression, however, the major threats to commerce had nothing to do with local governmental obstructions; systematic economic problems of various sorts had "choked off" the flow.

${ }^{345}$ Justice McReynolds writes:

It is gravely stated that . . . discontent may follow and this in turn may lead to a strike, and as the outcome of the strike there may be a block in the stream of interstate commerce. Therefore Congress may inhibit the discharge! Whatever effect any cause of discontent may ultimately have upon commerce is far too indirect to justify congressional regulation. Almost anything - marriage, birth, death, - may in some fashion affect commerce.

Jones $\mathcal{E}$ Laughlin, 301 U.S. at 99 (McReynolds, J., dissenting). Note that McReynolds, in contrast to Hughes, is still conceiving the issue in terms of "a block in the stream of commerce."

${ }^{346}$ Id. at 41 (majority opinion) (emphasis added). 
interstate journey, Hughes rejects the previous container schema approach to federalism by focusing on the wide scope of economic operations and the concomitant breadth of the danger that Congress may be called upon to meet.

When industries organize themselves on a national scale, making their relation to interstate commerce the dominant factor in their activities, how can it be maintained that their industrial labor relations constitute a forbidden field into which Congress may not enter when it is necessary to protect interstate commerce from the paralyzing consequences of industrial war? ${ }^{347}$

Silently invoking a conception of balance, he is able persuasively to assert that the scope of congressional power must be commensurate with the national scope of the manufacturer's operation and its vulnerability to violent disruption. A threat to interstate commerce cannot hide behind state borders; Congress must be empowered to reach where it must. How much more so when it is "war" that must be prevented?348 In the end, Hughes makes his point not so much by "[r] igorous argumentation issu[ing] in agreement in propositions, ${ }^{\text {"349 }}$ as by a cognitive and metaphoric tour de force.

Jones $\mathcal{E}$ Laughlin is the paradigm shift in the ICM of the congressional commerce power. Congress is no longer the sluice gate operator who regulates this flow in the channels of commerce. It is now the interstate police for the market. The core of the commerce clause question is how far "the reach of that power extends." 350 The focus has shifted away from the definition of the width and breadth of the channel itself. And the Court does not look back. Once it focuses on the threat to interstate traffic arising from intrastate activity, it concludes that federal "control is essential . . . to the security of that traffic."351 Wickard v. Filburn, ${ }^{\mathbf{3 5 2}}$ the avatar of modern commerce clause analysis,

347 Id. (emphasis added).

348 Hughes goes on to elaborate the role of collective bargaining in the maintenance of "industrial peace" and the duty of Congress to "exercise its protective power" and "safeguard" commerce from "jeopardy" and "dangers." Id. at 42-43.

349 R. RORTY, CONSEQUENCES, supra note 5, at xli.

350 United States v. Wrightwood Dairy Co., 315 U.S. 110, 119 (1942).

351 The Shreveport Rate Cases, 234 U.S. 342, 351 (1914). The fact that this case with its traffic and security metaphors predates Jones \& Laughlin does not diminish the latter's significance as a paradigm shift. To the contrary, the preexisting usage of these metaphors illustrates my earlier point that such paradigm shifts will be prefigured and constrained by the existing metaphors conventional in legal discourse. See supra text accompanying notes 254-55.

362317 U.S. 111 (1942). In Wickard, the Court upheld regulation of wheat grown only for home consumption on the theory that it affected the interstate market 
is the inevitable result. Quoting this last passage, Justice Jackson proclaims "the Commerce Clause exemplified by this statement has made the mechanical application of legal formulas no longer feasible." 353 Propositional, categorical distinctions between "production" and "commerce," "direct" and "indirect,"354 are no longer pertinent to the appropriate model. That discourse is dropped from the constitutional lexicon and a new model gives voice to the modern commerce clause.

IV. The Gognitive Stakes: Metaphor, Meaning, and the Possibility OF Rights

"Social systems are constructed out of, as well as constrained by, what human beings are; and how human beings cognize their worlds constrains and shapes how humans-in-societies reproduce them." 355

"[W]hen we realize that we routinely speak these ideas and images to each other. . . we can begin to form an understanding of how the law is actually constitutive of our social existence." $" 356$

For many, knowledge is valuable for its own sake; but I am engaged in this exercise because of what I believe is at stake. ${ }^{\mathbf{3 5 7}}$ In the previous sections, I have examined the ways in which we employ idealized cognitive models to structure and understand concepts like lie, simple legal rules like a rule prohibiting vehicles in the park, and more complex doctrinal areas like the first amendment and the scope of congressional commerce clause power. In these final subsections, I bring together the different threads of my analysis of social and legal meaning to focus on the possibility of rights. First, I explore the idealized cognitive model that motivates our thinking about LAw. Second, I extract the entailments of that model to demonstrate why legal positivism misses most of what is socially important about law. Third, I examine another version of the critique of rights offered by some associated with the critical legal studies movement. I employ Cover's insights together

for wheat by reducing demand. Once the Court focuses on the power of Congress and upholds its reach, the Court simply accepts the resulting unfairness to the local farmers. "It is the essence of regulation that it lays a restraining hand on the self-interest of the regulated." Id. at 129 (emphasis added).

${ }^{383} I d$. at 123-24.

354 See id. at 119-20, 123-25.

${ }^{355}$ Keesing, Models, "folk" and "cultural": Paradigms Regained? in D. HoLLAND \& N. QUINN, supra note 1, at 388-89.

${ }_{356}$ Gabel, supra note 272, at 1564.

${ }^{367}$ See Standing and Metaphor, supra note 1, at 1514-16. 
with the experientialist approach to meaning to reply to this critique. The purpose of this argument is to empower and to validate a reconstructive, transformative theory of rights: a vision of 'the 'is,' the 'ought,' and the 'what might be." "368

\section{A. Talking About Law}

In his Supreme Court Foreword of 1983, Robert Cover speaks to us movingly about the jurisgenerative quality of communal life, about law as the constitutive nomos of the group, and about the "jurispathic" (i.e., law killing) role of the State's judges and courts. ${ }^{359}$ I begin by abstracting one part of his jurisprudence: his description of the jurisgenerative process, the creation of a nomos by a community. In the course of a larger section that explores the relationship between commitment and the making of legal meaning, Cover makes the following observation:

Creation of legal meaning, however, requires not only the movement of dedication and commitment, but also the objectification of that to which one is committed. The community posits a law, external to itself, that it is committed to obeying and that it does obey in dedication to its understanding of that law. Objectification is crucial to the language games that can be played with the law and to the meanings that can be created out of it. If the Amish lived as they do because it was fun to do so, they might still fight for their insularity. They would not, however, be disobedient to any articulable principle were they to capitulate. And they could not hold someone blameworthy - lawless - were he to give in.

358 Cover, supra note 99, at 10. Related efforts include Minow, Interpreting Rights: An Essay for Robert Cover, 96 YALE L.J. 1860 (1987), and Cornell, supra note 23.

358 See Cover, supra note 99. Of the "jurispathic" quality of courts, Cover writes:

It is remarkable that in myth and history the origin of and justification for a court is rarely understood to be the need for law. Rather, it is understood to be the need to suppress law, to choose between two or more laws, to impose upon law a hierarchy. It is the multiplicity of laws, the fecundity of the jurisgenerative principle, that creates the problem to which the court and the state are the solution.

$I d$. at 40 . Just before his death, Cover returned to the implications of this insight in his haunting piece Violence and the Word, 95 YALE L.J. 1601, 1610 (1986) ("I am not writing of the jurispathic quality of the office [judge], but of its homicidal potential." (footnote omitted)). I shall consider portions of that piece below in my exploration of the concept of rights. 
Creation of legal meaning entails, then, subjective commitment to an objectified understanding of a demand. It entails the disengagement of the self from the "object" of law, and at the same time requires an engagement to that object as a faithful "other." The metaphor of separation permits the allegory of dedication. ${ }^{360}$

This passage is as rich in metaphor as it is deep in insight: the use of the source-path-goal schema for the conceptualization of commitment $^{361}$ ("the movement of dedication and commitment"); the container metaphor to structure the concept of the group ("a law, external to itself"); and the centrality of the object metaphor to the major insight of the passage. It is "the 'object' of law" that the community "creates;" LAw is "the objectification of that to which one is committed;" its elaboration "entails . . . subjective commitment to an objectified understanding of a demand."

Cover makes a distinctly linguistic assertion about the indispensability of this process of metaphoric reasoning to the creation of LAw: "Objectification is crucial to the language games that can be played with the law and to the meanings that can be created out of it." ${ }^{\text {362 }}$ We cannot talk about law without the metaphor of object: To know that someone has broken the law, we must first conceptualize it as something that can be broken; it is something that the outlaw or vigilante can take into her own hands. We must also be able to ascertain what the law is. It must (metaphorically) be given physical form as an object that can be found, discovered, or made. No law exists without reification.

But Cover also tells us that this process of objectification of law must take a specific form to function as LAw. It is the kind of "object" that can be obeyed or disobeyed: LAW is a person, ${ }^{\mathbf{3 6 3}}$ an "other" from whom we "disengage" but whom we continue to perceive as "faithful" to us and thus deserving of obedience. "The metaphor of separation" that Gover invokes is not just a generalized metaphor of personification, but rather a specific invocation of the childhood experience of separation from parent. The process of law-creation is a projection of child-

360 Cover, supra note 99, at 45 (emphasis added).

361 The conceptualization of "commitment" in terms of the source-path-goal schema follows from the use of that schema to conceptualize "purpose." See supra text accompanying notes $92-95$.

${ }_{362}$ Cover, supra note 99 , at 45.

${ }^{363}$ See N. GHOdorow, supra note 87 , at 42 n.** ("In psychoanalytic parlance 'objects' are people, aspects of people, or symbols of people."). 
hood experience. ${ }^{364} \mathrm{LAw}$ is the projected parent, the internalized superego. ${ }^{365}$ In Brandeis' quite Freudian metaphor, the "Government is the potent, the omnipresent teacher."368 When it is no longer faithful, when "Government becomes a lawbreaker" and not the embodiment of LAW, "it breeds contempt for law; it invites everyman to become a law unto himself; it invites anarchy."3367

In The Genealogy of.Morals, Nietzsche describes, "[h]istorically speaking, all the law" as a human construct of a similar sort:

Wherever Justice is practiced and maintained, we see a stronger power intent on finding means to regulate the senseless raging of rancor among its weaker subordinates. This is accomplished by wresting the object of rancor from vengeful hands . . . . But above all, by the establishment of a code of laws which the superior power imposes upon the forces of hostility and resentment whenever it is strong enough to do so; by a categorical declaration of what it considers to be legitimate and right, or else forbidden and wrong. Once such a body of law has been established, all acts of highhandedness on the part of the individuals or groups are seen as infractions of the law, as rebellion against the supreme power. . . . It follows that only after a corpus of laws has been established can there be any talk of "right" and "wrong" (and not, as Dühring maintains, after the act

384 See I. Boszormenyi-Nagy \& J. Spark, Invisible Loyalties 54 (1984) ("We believe that the concept of justice of the human order is a common denominator for individual, familial, and societal dynamics. Individuals who have not learned a sense of justice within their family relationships are likely to have a distorted judgment of social justice."); $c f$. J. FRANK supra note 198, at 21 ("Why do men seek unrealizable certainty in law? Because . . . they have not yet relinquished the childish need for an authoritative father and unconsciously have tried to find in the law a substitute for those attributes of firmness, sureness, certainty and infallibility ascribed in childhood to the father." (footnote omitted)).

${ }^{365}$ Cf. N. CHoDorow, supra note 87, at 50 ("[S]ociety constitutes itself psychologically in the individual not only in the moral strictures of the superego. All aspects of psychic structure, character, and emotional and erotic life are social, constituted through a "history of object-choices." "); E. JacoBson, The SELF and THE OBJECT World 50 (J. Am. Psychoanalytic A., Monograph Series No. 2, 1964) ("[T]he child's desires to remain part of his love objects, or to make them part of his own self, will slowly recede and give way to wishes to realistic likenesses with them. This goal can be achieved by virtue of selective identification, based on mechanisms of 'partial introjection." ").

${ }^{368}$ Olmstead v. United States, 277 U.S. 438, 485 (1928) (Brandeis, J., dissenting).

${ }^{367}$ Id. Brandeis uses a kinship metaphor to express the way in which lawless government causes anarchy: thus, the potent teacher who breeds contempt. On the systematicity in literature of kinship metaphors for causation, see the analysis in M. TURNER, supra note 1. 
of injury)..$^{368}$

Although Nietzsche uses them to express very different conceptions of the origins and meaning of law, here too we see the object, container, and personification metaphors at work. Nietzsche has the strong "wresting the object of rancor from vengeful hands" and transmuting the object into a thing called "Justice" which is "maintained." This thing is organized according to the objectivist categorization of the container metaphor: It is either $\mathrm{P}$ or $~ \mathrm{P}$, a "categorical declaration of what it considers to be legitimate and right, or else forbidden and wrong."368

But Nietzsche's law is a very particular kind of object and a very particular kind of container: It is "a body of law." The use of a personification metaphor for law enables us to elaborate conventional legal expressions motivated by our knowledge of human physiology. We speak of the corpus juris. Fundamental legal principles are described as embodied in the Constitution or statutes. ${ }^{370}$ Thus we warn criminals of the "long arm of the law." statute/case/constitutional provision say?" In first amendment cases, we determine whether a statute is unconstitutional on its face, in which case the court strikes it down ${ }^{372}$ - a confluence of the personification

${ }^{368}$ F. Nietzsche, The Genealogy of Morals, reprinted in The Birth of Tragedy and The Genealogy of Morals, Essay II, § 11, at 207-08 (F. Golffing trans. 1956) (emphasis added). Nietzsche states that he is referring to ideas of E. Düring, found in several of his works. See id. at 206. For a discussion of Nietzsche's view as an assertion of "textual materialism" and the objectivity of "strong" texts, see Weisberg. Text into Theory: A Literary Approach to the Constitution, 20 GA. L. REv. 939, 962-76 (1986).

${ }^{369}$ Once we have structured our concept of LAw by means of these metaphors, Nietzsche says that we can treat "all acts of highhandedness . . . as infractions of the law," - i.e., as "breakings" (from the Latin fractus meaning broken). See id. Nietzsche goes on to characterize these infractions in terms similar to Brandeis' Freudian metaphor in Olmstead, 277 U.S. at 485. Nietzsche says that these infractions are "rebellion against the supreme power." F. NieTzSCHE, supra note 368, at 208.

${ }_{370}$ See, e.g., United States v. Bailey, 444 U.S. 394, 414 (1980) (invoking "[t]he Anglo-Saxon tradition of criminal justice, embodied in the United States Constitution and federal statutes"); Fay v. Noia, 372 U.S. 391, 433-34 (1963) (referring to "the ancient principles of the writ of habeas corpus, embodied both in the Federal Constitution and in the habeas corpus provisions of the Judicial Code"); Weeks v. United States, 232 U.S. 383, 393 (1914) (describing "those great principles established by years of endeavor and suffering which have resulted in their embodiment in the fundamental law of the land").

${ }^{371}$ Similarly, problems of jurisdiction in our multi-state, federal system are handled by the concept of long arm jurisdiction pursuant to long arm statutes.

${ }^{372}$ See, e.g., Gooding v. Wilson, 405 U.S. 518, 520 (1972) (striking down a statute "on its face"); Coates v. City of Cincinnati, 402 U.S. 611, 620 (1971) (White, J., dissenting) ("The statute, in effect, is stricken down on its face."); see also Broadrick v. Oklahoma, 413 U.S. 601, 615 (1973) (limiting doctrine of facial invalidity by requiring 
and Rational Argument is War metaphors. Personified entities will have the capacity to reproduce: thus we frequently refer to important cases as seminal cases and to the cases that follow as their progeny. ${ }^{373}$ And we know that legal concepts, like people, have determinate life spans; consider Grant Gilmore's famous account of the "brief, happy life of the general theory of contract." ${ }^{\text {"374 }}$ Moreover, like our real-life forebearers, "dead" legal concepts may yet retain surprising power to influence their offspring: thus Maitland's famous dictum that "[ $t]$ he forms of action we have buried, but they still rule us from their graves."375

These personification metaphors are not just fortuitous linguistic expressions. Rather, as Cover suggests, they are systematic reflections of a fundamental conceptualization grounded in childhood experience that we use for the creation of legal meaning. This too is reflected in Nietzsche's point that "only after a corpus of laws has been established can there be any talk of 'right' and 'wrong'."376

At the literal level, Nietzsche is simply making a positivistic observation about law: It is the creation of the strong, imposed upon the weak by superior power. Armed with this understanding, we can see through the false legitimation often entailed by the assertion of legality. "Legal positivism may be seen, in one sense, as a massive effort that has gone on in a self-conscious . . . way to strip the word 'law' of these resonances."377 The advantage of positivism is that it "breaks down psychological barriers to outright conscription of the word 'law' to nefarious purposes which natural law thinking might create."378 Thus, Nietzsche's description of law as a human construct is iconoclastic and liberating; it is intended to free us from the tyranny of false, imposed delineations of "right" and "wrong."

But I want to make a much stronger, cognitive claim about Nietzsche's statement. That is, the medium motivates the message; his positivistic point is entailed in the metaphor he uses; the passage works precisely because the metaphor it employs is intimately related to (and revealing of) our deepest psychological conceptions of LAW. When

that "the overbreadth of a statute must not only be real, but substantial as well, judged in relation to the statute's plainly legitimate sweep.") (emphasis added).

${ }^{373}$ Indeed, Nietzsche invoked just this entailment of the metaphor when he entitled his treatise The Genealogy of Morals.

374 G. Gilmore, The Death of Contract 85 (1974). See also Brandeis \& Warren, The Right to Privacy, 4 Harv. L. REv. 193 (1890) ("[T]he common law, in its eternal youth, grows to meet the demands of society.") (1909).

${ }^{375}$ F. Maitland, Equity and the Forms of Action at Common Law 296

${ }^{376} \mathrm{~F}$. NiETzSCHE, supra note 368, at 180 (citation omitted).

377 Cover, supra note 239, at 180 (citation omitted).

${ }^{378} I d$. at 180 n.7. 
Nietzsche says that it is "only after a corpus of laws has been established" that there can "be any talk about right," cognitive relationship between the personification metaphor and the meaning of "right."

It is not fortuitous that we use the same word in these two, "objectively" distinct ways: "correct" and "the opposite of left." As with most cases of apparent homonymy, there is a cognitive connection. The polysemous character of these two senses of the word right, therefore, can be understood as related by a single conceptual metaphor that is part of an idealized cognitive model for the concept LAW - the personification metaphor invoked both by Cover and by Nietzsche. If LAw is to have a body it will have as well a right arm with which to enforce its commands. The long arm of the law has been identified: It is the right arm which enforces that which is acceptable and that which is not ${ }^{\mathbf{3 8 0}}$; it is the LAw's sanction (that is, the potential sanction of physical violence) that determines what is right. Might makes right.

This underlying image and metaphoric conceptualization of LAw is widely shared, cognitively real, and therefore, constitutive of our social reality. The degree to which this is so is reflected both in cultural imagery and common language. Consider, for example, the dominant Western iconography of Justice: the Goddess Justitia, the familiar image of the blind-folded woman who holds aloft the scales of justice in her left hand, also carries a sword in her right. ${ }^{\mathbf{3 8 1}}$ Moreover, in many

379 F. Nietzsche, supra note 368 , at 208.

380 Perhaps my favorite unconscious (and incongruous) usage of the metaphor in this way is John Finnis' brief for natural law: "The modern language of rights provides... a supple and potentially precise instrument for sorting out and expressing the demands of justice." J. Finnis, Natural Law and Natural Rights 210 (1980) (emphasis added). Here, Finnis has personified Justice, which issues demands and expresses them by (moral) force. The metaphor of rights as physical appendages (that is, literal rights) appears as well in Grotius' seventeenth century work, De Iure Bellis: "Right is a moral Quality annexed to the person, enabling him to have, or do something justly." R. TuCK, Natural Rights Theories 74 (1979) (translation by Tuck) (emphasis changed from original).

${ }^{381}$ See Curtis \& Resnik, Images of Justice, 96 YALE L.J. 1727, 1732-33, 1735, 1740,1751 (1987) (presenting various artistic depictions of Justicia). Occasionally, the sword is in Justicia's left hand, as in the painting by Sir Joshua Reynolds that appears in the overleaf of R. Cover, O. Fiss, \& J. Resnik, Procedure (1988). This painting, however, contains other variations of the conventional image; for example, Justicia's eyes are not blindfolded, but rather are shaded by the scale she holds aloft in her right hand. See id.

Sometimes, Justicia holds the fasces or bundle of rods (often with a protruding ax blade) that symbolized the authority of the Roman magistrates. See Curtis \& Resnik, supra, at 1742 n.35. Fasces is the Latin source of the familiar term "fascism."

The image of the sword of justice also derives from the biblical story of Solomon, in which he threatens to split the baby and divide it between two competing claimants. See Minow, The Judgment of Solomon and the Experience of Justice, in R. Cover \& 
European languages the predominant word for the concept LAw is the same word that connotes the opposite of left. Thus, in French, there is droit and Droit; in Spanish, derecho and Derecho; in German, recht and Recht; and, in English, right and legal rights. ${ }^{382}$

This last polysemous usage suggests another connotation of "right," closely related to the Nietzschean, positivistic description of LAw. The concept of legal rights is another entailment of the personification of LAw. A person has a right to do what the law specifies is allowed. For that right to be meaningful, it must be backed up by the sanction of the State. Thus, the concept of legal rights is parasitic on State power; it has a specific entailment of violence. ${ }^{383}$ This is the connection between private law and the State that legal realists like Robert Hale and Morris and Felix Cohen have stressed since the 1920s. ${ }^{384}$

O. Fiss, The Structure of Procedure 447 (1979). In this story, the violence of the law is readily apparent.

${ }^{382}$ Italian seems to be the exception: There the terms are, respectively, destra and Dirreto. The latter, however, shares with the English right the same root in the Latin rectus for straight. See supra text accompanying notes 385-90.

383 Consider the interrelationships of the personification metaphor, the concept of rights, and the potential of state sanctioned violence in the conventional definition of jus:

In Roman law. right; justice; law; the whole body of law; also a right. The term is used in two meanings:

1. "Jus" means "law," considered in the abstract that is, as distinguished from any specific enactment, the science or department of learning, or quasi personified factor in human history or conduct or social development, which we call, in a general sense, "the law." . . .

2. In a second sense, "jus" signifies "a right;" that is, a power, privilege, faculty, or demand inherent in one person and incident upon another; or a capacity residing in one person of controlling, with the assent and assistance of the state, the actions of another. . . .

It is thus seen to possess the same ambiguities as the words "droit," "recht," and "right"....

Black's Law Dictionary 770 (5th ed. 1979).

${ }_{384}$ See, e.g., Cohen, Property and Sovereignty, 13 CoRnel. L.Q. 8, 22-30 (1927) (Morris Cohen) (noting the relationship of private property rights to state political power); Hale, Law Making by Unofficial Minorities, 20 Colum. L. Rev. 451, 452-53 (1920) (discussing the connection between private rights and state power). As Felix Cohen writes:

Suppose we say, that $\mathrm{X}$ is property to which the following label can be attached:

To the World:

Keep off $X$ unless you have my permission, which I may grant or withhold.

Signed: Private citizen

Endorsed: The State

Let me offer the caution that such a label does not remove the penumbra of ambiguity that attaches to every word that we use in any definition. . . . Any definition of property, to be useful, must reflect the fact that property merges by imperceptible degrees into government, contract, force, and value.

Cohen, Dialogue on Private Property, 9 Rutgers L. Rev. 357, 374 (1954). 
There is, however, a second metaphoric derivation of the term "rights" that is central to the way we conceptualize Law. The English word "right" derives most immediately from the German "recht," which in turn derives from the Latin rectus or straight. Thus, the word "right" is a metaphor motivated by the source-path-goal schema. Its systematic relationship to the concept of LAW dates at least to the Bible $^{385}$ and is related to the Life is a Journey metaphor discussed above. The concept of right is understood in terms of the notion of following the correct path in life. So too, the notion of legal rights is understood in terms of the legally defined behaviors or paths marked out by the law. ${ }^{\mathbf{3 8 6}}$ This conceptualization of morally and legally appropriate behavior in terms of the source-path-goal schema is what motivates the familiar phrases "following the rules laid down"387 and "the straight and narrow," which is illustrated in Figure $3 .{ }^{388}$

s8s In Deuteronomy, God warns the children of Israel: "And thou shalt not turn from the words that I command you today, neither right nor left, to walk after other gods to serve them." Deuteronomy 28:14 (translation from original Hebrew by author); see also Leviticus 26:3 ("If ye walk in my statutes. . . ."). In the latter quote, the Hebrew word that is usually translated as "statute" actually has a connotation closer to "fiat."

${ }^{386}$ Cf. Holmes, The Path of the Law, 10 HARv. L. Rev. 457 (1897)(illustrative title); Cohen, supra note 164, at 251 (quoted in text accompanying note 199).

${ }_{387}$ For a conventional legal usage of the latter phrase, see Tushnet, supra note 8. See also Gabel, supra note 272, at 1573-74 (referring to "the schema by which we are to reproduce our group connection ... through 'the following of laws' created and interpreted by this 'State.' These laws define how we are 'allowed to act' in the form of 'rights." ").

${ }^{388}$ Copyright 1988 by the New York Times Company. Reprinted by permission. This illustration, by David Gothard, appeared in connection with an article on recent controversies concerning the ethics of various government officials. See Herbers, Pentagon Bribery Inquiry: Demand for Ethics in Government Has Outstripped Supply, N.Y. Times, June 19, 1988, $\S 4$, (Week in Review) at 4 , col. 1. 


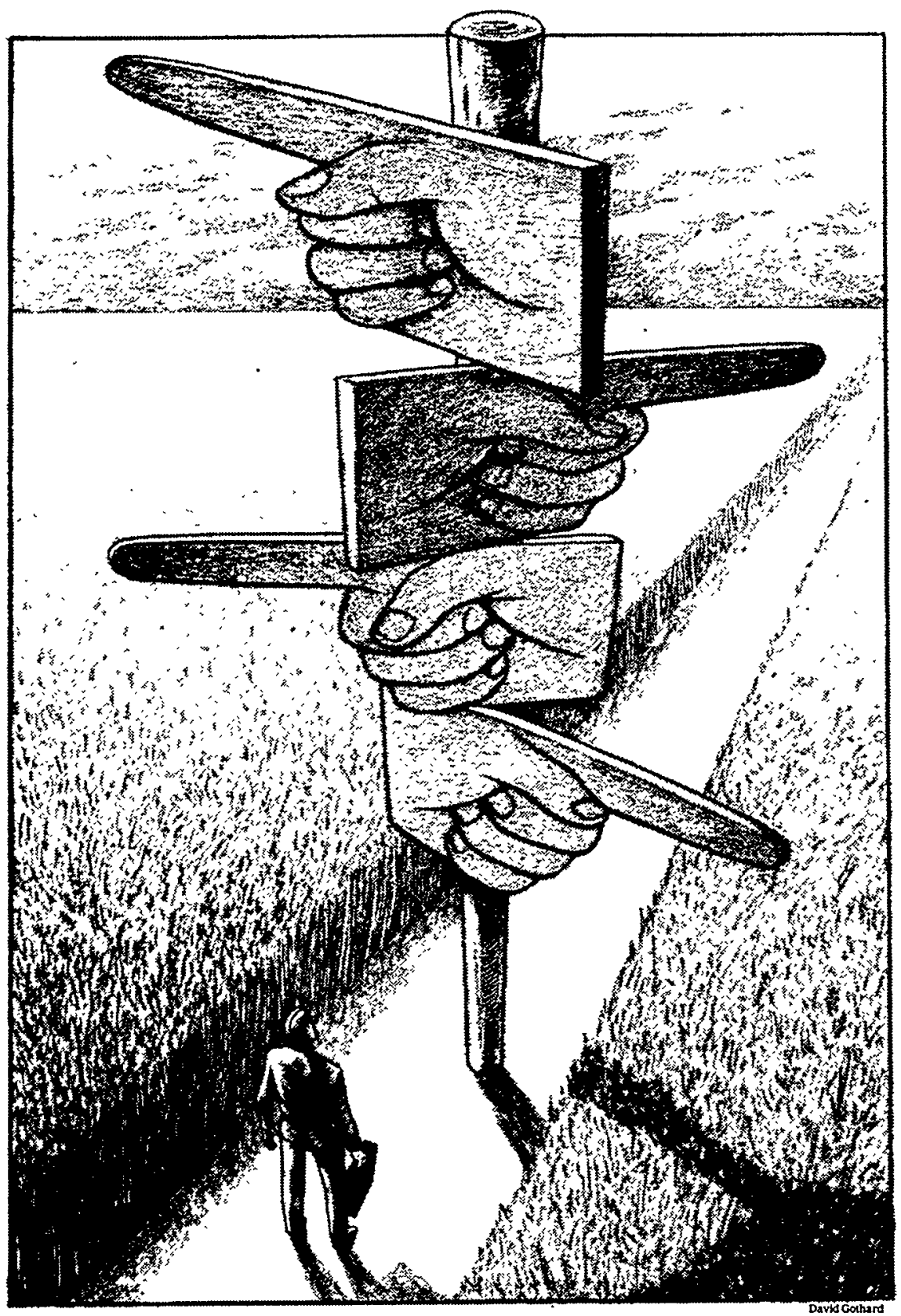


This second metaphoric derivation of the concept rights is, however, coherent with and closely related to the personification metaphor of LAw. It is LAw personified that lays down the rules (from the Latin regula, meaning straightedge, and regere, meaning to lead straight) or paths that we are to follow, as in "the rule of law." This understanding of the concept of rights uses a conventional Actions are Motions metaphor $^{388}$ and views LAW as a constraint on motion, much as a path constrains travel. ${ }^{\mathbf{3 9 0}}$ Thus, to be law-abiding is to be within the bounds of the law. To violate the law is a breach. One who strays outside these boundaries is an outlaw. ${ }^{391}$ Thus, it is the objectified constraint of the

380 This is an entailment of the Life is a Journey metaphor. Examples of the Actions are Motions metaphor include the description of a person active in the community as a mover and shaker; the description of someone who pulls rank as really throwing her weight around; and the characterization of being too busy to do something as being all tied up with work.

The imagery of actions and motions along a path to conceptualize specifically legal operations that involve very little physical activity is revealed in civil procedure. For example, Rule 2 provides: "There shall be one form of action to be known as "civil action'." FED. R. Crv. P. 2. Having filed a lawsuit, lawyers makes motions. The judge or opposing counsel challenges a motion by asking on what grounds. The reply, often as not, is pursuant to some rule. "Pursuant" is derived from the same source as "pursue": the lawyer thus asserts that she is following a rule.

390 This metaphoric conceptualization of LAw is clear in the explanation of the 15th century scholar, Jean Gerson, whom Richard Tuck credits with the first natural rights theory. See R. Tuck, supra note 380 , at 25 . "Lex is a practical and right reason [recta ratio practica] according to which the movements and workings of things are directed toward their ordained ends." Id. at 27 (translation by Tuck) (quoting and translating Jean Gerson) (emphasis added).

Similarly, the conception Actions are Motions and its entailment Law is a Constraint on Motion is prominent in Justice Black's dissent in Goldberg v. Kelly, 397 U.S. 254 (1970). Expressing his concern over the power of judicial review and the need for judicial restraint, he refers to the "ambulatory power to declare laws unconstitutional" and characterizes the Court's decision as "a drastic and dangerous departure." Id. at 276-77 (Black, J., dissenting) (emphasis added). Justice Black also notes: "[T]he early settlers undertook to curb their governments by confining their powers within written boundaries, which eventually became written constitutions." Id. at 272-73 (emphasis added). But this conceptualization, in which constitutional law is a constraint on judicial motion, is not unique to Black. His critics express their point in much the same terms. See, e.g., Adamson v. California, 332 U.S. 46, 68 (1947) (Frankfurter, J., concurring) ("The judicial judgment in applying the Due Process Clause must move within the limits of accepted notions of justice") (emphasis added); Kadish, Methodology and Criteria in Due Process Adjudication - A Survey and Criticism, 66 YALE L.J. 319, 338 (1957) (The Court's opinions "belie the notion that the literal language of certain constitutional provisions directs and confines judicial inquiry along specific lines.") (emphasis added).

${ }^{391}$ The source of this term is the Anglo-Saxon legal practice of outlawry as punishment: "The effect was that [the outlaw] was put outside the king's peace and protection, and until 1329, could probably be slain by anyone." $3 \mathrm{~W}$. HoLDsworTH, A History OF ENGLish LAW 605 (3d ed. 1923) (footnotes omitted). See also 2 id. at 46 (4th ed. 1936) (The outlaw "was outside the law, and as a wild beast could be pursued and slain.").

The word "forfeit" shares this source with "outlaw." It comes from the Old 
path that is the object referred to in the phrase "to break the law."

To those who follow its paths, the LAw offers the benefits of its protection. This is the positive entailment of the confluence of the personification of LAW and the Control is Up metaphor; it yields the meaning of rights under the law. ${ }^{392}$ If someone violates or obstructs my rights, I may take that person to court and invoke my legal rights to correct the legal wrong and to obtain from the judge an order directing the defendant to respect my rights or otherwise redressing my grievance. Each of these propositions entails multiple uses of the sourcepath-goal schema. ${ }^{393}$ The role of the law is to restore and secure my rights - that is, to put me back on track. ${ }^{394}$

In our most highly developed conceptualizations, the metaphoric personification of the LAw offers protection even against the government itself. This is perhaps clearest in the concept of due process and other procedural rights. It is reflected in a set of metaphors, ubiquitous in lawyers' everyday practice, that are entailments of the path metaphor for "rights." Thus, for example, a defendant has a right to a trial by jury. He or she may waive that right, as if to pass up the procedural path offered by the law. Indeed, the defendant may choose to forgo [forego] the right to trial altogether and accept its outcome in advance. And, consonant with the connection between the personification metaphor for LAw and the path metaphor, it is the function of the law to secure these rights and make sure that they are not undermined.

The use of metaphors derived from the source-path-goal schema to reason about the role of law is prominent in Holmes' opinion for the

French fors, or out, and faire, to make. In modern usage, however, its use with the concept of rights appears to be related to the Rights are Possessions metaphor. See infra text accompanying notes 411, 413-14.

392 See, e.g., Valley Forge Christian College v. Americans for Separation of Church and State, Inc., 454 U.S. 464, 492-93 (1982) (Brennan, J., dissenting) (suggesting that the Court's use of the standing doctrine obfuscates the meaning of rights under the law); Walker v. City of Birmingham. 388 U.S. 307, 321 (1967) (extolling "the civilizing hand of law, which alone can give abiding meaning to constitutional freedom"); $C f$. M. Ball, Lying Down Together: Law, Metaphor, and TheolOGY 23 (1985) (discussing the inscription in the frieze of the Supreme Court building: "Equal Justice Under Law," as compared to the prophet Amos' insistence that "justice has priority over law and that equal law under justice is the more fit order").

${ }^{393}$ The words "correct," "direct," and "redress" all derive from the Latin rectus. The derivation of "redress" is more complicated than the others: It comes from the Old French redrecier, meaning to make straight, which in turn derives from the Latin redirectus. In Standing and Metaphor, supra note 1, I explain that the concept of adjudication is structured in terms of the source-path-goal schema. See id. at 1388-91.

${ }^{394}$ Here, we see the deeper metaphoric structure of the concept of LAw that makes Hughes's reconstruction of the commerce clause power extremely powerful. See supra text accomapnying notes 326-49. 
Court in Moore v. Dempsey. ${ }^{395}$ In Moore, the Court upheld the availability of federal habeas corpus to consider a claim of a mob-dominated atmosphere at the petitioners' capital trial. Toward the close of his opinion, Holmes argues:

In Frank v. Magnum . . . it was recognized of course that if in fact a trial is dominated by a mob so that there is an actual interference with the course of justice, there is a departure from due process of law. . . . We assume in accordance with that case that the corrective process supplied by the State may be so adequate that interference by habeas corpus ought not to be allowed. It certainly is true that mere mistakes of law in the course of a trial are not to be corrected in that way. But if the case is that the whole proceeding is a mask - that counsel, jury and judge were swept to the fatal end by an irresistible wave of public passion, and that the State Courts failed to correct the wrong, neither perfection in the machinery for correction nor the possibility that the trial court and counsel saw no other way of avoiding an immediate outbreak of the mob can prevent this Court from securing to the petitioners their constitutional rights. ${ }^{396}$

In this passage, Holmes conceptualizes rights as the proper procedural path that we identify with "the course of justice." Federal habeas may be appropriate when the complaint is not about "mere mistakes of law in the course of a trial", but rather about serious deviations from the path - that is, "a departure from due process of law." 397

Notwithstanding a similar argument, the Frank Court had denied habeas review over a Holmes dissent because in its view the state had provided "adequate corrective process" on appeal. Accordingly, Holmes recognizes that more is necessary to sustain federal review in the subsequent case of Mr. Moore and his co-petitioners; he therefore argues that the Moore case involves something quite different than a mere departure which may easily be noticed and corrected. Holmes invokes a conventional fluid metaphor for anger" ${ }^{398}$ and argues "that counsel, jury

${ }^{305} 261$ U.S. 86 (1923).

${ }^{396}$ Id. at 90-91 (citing Frank v. Magnum, 237 U.S. 309, 335 (1915)).

307 Holmes took these phrasings verbatim from the majority opinion in Frank, 237 U.S. at 335.

${ }_{398}$ This is the source of the common phrases: it makes my blood boil; he's prone to frequent outbursts; she's all steamed up; he blew a gasket; I try to channel my anger. For a discussion of the other metaphors used to conceptualize anger, the systematic entailments of these metaphors, and their experiential bases, see Lakoff \& Kövecses, The Cognitive Model of Anger Inherent in American English, in D. HoLLAND \& N. QUINN, supra note 1, at 195-220. For a discussion of the overlap between 
and judge were swept to the fatal end by an irresistible wave of public passion." 399 Holmes acknowledges "the possibility" that the power of this passion might be such "that trial court and counsel saw no other way of avoiding an immediate outbreak of the mob" -i.e., that there was no possibility of staying on the true path and not having to confront the passion of the mob, that the only alternative to a full scale riot was to "go with the flow." In that case, neither the existence of corrective process nor the appearance of regularity can vitiate the fact that "the whole proceeding is a mask." The Court, therefore, must restore to the defendants the meaningful paths marked out by due process, "securing to the petitioners their constitutional rights."

This account of Holmes' opinion in Moore demonstrates the systematicity of the rights as paths metaphor and the way in which it operates in legal analysis. The only thing missing from this account is the meaning of the mask. It serves a double metaphoric role. On one hand, it is what holds in the fluid of the mob's anger, what prevents the outbreak of the mob. In this sense, it is like a "poker face" that masks one's emotions and is related to Milner Ball's notion that Law is a Bulwark holding back the forces of chaos. ${ }^{400}$ On the other, it is a play on the conventional image of Justicia's blindfold. As Cover puts it: "Procedure is the blindfold of Justice." ${ }^{01}$ In Moore, however, Justice wears not a blindfold but a mask. The procedure is neither blind nor true to the straight and narrow, but sighted and moving in tandem with the mob.

The conceptualization of law in terms of the source-path-goal schema is, of course, not limited to procedural matters; it includes substantive law as well. It is integral to Cover's position that nomos and narrative are central to LAw. For him, these "interpretive trajectories"402 are the bridges that we build to our future. "Law may be viewed as a system of tension or a bridge linking a concept of a reality

the metaphors for anger and for sex, and how that interrelationship affects male conceptualizations of rape, see G. LAKOFF, supra note 1, at 409-15.

${ }^{309}$ As pointed out to me by Lynn Winter, Holmes' metaphor of being swept along by the mob's passion is also grounded in the physical experience of being physically carried forward by the surge of a crowd. A fatal example occurred at the Cincinnati rock concert in 1979 featuring The Who when the stampede of the crowd not only carried people forward, but also trampled several of them underfoot. See Thomas, 11 Killed and 8 Badly Hurt in Crush Before Rock Concert in Cincinnati, N.Y. TIMEs, Dec. 4, 1979, at A1, col. 3. One aspect of the resulting litigation is reported in Bowes v. Cincinnati Riverfront Coliseum, Inc., 12 Ohio App. 3d 12, 23, 465 N.E.2d 904, 916 (1983).

100 See M. BALL, supra note 392, at 23-27.

101 R. Cover, O. FISS \& J. RESNIK, supra note 381, at 1332.

402 Cover, supra note 99, at 60 . 
to an imagined alternative." ${ }^{403}$ This entailment of the metaphoric conceptualization of rights is not only positive, but hopeful. It is this understanding that suggests the possibility and importance of rights.

There is a third metaphoric derivation of the term "legal rights" that returns us more directly to the concept of violence. This concept of rights is an entailment of the conventional metaphor Rational Argument is War: It is systematic in the way we talk about rights, whether one advocates for or against them. "The language of rights attempts to describe how people can defend the interests they have by virtue of their humanity." 404 "The vocabulary of rights is enlisted as a rhetorical weapon in a larger ideological and political conflict."405 Rights are "the language we use to try to persuade others to let us win this round."406 And, in the darkest but most colorful expression of all, Roberto Unger describes legal rights by means of a Wild West metaphor: "The right is a loaded gun that the rightholder may shoot at will in his corner of town. Outside that corner the other licensed gunmen may shoot him down."407

Despite its imagery of violence, this derivation of the rights metaphor also has positive entailments. For one thing, this metaphoric grounding of the concept of rights is a source of the power of natural law thinking: People have rights by virtue of their human form; it is natural to employ rights to defend oneself. ${ }^{408}$ This is the grounding for the natural law conceptualization of rights as inalienable, ${ }^{400}$ and the

40 Id. at 9.

104 Tushnet, supra note 260, at 1382 (emphasis added).

105 Hutchinson \& Monahan, supra note 164, at 1482 (emphasis added).

${ }^{108}$ Minow, supra note 358, at 1876 (emphasis added). In personal correspondence, Martha Minow has informed me that when she wrote this line she had in mind not boxing, but a round of cards. Even so, a highly competitive agon like a card game is structured metaphorically in terms of combat. In any event, the point common to both our perspectives is the role of rational argument and law as a sublimation of naked violence. See infra text accompanying notes 412 \& 450.

407 Unger, The Critical Legal Studies Movement, 96 Harv. L. Rev. 561, 597 (1983). Unger's metaphor directly calls up the sense that the exercise of a right is an exercise of power backed by the State. See supra text accompanying notes 383-84. It also uses a spatial metaphor ("his corner of town"), which is common to rights-talk and reflects the relationship between the concepts of rights and of property. See also Karst, supra note 87, at 501 (discussing a model of judicial review premised on "[t]he morality of the ladder" that "define[s] rights . . . within assigned zones of noninterference").

${ }^{408}$ See Tushnet, supra note 260, at 1382 ("The language of rights attempts to describe how people can defend the interests by virtue of their humanity."). These metaphoric inferences lead inexorably to the conclusion, acknowledged as an extraconstitutional principle by Justice Story, that it is "the ultimate right of all human beings in extreme cases to resist oppression, and to apply force against ruinous injustice." 1 J. StORY, Commentaries on the Constitution of THE UNited STATES $\S 395$ (1833) (emphasis added) (footnote omitted).

${ }^{409}$ See, e.g., The Declaration of Independence para. 1 (U.S. 1776) ("We hold 
conception of classic liberalism that rights are absolute when they are "self-regarding." 110 It continues in the common lay conceptualization Rights are Possessions (as in "It's my right!"), which is why people have rights. ${ }^{411}$

Secondly, the derivation of "rights" from the Rational Argument is War metaphor entails a sublimation of violence into reasoned disputation: One invokes rational argument, instead of force, in making a claim against another ${ }^{412}$ or, in the case of constitutional rights, against the government itself. Despite these positive entailments, the cognitive relationship between rights and violence remains strong. For rational argument is only a sublimation, a means of channeling violence. As Cover reminds us:

Legal interpretation takes place in a field of pain and death. This is true in several senses. Legal interpretive acts signal and occasion the imposition of violence upon others: A judge articulates her understanding of a text, and as a result, somebody loses his freedom, his property, his children, even his life. Interpretations in law also constitute justifications for violence which has already occurred or which is about to occur. When interpreters have finished their work, they fre-

these truths to be self-evident that all men are created equal, that they are endowed by their Creator with certain unalienable Rights").

410 For a discussion of this classical theory of rights from Bentham through Mill and Austin, and its collapse by Hohfeld into the right-duty tautology, see Singer, The Legal Rights Debate in Analytical Jurispmedence from Bentham to Hohfeld, 1982 WISC. L. REV. 975, 986-1024.

411 In our society, the strongly individualistic nature of rights appears as an entailment of the Rights are Possessions metaphor. See Lynd, Communal Rights, 62 TEX. L. Rev. 1417, 1418-19 (1984).

The connection between the individualistic metaphor standing and the sourcepath-goal schema used to conceptualize adjudication lies in the mutual entailments of standing and the path and journey metaphors: The traveller in a journey, the individual, is standing on the path. Note that the individualistic version of the journey metaphor is naturally grounded but culturally reenforced. We could alternatively conceptualize life's journey as a communal effort; cultural experiences like the exodus from Egypt and the trek through Sinai to the promised land provide alternative cultural models. Cf. Standing and Metaphor, supra note 1, at 1387-89, 1478, \& 1495-1500.

412 This is clearly reflected in Tyler v. Judges of the Court of Registration, 179 U.S. 405, 406 (1900), where the Court observed that: "The primary object of all litigation is to establish a right asserted by the plaintiff or to sustain a defense set up by the party pursued." Id. at 410 . The conceptions of litigation both as having an object and as a pursuit of the defendant are uses of the source-path-goal schema. These conceptions also use the Rational Argument is War metaphor to structure the concept litigation: The defendant is pursued and attempts to put up a defense while the plaintiff asserts her right. This passage illustrates how the source-path-goal and Rational Argument is War metaphors operate together in our ordinary thinking because of their metaphoric coherence and cognitive systematicity. See Standing and Metaphor, supra note 1 , at $1498-99$. 
quently leave behind victims whose lives have been torn apart by these organized, social practices of violence. Neither legal interpretation nor the violence it occasions may be properly understood apart from one another. ${ }^{413}$

In recognizing and focusing on these connections, Cover is seeking actively to strip away the veil of "objective" rationality with which we too easily obscure the real world consequences of legal practices.

This, I think, is the value of understanding the metaphors that structure our concepts of law and legal rights. To know that the ICM that structures our concept of rights is partially defined in terms of the Rational Argument is War metaphor - that is to say, that our very practice of argument is grounded in, and is a sublimation of, naked violence - is to forestall the process by which these real world consequences of law are so easily obscured. It is to be less vulnerable to the sanitizing effect of the dispassionate and disembodied pretensions of what we do as lawyers, judges and, especially, academics. The point of exposing the underlying cognitive model of rights is to reveal just these kinds of obfuscations and to open us to the reconstructive possibilities.

To summarize, the full ICM of rights is structured in terms of the metaphors we have explored:

- Law is person

-actions are motions

- constraints on actions are constraints on motions

-control is up

-rights (and other legal rules) are paths

-rational argument is war

-rights are possessions.

To understand this multidimensional ICM is to understand the deep cognitive meaning of LAW. LAW is not an objective "thing" in the world; it is not "a brooding omnipresence in the sky." 414 LAW is a purely human creation, an imaginative product of the human cognitive capacity. To understand the cognitive structure of LAW is to understand what law "really is"; it is to understand law's social meaning. Because we "routinely speak these ideas and images to each other,"

413 Cover, supra note 359, at 1601 (footnotes omitted). For Cover's earlier explication of the relationship between the judge, state violence, and doctrines of jurisdiction, see Cover, supra note 99, at 55-56.

\$24 Southern Pac. Co. v. Jensen, 244 U.S. 205, 222 (1917) (Holmes, J., dissenting); see also Fuller, supra note 124, at 632 ("Law, as something deserving loyalty, must represent a human achievement."). 
they are constitutive of our social reality. ${ }^{415}$ To understand law as a cognitive construction from these lived dimensions of experience is to see that theories of law based on positivism and natural law are inherently wrong because they are incomplete; each procrustean principle merely captures one aspect of a more complex cognitive dynamic. ${ }^{416}$ By the same token, any theory of law that does not come to grips with its pragmatic underside - its inevitable violence - is equally false. ${ }^{\mathbf{4 1 7}}$

The social meaning of LAW is encoded in and institutionalized through our ICM of rights. For us, LAw is two parts violence and three parts hope. There is the ever-present potential of State violence - the long arm of the law that ultimately backs up LAw's commands. There is the sublimated violence of rational disputation - the assertion of rights as in Rational Argument is War. Yet, despite the reality of conflict, the promise of rights is to channel and transform actual interpersonal violence into the sublimated violence of rational disputation. And rights are about the actions of real persons as they make their way through life. That means that rights are always also about the shape of the future. "Only by . . . projecting beyond the decision the lines of its force upon the future, do we come to the meaning of the decision itself." 18 LAW always contains an element of the "ought" and the "should be," the designation of the desirable trajectories of human behavior. ${ }^{419}$ In the subsection that follows, I explore the hopeful dimen-

410 See Gabel, supra note 272, at 1564.

416 This is the flaw that afflicts Judge Posner's subtle reformulation of the Holmesian notion that law is just a prediction of what judges will do. See Holmes, supra note 386, at 460-61. Reasoning in a quite Rortyian fashion, Judge Posner posits that: "The law is not a thing [judges] discover; it is the name of their activity. They do not act in accordance with something called 'law,' they just act." Posner, supra note 142 , at 881 . What this description misses entirely is the social meaning of LAw. Compare Cover, supra note 239, at 181 ("[Law] is the bridge - the committed social behavior which constitutes the way a group of people will attempt to get from here to there."). The danger of Judge Posner's description is that it seems to free judges to decide cases that are in accordance with the "law" simply because they (together with enough of their colleagues to constitute a majority) decided it.

117 This, in essence, is Cover's critique of the "interpretive turn" in law. See Cover, supra note 359, at 1602, and Tushnet's critique of Robert Burt's Constitutional Law and the Teaching of the Parables, 93 YALE L.J. 455, 500 (1984) (arguing that the proper role for the Supreme Court is to "hold out the possibility for sustained serious deliberation" and to resurrect a sense of community "from apparent defects inflicted in majoritarian institutions"); Tushnet, Anti-Formalism in Recent Constitutional Theory, 83 MrCH. L. REv. 1502, 1521-25 (1985) (concluding that despite his intentions, Burt's arguments support the mistaken proposition that law is not coercion).

${ }^{418}$ Cohen, supra note 163 , at 843 . See also Cornell, supra note 23, at 1204 ("The very statement of what the law is in turn implicates the 'should be' because it depends on justification of a particular interpretation since there can be no pure statement of what the law 'is.' ").

419 As Shapiro writes:

A claim about rights generally involves a fourfold assertion about the sub- 
sions of this ICM. I examine how Cover's insights, together with the experientialist approach to meaning, enable us to rediscover the possibilities and make rights meaningful again.

\title{
B. The Possibility of Rights
}

Although Western societies have adopted the model for law implicit in the word "right," there is an alternative linguistic possibility for the concept we now identify as legal rights. In Latin, the corresponding term is jus or ius - the source of the English word "justice." Related to Sanskrit words for joining, ${ }^{420}$ it reflects a communal conception of the jurisgenerative process: As Cover characterizes his own work, "the thrust of Nomos [i]s that the creation of legal meaning is an essentially cultural activity which takes place (or best takes place) among smallish groups." ${ }^{\prime 21}$

In his critique of rights piece, Peter Gabel takes a substantially different position on the meaning of rights. In his view, the State is a hallucinatory projection that takes the place of real community ${ }^{\mathbf{4 2}}$ and

\begin{abstract}
ject of entitlement, the substance of entitlement, the basis for entitlement, and the purpose of entitlement. It generally makes sense, therefore, to ask: who is entitled, to what, on what basis, for what purpose? . . . The relational schema should be conceived of as part of the underlying grammar of the term "right," and just as in other areas speakers can be more or less aware of the grammatical rules that structure their discourse, so here these rules of intelligibility will often function invisibly.
\end{abstract}

I. Shapiro, The Evolution of Rights in Liberal Theory 14 (1986) (emphasis in original) (footnote omitted). Note that the phrase "to what, on what basis, and for what purpose" is an expression of the source-path-goal schema that is part of the ICM of rights. On the "who" and the "what," see generally Standing and Metaphor, supra note 1 , at $1392-93,1460-63$.

120 The Latin jus is related to the Sanskrit yu (to join), yus (stew), and yush (same), and therefore defines that which is binding or obligatory such as law. C. Lewis \& C. Short eds., A LATIN Dictionary FOUNDED ON ANDREw's Edition of FREUND's Latin DiCTIONARY 1019 (1955). A related etymology is the derivation of the English "yoke" from the Sanskrit yuga. Thus, there are two alternative hermeneutics to the derivation of jus. In one, law is that which binds the community or society together. In the second, more authoritarian hermeneutic, law is that which binds or yokes each of us as individuals.

The original Roman concept of $j u s$ was a religious ritual in which each side took oaths and was subject to the judgment, or jus of an ordeal or other divine source. As jus took on a civil meaning in Roman law, it described something more akin to duties and servitudes than to our modern conception of rights. See R. TUCK, supra note 380, at $8-9$.

121 Cover, supra note 359, at 1602 n.2. See also Llewellyn, Law and the Social Sciences - Especially Sociology, 62 HARv. L. Rev. 1286, 1292 (1949) ("The fundamental law-and-government job is, then, . . . the job of producing and maintaining the groupness of the group." (footnote omitted)).

${ }_{422}$ See Gabel, supra note 272 , at 1573 ("How can a group haunted by an absence of community reassure itself that it is characterized by the presence of connection? By conspiring to represent itself to itself as politically constituted ...."). 
legal rights are the media of alienation that, in ordering our relationships, take the place of real relatedness. ${ }^{423}$ On the former, Gabel's position partially coheres with that of Robert Cover: Both are anti-statist. But Gabel diverges sharply from Cover on the latter point. Where Cover sees a healthy, spontaneous jurisgenesis in group life, Gabel sees rights and similar legal constructions as inevitable reifications "intended to solve the problem of contingency by pretending that the next moment can be colonized in advance"424 and, thus, displacing "the immediacy and contingency of truly lived encounters." ${ }^{\prime 25}$ To put the conflict in even clearer relief, Gabel sees law as the product of alienation and the hallucinated State. Cover sees it exactly the other way round: For him, law is the product of the fecund jurisgenerative process of communal life; it is the State's courts that are jurispathic.

Despite these distinct differences concerning law, there is an additional point on which Gabel and Cover agree. Gabel sees true social movements like the labor or civil rights movements as sparked by genuine connectedness and, thus, capable of generating unalienated meanings. In this, he seems to agree with Cover on the positive, ontological power of communal experience. But for Gabel, these movements are capable of creating "real" meaning only because they draw upon the "transcendental desire" for connection that the alienated structure of legal thought operates to deny. ${ }^{43}$ They do so by speaking "through these alienated forms from the vantage-point of their own disalienating experience"427 and by disdaining the recognition of the "hallucinatory" State. Thus, Gabel argues that empowering social movements are doomed to cooptation and failure the moment they turn to the State and accept the offer of rights. ${ }^{428}$

423 Id. at 1577 (our conception of legal rights is part of an "effort to distance ourselves from each other by representing our false selves as our real selves"). Gabel's explanation of why we might find this substitution necessary is rooted in the conflict between the desire to connect and the perception of alienated distance both in ourselves and others. See id. at 1566-67. Gabel disclaims Duncan Kennedy's ontological version of the "fundamental contradiction" between self and others. See id. at 1568 \& n.13. Instead, he provides an account of the same contradiction as a social construction. See id. at $1569,1570,1572$. Robin West criticizes Gabel's position as prototypically male in its focus on the inherent problem of separation, rather than the naturalness of connection. See West, Jurisprudence and Gender, 55 U. CHI. L. REv. 1, 44-46 (1988). Gabel and West may both be correct: Chodorow suggests that the masculine sense of separation and "[d]enial of sense of connection" is socially reproduced by developmental experience. N. CHODOROw, supra note 87, at 166-69.

\$24 Gabel, supra note 272, at 1569. In this phrase, Gabel gives a downbeat twist to the source-path-goal conceptualization of rights.

126 Id. at 1576.

${ }^{428}$ See id. at 1588.

${ }^{227}$ Id. at 1589-90 (emphasis deleted).

${ }^{428}$ See id. at 1594-97. 
Gabel acknowledges that

the rights [these movements] win never entirely lose the resonance of authentic meaning that gives rise to their expression. For once this meaning has been realized in social experience even a little bit, we retain it like an ethical memory enveloped by its alienated meaning but not wholly erased by it. ${ }^{429}$

There are several problems with Gabel's argument. If meaning is, as he says, grounded in the lived experience prior to cooptation, then why is it that the State has such power to manipulate and control the meaning of those rights? His answer must be that, once ensconced in "alienated" rights-consciousness, the meaning is experienced in a way that is fundamentally changed. ${ }^{430} \mathrm{But}$, if so, then how is it that the ethical memory persists?

For Gabel, this is yet more problematic because he firmly rejects the possibility of objectification and retention of the meaning of the prior lived experience.

[I]t is also wrong to think that . . . we could produce a quantity of movement and freeze it in stone, and then another and freeze that in stone, until we had the right to everything we wanted. To think any of these things is to participate in the illusion that the right to an experience can create the experience itself, and to reverse the true relationship between the meaning of verbal concepts and the qualitative or lived milieu out of which they arise. ${ }^{\mathbf{4 3 1}}$

In taking this extreme holistic approach to meaning - that is, locating it only in the existential moment of experience - Gabel risks being trapped in a series of two-dimensional, either/or epistemological warps: Either meaning can be fixed in stone (i.e., given an unequivocal objectivist meaning) or it cannot and can only be lived in its

${ }^{429}$ Id. at 1597 . In a footnote at this point, Gabel notes that his article "could be rewritten from this point of view, focusing on the ways that rights exert a positive force on social relationships in the form of such ethical memories." Id. at 1547 n.41. I am undertaking just such a rewrite, but from the perspective of the experientialist epistemology.

430 I take this to be his position in light of his adoption of the "empirical" critiques that document the interpretive strategies by which the courts and legislatures have manipulated rights gains. See id. at 1595-96 \& nn.38-39. In contrast, I would argue that the success of these interpretive strategies of limitation have less to do with the statist identity of the interpreters than with the objectivist cast of their reasoning. This is what I have identified as indeterminacy of paradigm. See supra text accompanying notes 316-18.

431 Gabel, supra note 272, at 1598. 
unalienated fullness (a sort of romantic subjectivist meaning); either the "true relationship" between experience and meaning is that the former creates the latter (as Gabel would have it) or it inheres in the application of theoretical truths expressed in legal language to the "correction" of concrete social realities (as Fiss would put it).

We know, however, that these are not our only epistemological alternatives. It is not stone or illusion, experience or theory. Meaning is not objectivist; it is grounded in particular social experiences. But neither is the process two-dimensional, with one pole of the dichotomy necessarily preceding the other. Rather, the cognitive process is multidimensional and interactive. Once something has been realized in actual experience, that experience remains as the motivation for the imaginative abstraction and encoding of idealized cognitive models. Those ICMs then frame and constrain both our subsequent behavior and our subsequent perception of our experience; there are no "inputs which are not in themselves to some extent shaped by our concepts . . . ."432 The interactive nature of the cognitive process respects the fact that knowledge can be accumulated and that social meaning can be shared and institutionalized.

The ICMs that function in every other aspect of our cognitive and communicative world are no less available to law. If we can encode social meanings in our understanding of the concept lie, and if we can use our experience with vehicles to structure a rule prohibiting vehicles in a park, then we can do it as well for important normative concepts like the first amendment, the equal protection clause, and other species of rights. In this way, rights and other legal meanings continue to be meaningful because we can continue to recall and reflect on the experience that gave them birth. That is what it means to be human and rational. And that is the way in which law contributes to social structure and the institutionalization of social meaning and change.

${ }^{432} \mathrm{H}$. Putnam, supra note 38 , at 54 (emphasis deleted). Mark Tushnet's critique of Cover's position suffers because he fails to take this point into account. Adopting a subjectivist position, Tushnet argues that if the polynomia of law is the result of radical autonomy of meaning, then any two people can always constitute a new "community" and create a new "meaning." In Tushnet's view, "Cover's radical autonomy means that every social interaction constitutes a community for those involved in it." Tushnet, supra note 417 , at 1529-30 \& $\mathrm{n}$. 116. This is consistent with his story about the meaning of "arbogast," recounted in the introduction. See supra text accompanying notes 15-16. It is refuted by the experientialist approach to meaning developed in this article, and implicit in Cover's work. Not every ad hoc interaction is a community, not every ad hoc "meaning" is possible. In both cases, the phenomenon must be rooted in experience and will be shaped by preexisting cultural conceptions. Two people could theoretically create a community, but in the real world most of us are deeply embedded in larger social structures that have a substantial homogenizing effect on our experiences. 
It does not follow, of course, that we can fix the meaning of these rights in stone. As we explored above, the meaning of these rights will always remain

contingent in the sense that it is rooted in the particularity of a concrete, lived experience, and determinate in the sense that it is expressive only of the existential quality of this experience, as this quality might be realized in its universality through an infinite number of particular, historical instances. ${ }^{433}$

But we can make rights that are meaningful if we understand that their meanings are located in lived experience and not in sets of abstract principles and propositions like "the meaning of due process" or "the intent of the framers." and imaginative growth, if we understand that they are not determinate "things" but imaginative idealizations (i.e., ICMs) grounded in and motivated by lived human experience. This is what it means for rights to be "disalienated."

The vice or flaw that makes the State the worm at the heart of meaning ${ }^{\mathbf{4 3 5}}$ is not the emptiness of the State as an hallucinatory projection - the State is real enough in its ability to marshal the organized forces of violence, as Cover so movingly points out. Rather, the flaw is in the emptiness of the dominant methodology of legal reasoning: abstracting meaning from context and reducing it to principles or rules. The emptiness of "rights" in this form - that is, their loss of meaning - is the inevitable consequence of cutting rationality loose from its grounding in human experience. Thus, to say that Brown v. Board of Education ${ }^{438}$ is a case about "freedom of association"437 or a constitutional requirement of State "color-blindness"

4s3 Gabel, supra note 272, at 1590.

434 In Nomos and Narrative, Cover observes that: "All Americans share a national text in the first or thirteenth or fourteenth amendments, but we do not share an authoritative narrative regarding its significance." Cover, supra note 99 , at 17 . At that point Cover notes that it is ludicrous to begin the "narrative" of the first amendment's religion clauses at 1787 , and treat the first amendment as "a specific answer to a specific question raised about the national compromises struck between 1787 and 1789." Id. note 47. I believe that it does no violence to Cover's insight to say that the first amendment is not a determinate, objectivist set of propositions or principles, but rather an idealized cognitive model drawn from lived experience that is the "moral" of a constitutional "narrative."

${ }^{436} C f$. J. Sartre, Being and Nothingness 21 (1956) ("Nothingness lies coiled in the heart of being - like a worm.").

438347 U.S. 483 (1954).

${ }^{437}$ See Wechsler, supra note 8, at 31-34.

438 Freeman, supra note 318 , at $1102-03$, provides an excellent and detailed ac- 
precisely because it fails to see that the meaning of Brown is written in the lived experience of slavery and segregation, of civil war and social struggle. ${ }^{430}$ This is why, in addition to the reasons highlighted by Cover, that courts are jurispathic.

But to the extent that we cannot, as Gabel observes, fix legal meaning in stone, neither can the State fix these "false" meanings in oppressive cement. As Cover notes, "prescription, even when embodied in a legal text, [cannot] escape its origin and its end in experience. . . " 440 Against the State's attempt to hijack legal meaning (whether by reification or otherwise), Cover tells us that those who are part of committed social movements have two tools. The first is our participation in the creation of our nomos: Whatever the Court says about civil rights, capital punishment, or abortion, the meaning of its constitutional interpretation is as much a matter of our understanding, our interpretive commitments, as it is a matter of the understanding of the Justices. We are part of the context, the larger frame, in which legal interpretation has meaning and resonance. ${ }^{441}$ This is the insight that follows when we understand that objectivism is a myth.

The second tool is our relative freedom of action. "The uncontrolled character of meaning exercises a destabilizing influence upon power. Precepts must 'have meaning,' but they necessarily borrow it from materials created by social activity that is not subject to the strictures of provenance that characterize what we call formal lawmak-

count of how the meaning of the rights won by racial minorities have been systematically eviscerated by their reduction to such "principles."

139 For two of the better accounts of the historical dimensions of this point, see Black, The Lawfulness of the Segregation Decisions, 69 YalE L.J. 421 (1960); Powell, supra note 254 , at 1430 . Pat Williams expresses the essence of this point as eloquently as one ever could:

[B]lacks believed in [rights] so much and so hard that we gave them life where there was none before. We held onto them, put the hope of them into our wombs, and mothered them - not just the notion of them. We nurtured rights and gave rights life. And this was not the dry process of reification, from which life is drained and reality fades as the cement of conceptual determinism hardens round - but its opposite. This was the resurrection of life from 400-year-old ashes; the parthenogenesis of unfertilized hope.

Williams, Alchemical Notes: Reconstructing Ideals from Deconstructed Rights, 22 HaRv. G.R.-G.L. L. REv. 401, 430 (1987) (footnote omitted).

${ }^{40}$ Cover, supra note 99 , at 5.

141 Cover identifies as examples the social opposition to the Court's rulings upholding the death penalty and recognizing a woman's right of reproductive freedom and choice. "Both for opponents of abortion and for opponents of capital punishment the principle that 'no person shall be deprived of life without due process of law,' has been given an ironic cast. The future of this particular precept is now freighted with that irony no less than with the precedents . . . themselves." Id. at 7. 
ing." ${ }^{\text {442 }}$ Because life continues, so does the opportunity to change the underlying experience in which meaning is grounded. ${ }^{443}$ This is the insight that follows when we understand the contingent, experiential grounding of all human rationality.

There are two faces to the continuing opportunity to create legal meaning through lived experience. The positive face is the ability to change our world, to create new meanings motivated by committed experience and, thus, to engender new legal ICMs. Thus, Cover's own view of his work locates LAw as

a bridge in normative space connecting [our understanding of] the "world-that-is" (including the norms that "govern" and the gap between those norms and the present behavior of all actors) with our projections of alternate "worlds-thatmight-be" (including alternative norms that might "govern" and alternative juxtapositions of imagined actions with those imagined systems of norms. In this theory, law . . . . is the bridge - the committed social behavior which constitutes the way a group of people will attempt to get from here to there. Law connects "reality" to alternity constituting a new reality with a bridge built out of committed social behavior. ${ }^{44}$

But to do this, we ultimately need to recognize the role that the State plays in bringing these hopes to fruition. For as long as the State maintains its near monopoly on force - and that is likely to be true until such time as we perfect the human condition - we will need to enlist its power, its force, and even its violence in our quest for betterment. ${ }^{445}$

The negative face of the opportunity to create new legal meaning, however, is also the violence of the State. In the face of inter-group conflict or official opposition and recalcitrance, committed social activity

412 Id. at 18.

${ }^{443}$ Cf. Cornell, supra note 23, at 1208 ("Because the discourse is always being reshaped, through the interpretation of law, there is no 'universal' language of right necessary to rights discourse.").

144 Cover, supra note 239, at 181 (punctuation and emphasis in original).

465 Even an anti-statist like Cover recognizes that in seeking redemptive reinterpretations we are dependent on the State: "The vision of slavery destroyed by the power of law requires for its fulfillment the participation of the larger community that exercises state power." Cover, supra note 99, at 39; accord id. at 43. Thus, Cover's support for the "achievements of federal courts in destroying apartheid in America" and "in reforming institutions when the other officials failed" is explicitly grounded in his commitment and not in any transcendental, "objective" legal methodology. "I support those efforts because I believe them right and justified, because I am sufficiently committed to them to join with others in imposing our will on those who disagree." $R$. Cover, O. Fiss \& J. ResNiK, supra note 381 , at 730. 
implicates what Cover calls the texts of resistance. This too can be transformative. Cover invokes the familiar example of the civil rights movement.

[I]n acting out their own, "free" interpretation of the Constitution, protesters say, "We do mean this in the medium of blood" (or in the medium of time in jail); "our lives constitute the bridges between the reality of present official declarations of law and the vision of our law triumphant"... .

.. . The community that disobeys the criminal law upon the authority of its own constitutional interpretation ... forces the judge to choose between affirming his interpretations of the official law through violence against the protesters and permitting the polynomia of legal meaning to extend to the domain of social practice and control. The judge's commitment is tested ....446

On this face of the experiential coin, the State's violence is the price of living in overlapping and sometimes conflicting normative worlds. ${ }^{447}$

A resuscitated conception of rights and a transformative legal practice are possible. They are dependent, however, upon a better understanding of the cognitive meaning of rights, of the location of meaning in lived experience, and of the potential uses of State power. The significance of the multidimensional ICM developed in the previous subsection is that it opens to normative view the implications that rights have for us. For us, the production and maintenance of legal meaning is dependent upon lived human experience. To make meaning, one must do meaning: It is only the humans who are bearers of literal rights who can provide the grounding for meaningful legal rights. This is one of the powerful insights of feminist and minority scholars: "Even the most fundamental negative rights, such as the right to speak or to control our bodies free from governmental constraint, acquire concrete meanings only as people act collectively to claim them."448 This legal meaning, moreover, cannot be grounded in the restricted experience of privileged human beings alone. For legal meaning to be meaningful in any democratic sense, it must be grounded as well in the often different lived experiences of blacks, women, and other traditionally disempowered human beings who have too long been excluded from the

46 Cover, supra note 99 , at $47-48$.

417 See id. at 53 ("But this is the sum of what the State has added.").

148 Law, Equality: The Power and Limits of the Law, 95. YALE L.J. 1769, 1783 (1986) (book review). 
official processes of meaning-making. ${ }^{449}$

There are, of course, real dangers. The potential violence of the LAW as wielded by the State necessarily produces risks as well as possibilities in our efforts to achieve rights. There is also danger in the cooptation of rights through their dissociation from life and their constriction into propositional rules or principles. An approach which does not recognize that rights must be grounded in the lived experience of real people is always open to the manipulations of power.

Revivified rights are worth having, however, because they provide a realistic alternative to more destructive social conflict. The meaning of rights that is the entailment of the Rational Argument is War metaphor testifies to the importance of the sublimation of interpersonal violence and inter-group conflict in reasoned disputation, and of the substitution of the potential of State violence for the actual coercion of unregulated private violence. ${ }^{450}$ There are no rights without harnessing the coercive power of the State to insure their actualization. This was the insight of the common law, expressed by the maxim $u b i$ jus $i b i$ remedium: "where there is a legal right there is also a legal remedy, by suit or action at law, whenever that right is invaded."451

Finally, the derivation of rights from the source-path-goal schema reminds us that rights always remain a question of direction: the ways in which groups of people will attempt to get from here to there. Rights are about the course of the future, and that future is made only through the commitments of real people: "To live in a legal world requires that one know not only the precepts, but also their connections to possible and plausible states of affairs. It requires that one integrate not only the 'is' and the 'ought,' but the 'is,' the 'ought,'and the 'what might

44 See Matsuda, Looking to the Bottom: Critical Legal Studies and Reparations, 22 HaRv. C.R.-G.L. L. REv. 323, 324 (1987) ("[T]hose who have experienced discrimination speak with a special voice to which we should listen."); Williams, supra note 439 , at 412-16 (describing the differences in the ways that blacks and whites experience rights); West, supra note 423, at 19-37, 58-61 (describing the difference between the kinds of harms experienced by men and women, and the ways in which the law protects the former and ignores the latter); West, The Difference in Women's Hedonic Lives: A Phenomenological Critique of Liberal and Radical Feminist Legal Theory, 3 WISC. WOMEN's L. REV. 81, 84-86 (1987) (same). This raises difficult questions about how those different experiences are to be communicated to majority groups. I attempt to deal with that problem in my forthcoming Legal Power and Narrative Meaning, supra note 4, at 49-70, where I describe and explain some methodologies for effective transformative argument.

${ }_{450}$ This is the point made by Cover, supra note 359, at 1628 , and by Minow, supra note 358 .

$4613 \mathrm{~W}$. Blackstone, Commentaries *23; accord Marbury v. Madison, 5 U.S. (1 Cranch) 137, 163 (1803). Cover also reminds us of the converse, that if the state is to exercise violence it is much better that it do so as directed by law, however imperfect. Cover, supra note 359 , at 1628. 
be.' "452

Rights are imaginative products of human rationality, their meaning is grounded in human experience, and the law is the trajectory toward our future that is always amenable to the contributions of committed people.

In Roll Over Beethoven, Duncan Kennedy made the ambivalent announcement that concepts like rights

are like organic things that live and die, and this concept is dead. I think. Maybe next month a sprout will suddenly appear in the absolutely dried-out earth in the flowerpot, where you basically just put it down in the cellar thinking it wouldn't even be worth throwing the dirt out. You go down in the cellar, and by God, there's a green sprout. And rights analysis once again has got some force and has some meaning for us. ${ }^{453}$

A primary purpose of this essay has been to reinvigorate the concept of rights by combining an understanding of our ICM of rights with an experientialist approach to meaning. I do not underestimate the difficulties - if not the radical underinclusiveness - of this effort. But I am convinced that the reports of the demise of rights are premature. The failure is not inherent in the concept of rights, but rather in limiting ourselves to a form of legal reasoning that clings to the familiar, but falsifying exercise of reasoning from abstractions to particulars. We are capable, however, of imagining rights in new and generative forms if we understand and utilize a human rationality that is grounded in human experience.

I believe that we can reinvigorate and regain our rights by putting people back at the center of the jurisgenerative process. Rights are possible when their meanings are grounded in the lived experiences of actual human beings. LAw in its largest sense is made possible only by committed people. With humans back at the center of the process, we will not only have rights with meaning, but we will also have LAw that is truly democratic and truly human: Humane law, within the limits of

452 Cover, supra note 99, at 10. Cf. Cornell, supra note 23, at 1208 ("We are always in the process of reinterpreting the meaning of the rights given to us in past decisions through the projection of hypothetical meaning in the future as we conjecture what the right means in the case at hand.").

${ }^{483} \mathrm{Gabel} \&$ Kennedy, supra note 69 , at 40 (Kennedy). Note that the metaphor employed in this passage - Ideas are Living Organisms - is a conventional one. See G. LAKOFF \& M. JoHNSON, supra note 1, at 47; Standing and Metaphor, supra note 1 , at 1494. 
human imagination.

\section{A Concluding Homage to Cover and Cohen}

\section{"People don't ride the buses today. Don't ride it for freedom."}

It should be clear that my concept of LAw and the possibility of rights, as well as the broader idealized cognitive model I have tried to reconstruct, is grounded in and influenced by a very particular set of experiences: the civil rights movement. I was ten and a half when I was introduced to that movement. It was the Sunday afternoon just after New Years Day 1964. I was upstairs watching a television review of the year past. There on the screen was the confrontation between Bull Connor and the courageous black men, women, and children of Birmingham, Alabama. The image of the civil rights struggle that seared my white, ten-year-old's conscience was that of Bull Connor releasing his police dogs on the crowd: a German Shepherd on its hind legs attacking a black child.

Fifteen years later, I went to Birmingham for the first time. I was a staff attorney for the NAACP Legal Defense Fund. Bonita Carter, a black woman, had been shot to death by a white police officer. The black community had taken to the streets to protest both the killing and the city's handling of it. When her family's case against the city came to trial in 1986, the relevant law was a case that we had just won in the Supreme Court. ${ }^{455}$ That legal victory had been obtained in large part by convincing the Court that, as a constitutional matter, resort to deadly force had to be limited by the norms already expressed in police regulations and practices. ${ }^{456}$ When the Carter case settled, the person

154 Hand-lettered sign on torn piece of cardboard hung at the Court Square stop during the Montgomery Bus Boycott, Monday, December 5, 1955, quoted in J. WILliams, Eyes on the Prize: America's Givil Rights Years, 1954-1965, at 72 (1987).

I am sure I am not the first to wonder about the connections between the imagery of the bus and the civil rights movement: the Montgomery Bus Boycott, the Freedom Rides, and the use of busing to effectuate school desegregation. Now, I understand the coherence and power of the imagery in terms of a three-staged set of related sourcepath-goal metaphors. First, blacks refused to ride the bus on someone else's terms: They insisted on their own conception of place in the journey through life. The movement was galvanized by this act of self-empowerment. It then fought not only to effect integration from within, but also to harness the energies of the larger, national community literally to bring integration to the South. In the final stage, the school bus symbolized the effort to bring people together at their most vulnerable, black and white children growing up together. It often failed, not only because of the resistance is provoked, but also because of the way the demand was accommodated: As effectuated, busing is mostly about allowing black children to attend white schools.

456 Tennessee v. Garner, 471 U.S. 1 (1985).

${ }^{458}$ See id. at 6-7; Winter, Tennessee v. Garner and the Democratic Practice of Judicial Review, 14 N.Y.U. Rev. L. \& Soc. Ghange 679, 683-92 (1986). 
who signed the settlement document for the city was black: Richard Arrington, Jr., the Mayor of Birmingham, elected to office in the wake of the protest over the killing of Bonita Carter.

The last time I was in Birmingham was in the summer of 1986. I was defending the Southern Christian Leadership Conference and the Rev. Joseph Lowry, Dr. King's successor. The claim was libel, the place was a state trial court, and the decision was to grant summary judgment on the authority of a case in which Dr. King had been a protagonist: New York Times v. Sullivan. ${ }^{\mathbf{4 5 7}}$

The libel claim was filed by the police officer who had killed Bonita Garter. He argued that he had been defamed when the defendants referred to him as a murderer. The precedents looked both ways: Some cases had held that allegations of a crime like "murder" involve legal categories defined by statute; such charges are therefore allegations of fact concerning intent and conscious culpability. ${ }^{458}$ Others had held that such charges are privileged opinions or part of the robust debate of heated political controversy. ${ }^{480}$ The case turned on how one categorized the allegation of "murder"; the choice was between the objectivist, propositional definition of the law and the relativistic domain of personal meaning and political opinion.

Both parties made the obvious doctrinal arguments. But our case citations and arguments from general first amendment principles seemed to leave the judge a little cold. He sat through most of the oral argument with that "I've heard it all before" look of ennui. It was something else that caught the judge's attention and spoke to his imagination.

One of my arguments for our characterization of the speech turned on a passage in the co-defendant's deposition. Reverend Woods had de-

457376 U.S. 254 (1964). The order dismissing Sands v. Woods, et al., is unreported. Sands v. Woods, et al., CV 80-02680 (10th Judicial Circuit of Ala. 1986).

${ }^{458}$ See, e.g., Lauderback v. ABC, 741 F.2d 193, 197 (8th Cir. 1984), cert. denied, 469 U.S. 1190 (1985) (stating rule that "allegations of specific criminal conduct generally cannot be protected as opinion"); Cianci v. New Times Pub. Co., 639 F.2d 54, 64 (2d Cir. 1980) (applying the rule to the allegation "rapist"); Buckley v. Littell, 539 F.2d 882, 895-96 (2d Cir. 1976), cert. denied, 429 U.S. 1062 (1977) (applying rule to the allegation "libeler"); Rinaldi v. Hold, Reinhart \& Winston, Inc., 42 N.Y.2d 369, 381-82, 366 N.E.2d 1299, 1307, 397 N.Y.S.2d 943, 951 (applying rule to the allegation of "corruption"), cert. denied, 434 U.S. 969 (1977).

458 See, e.g., Letter Carriers v. Austin, 418 U.S. 264, 270-79, 286 (1974) (holding federal labor law precludes state libel action for publishing colorful denunciation of "scabs"); Greenbelt Coop. Publishing Ass'n v. Bresler, 398 U.S. 6, 13-14 (1970) (precluding libel action for newspaper's characterization of "blackmail"); Information Control Corp. v. Genesis One Computer Corp., 611 F.2d 781, 784 (9th Cir. 1980) (no libel action for reporting opinion that party intended to avoid payment obligations). 
scribed himself, and his role in the protests over the shooting, as "a drum major for justice" - a deliberate paraphrase of a speech by Dr. King. I cited that as a contextual indication that the allegation of "murder" was privileged political discourse. The judge immediately asked for the page in the deposition at which that statement appeared. $\mathrm{He}$ stopped the argument while he looked it up. After he had read the passage, he settled back into inattention. He ended the argument shortly thereafter.

At the time, my co-counsel and I both experienced that argument as the clincher. ${ }^{400}$ It worked by making an abstract precedent cognitively real, evoking the experiential basis of a legal ICM and enabling the judge to experience a prototype effect - "that intuitive flash of understanding which makes the jump-spark connection between question and decision." "61 What better proof that the allegation of "murderer" was protected speech than that it was linked with something Dr. King would have said in the same circumstance? What better fit with the idealized cognitive model of the first amendment instantiated by N.Y. Times v. Sullivan than to find Dr. King at the heart of this case too?

These are my experiences of rights-consciousness. I find nothing reified or abstract about them, although the reader may experience my account of them as idealistic. But these are real world examples, legal decisions that were the affirmative products of the committed behavior of real people in an effort to make the world better. In each circumstance, law was an agent used to "connect[] 'reality' to alternity" and to constitute "a new reality with a bridge built out of committed social behavior." ${ }^{462}$

For me, these are the most important lessons taught by people like Felix Cohen and Robert Cover. Despite the substantiality of his oeuvre, Felix Cohen spent only a small proportion of his professional life writing and teaching. He was a practicing lawyer whose specialty was advocacy on behalf of Native Americans. ${ }^{463}$ As a member of the SNCC in 1963 and 1964, Robert Cover spent nine months working in places like Albany and Americus, Georgia. ${ }^{\mathbf{4 6 4}}$ Cover's scholarly writings always bore the marks of this committed experience.

I did not know Felix Cohen or Robert Gover during their too

460 Rev. Woods was seated in the courtroom. He liked it too.

161 Hutcheson, supra note 198, at 278.

162 Cover, supra note 239, at 181.

463 See Biography of Felix S. Cohen, 9 Rutgers L. Rev. 345, 347-49 (1954).

464 See Tributes to Robert M. Cover, 96 YALE L.J. 1699, 1703-05 (1986). 
short lifetimes. ${ }^{465}$ For those of us who were deprived of that opportunity, there are the many messages they left us in their writings. From Felix Cohen, we may take and nurture the hope that "uncover[ing] the inarticulate value premises of ourselves and others" and "see[ing] more clearly the moral implications of our human egocentric limitations" will lead to "a greater degree of tolerance and freedom for our society."466 From Robert Cover, we may take and struggle with the understanding that LAW is simultaneously about violence and about hope. It is the attempt to mediate our existence in a violent, physical world by building bridges to a vision of the future.

Those bridges are metaphors constructed by committed people. They are not constructed from syllogistic rules, reified abstractions, nor disembodied logic. There are only us and our fellow human beings grappling, both physically and metaphorically, with our problems on the journey through life. There are no short cuts, no express lanes, no buses to get us there faster, no uniformed drivers at the front. Just us. And the LAw we make.

165 Felix Cohen died in October 1953 at the age of forty-six. See Biography of Felix S. Cohen, supra note 463, at 344. Robert Cover died in July 1986 at the age of forty-two. See Tributes to Robert M. Cover, supra note 464, at 1699.

${ }^{468}$ See Felix Cohen, The Vocabulary of Prejudice, in F. CoHen, supra note 167, at 435. Martha Minow's recent Supreme Court Foreword is an exquisite effort of this sort. Minow, The Supreme Court 1986 Term — Foreword: Justice Engendered, 101 Harv. L. Rev. 10 (1987). 
. 